\title{
MERISTELOIDEOS DEL DEVÓNICO INFERIOR DE LA COR- DILLERA CANTÁBRICA (N DE ESPAÑA)
}

\author{
Jenaro L. GARCÍA-ALCALDE \\ Departamento de Geología (Área Paleontología) de la Universidad de Ovie- \\ do, c/ Jesús Arias de Velasco s/n, Oviedo (Asturias, España). 33005. Email: \\ jalcalde@geol.uniovi.es
}

García-Alcalde, J. L. 2011. Meristeloideos del Devónico Inferior de la Cordillera Cantábrica (N de España). [Lower Devonian meristelloids of the Cantabrian Mountains (N Spain).] Revista Española de Paleontología, 26 (2), 69-100. ISSN 0213-6937.

\begin{abstract}
Meristelloids (Superfamily Meristelloidea Waagen, 1883) are relatively diverse, Ordovician to Carboniferous articulate brachiopods. The meristelloid shell is commonly smooth and the brachial system is composed by spiralia and a more or less complex jugum. Specialists have paid scarce attention to Spanish Devonian meristelloids. This has probably been due both to the poor external ornamentation and to the complex internal structure. The smooth shell involves usually homeomorphies both among different meristelloid taxa and between them and another separate groups (i.e. the terebratulids). In turn, the internal complexity calls for very extended and careful serial sections studies to reconstruct the brachial apparatus that take very long time. Several Cantabrian Mountains (N Spain) Lower Devonian meristelloid taxa are described and figured herein. Saberaia n.gen. is only composed by its type-species $S$. truyolsae n.sp., an external homeomorph of the terebratulid Terebratula Bordini Verneuil, in Prado \& Verneuil, 1850. Meristella esbelta n.sp. and Camarium collensis n.sp. are the first known species of both genera in Spain. Triathyris mucronata (Verneuil, 1850) is the type species (by posterior designation due to Le Maître, 1954) of Triathyris. The taxonomic history of Triathyris is analyzed. T. mucronata is redescribed from abundant topotypical material and numerous serial sections that show a typical meristelline brachidium.
\end{abstract}

Keywords: Lower Devonian, brachiopod meristelloids, Cantabrian Mountains, Spain.

\section{RESUMEN}

Los meristeloideos (Superfamilia Meristelloidea Waagen, 1883) constituyen un grupo relativamente diverso de braquiópodos articulados que existieron del Ordovícico al Carbonífero, con escasa ornamentación externa y aparato yugal con espiralio y yugo más o menos complejos. Los representantes del grupo en el Devónico de España recibieron poca atención por parte de los especialistas, probablemente por su escasa diferenciación externa, involucrando numerosas homeomorfías entre los taxones del grupo y entre ellos y otros de grupos alejados (terebratúlidos, por ejemplo), y por su compleja estructura interna. En este trabajo se describen varias formas del Devónico Inferior de la Cordillera Cantábrica (N de España). Saberaia n.gen., comprende sólo la especie-tipo, S. truyolsae n.sp, un homeomorfo externo del terebratúlido Terebratula Bordini Verneuil, en Prado \& Verneuil, 1850. Meristella esbelta n.sp. y Camarium collensis n.sp. son las primeras especies de ambos géneros conocidas hasta ahora en España. Triathyris mucronata (Verneuil, en Prado \& Verneuil, 1850) es la especie-tipo (por designación posterior de Le Maître, 1954) del género Triathyris. Se analiza en detalle la historia del género y los problemas taxonómicos relacionados. Se redescribe la especie-tipo, T. mucronata, a partir de abundante material topotípico y numerosas secciones seriadas que muestran la indudable naturaleza meristelina del braquidio.

Palabras clave: Braquiópodos meristeloideos, Devónico Inferior, Cordillera Cantábrica, España.

\section{INTRODUCCIÓN}

Entre los elementos de la fauna de braquiópodos del Devónico de la Cordillera Cantábrica (Fig. 1) que menos atención recibieron por parte de los autores clásicos, hay que destacar a los meristeloideos (Superfamilia Meristelloidea Waagen, 1883). En ello influyó, sin duda, de manera poderosa, la escasa diferenciación externa de la concha 


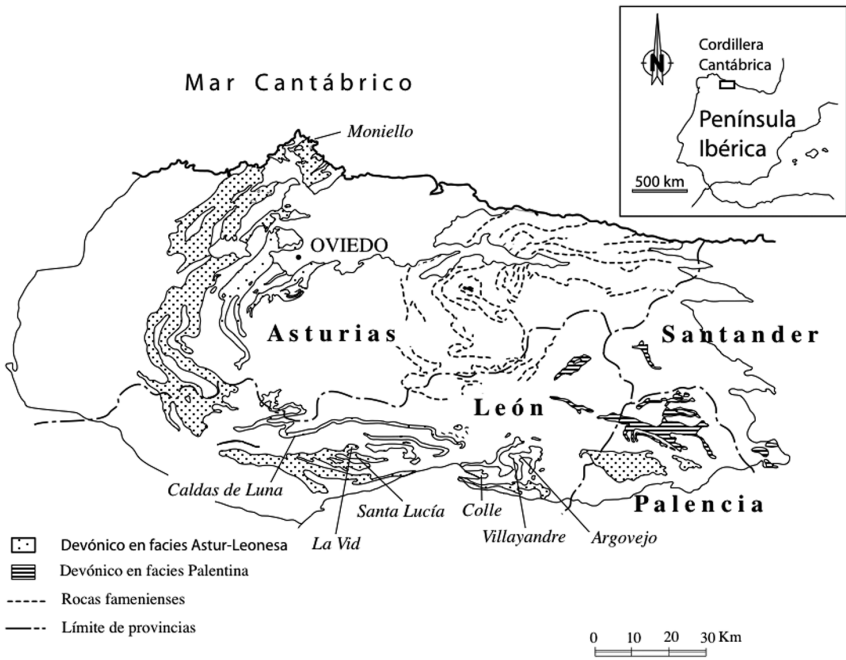

Figura 1. Situación geográfica y geológica de los yacimientos de meristeloideos del Devónico Inferior de la Cordillera Cantábrica citados en el trabajo.

Geographic and geologic setting of the Cantabrian Mountains Lower Devonian meristelloid localities cited herein.

tanto en contorno como en ornamentación, con numerosas homeomorfías entre los distintos taxones del grupo y con otros taxones alejados (terebratúlidos, por ejemplo), lo que obliga, en ausencia de valvas aisladas o secciones naturales afortunadas, a realizar e interpretar cortes seriados para zanjar filiaciones, labor lenta y tediosa que sólo de manera esporádica acometieron los naturalistas del siglo XIX y buena parte del XX.

De hecho, en los trabajos de los autores pioneros se citan muy pocos taxones meristeloideos y su naturaleza, incluso, no se puso en evidencia hasta tiempos relativamente recientes. Terebratula mucronata Verneuil, en Prado \& Verneuil, 1850, por ejemplo, es el único meristeloideo en la extensa lista de especies descritas por su autor en el Devónico de Asturias y León y la especie fue reunida por Comte (1938) con otras dos no meristeloideas: Terebratula Bordini Verneuil, en Prado \& Verneuil, 1850 (grafía original del autor) y T. Schulzii Verneuil, en Prado \& Verneuil, 1850 (grafía original del autor) en el nuevo género Triathyris (ver Discusión, más abajo). Barrois (1882) y Oehlert \& Oehlert (1897, 1901), no citaron ningún meristeloideo en sus trabajos en España. El propio Comte (1938), aparte de Triathyris mucronata, tampoco cita ningún meristeloideo. Este autor, en una recopilación posterior (Comte, 1959) repite la cita de T. mucronata y añade la de Dicamara plebeja Sowerby, de la caliza de Portilla, del Devónico Medio, en el valle del Bernesga (op. cit., pp. 190, 403), pero no la recoge en la Tabla de especies (op.cit., Tabs II-IV, pp. 245-251). Curiosamente, en este último trabajo Comte (1959, pp. 217-218), no relacionó Triathyris mucronata entre los fósiles de Colle (localidad-

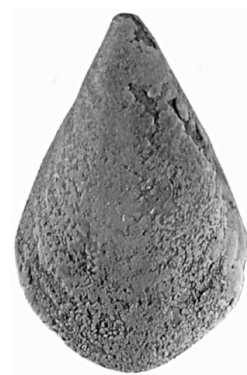

a1

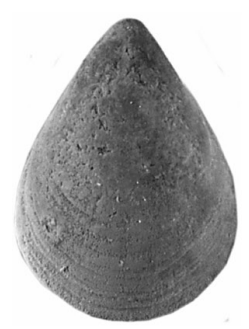

b1

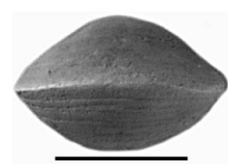

b2

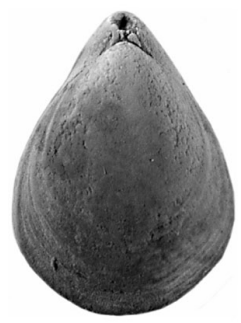

b3

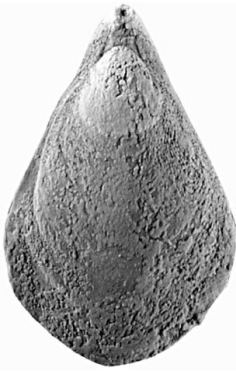

a2

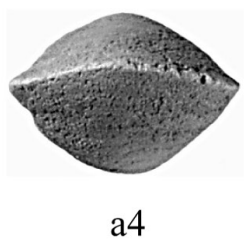

a4

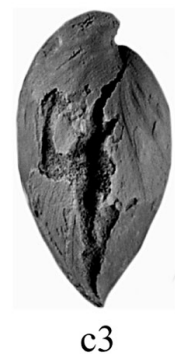

c3

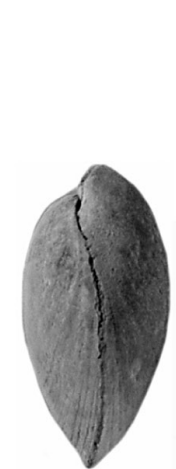

b4

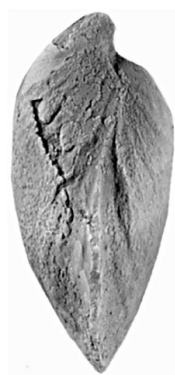

a3

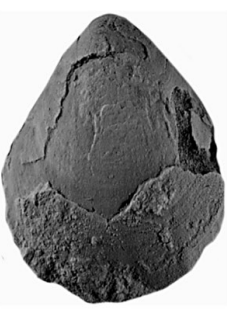

c1

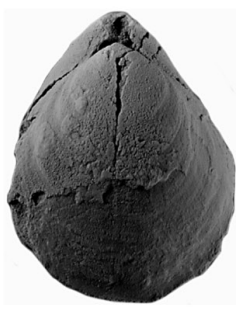

$\mathrm{c} 2$

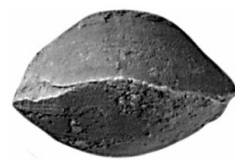

c4

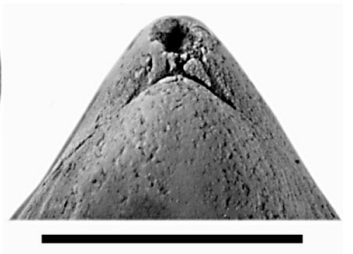

b5
Figura 2. Meristella esbelta n.sp. a1-a4: Holotipo DPO39045, de Argovejo (León), vistas ventral, dorsal, lateral y anterior. b1-b5: Paratipo DPO 39048, misma procedencia, vistas ventral, anterior, dorsal y lateral y detalle del deltidio. c1-c4: DPO 39061, de Moniello (Asturias), vistas ventral, dorsal, lateral y anterior. Barras de escala: $5 \mathrm{~mm}$. La pequeña es la escala de todas las figuras menos de la b5.

Meristella esbelta n.sp. a1-a4: Holotype DPO 39045 from Argovejo (León), ventral, dorsal, lateral and anterior views. b1-b5: Paratype DPO 39048, same locality, ventral, anterior, dorsal, and lateral views, and enlarged view of the deltidium. c1-c4: DPO 39061 from Moniello (Asturias), ventral, dorsal, lateral, and anterior views. Scale bars: $5 \mathrm{~mm}$. The small bar corresponds to all figures excepting $\boldsymbol{b 5}$. 
tipo de la especie; ver García-Alcalde \& Álvarez, 1976, pp. 42-43), y sólo la señaló con un punto de interrogación en la parte alta de La Vid, en la Tabla de fósiles (op. cit., Tableau II, p. 247), dando la impresión de que el mismo no conocía la especie más que a través de los ejemplares de la colección Verneuil.

Resulta chocante que Verneuil (en Prado \& Verneuil, 1850) y Comte (1938) ignorasen casi todo sobre el interior de Triathyris mucronata, salvo que poseía braquidio espiralado (que debieron apercibir en algún ejemplar desgastado naturalmente). La situación se prolongó en el tiempo, hasta el punto que Boucot et al. (1965) incluyeron todavía el género entre los Athyridinae. García-Alcalde \& Álvarez (1976) discutieron y figuraron los tipos de T. mucronata (que el primero de ellos y otros colegas de la Universidad de Oviedo habían reencontrado en la colección Verneuil, depositada entonces en la Facultad de Ciencias de Orsay). García-Alcalde (en García-Alcalde \& Álvarez, 1976, p. 43), basándose en parte en observaciones de Barrois (1882) y de Le Maître (1952) sobre T. schulzii, llegó a la conclusión de que dicha especie y $T$. bordini pertenecían al género terebratúlido Cimicinella, observación que se confirmó posteriormente en otro trabajo (García-Alcalde, 1999). Por diversas razones, los datos sobre la verdadera naturaleza de la especie tipo de Triathyris, bien conocida ya para el autor en la época, no llegaron a publicarse, de manera que la primera información fiable sobre la estructura interna del género la adelantó Álvarez (en Álvarez et al., 1998), aportando una breve diagnosis y secciones seriadas del topotipo DPO/F24235 de T. mucronata, donde se aprecian el septo dorsal, septalio y braquidio espiralado con estructura yugal formada por ramas yugales accesorias unidas al tallo yugal (op. cit., Fig. 7). Dichas característi-

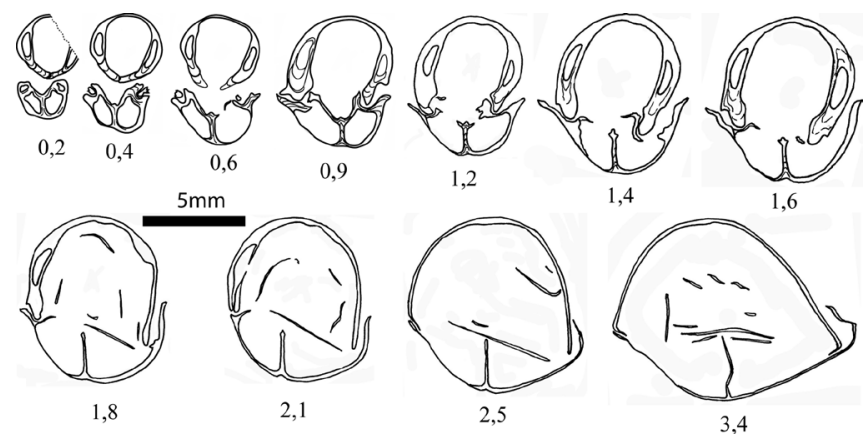

Figura 3. Meristella esbelta n.sp. DPO 39063, de Argovejo (León). Dibujos con cámara clara de secciones seriadas, perpendiculares al plano de simetría y al plano comisural. Braquidio destruido. Distancias medidas en $\mathrm{mm}$. al ápice ventral.

Meristella esbelta n.sp. DPO 39063, from Argovejo (León). Camera lucida drawings of serial sections, normal to both the symmetry and the commisural planes. Brachidium broken. Distances in $\mathrm{mm}$ measured from the ventral apex. cas y la peculiar ornamentación externa de Triathyris y del género próximo Septathyris, fueron la base de la propuesta por parte de dichos autores de la nueva familia meristeloidea Triathyrididae, con dos subfamilias, también nuevas, Triathyridinae (género tipo, Triathyris) y Septathyridinae (género tipo, Septathyris Boucot et al., 1964).

García-Alcalde (2002, 2003), añadió más información sobre los meristeloideos cantábricos describiendo un nuevo género, Bimeristina, del Praguiense de la Zona Palentina ( $\mathrm{N}$ de España), caracterizado por la posesión de un braquidio muy original, a partir de material descrito y figurado previamente por Binnekamp (1965) como Whitfieldella spec. y de nuevas colecciones. García-Alcalde (1992, 1995, 1996, 1999, 2001a, 2001b, y en Truyóls et al., 1990, García-Alcalde \& Truyóls-Massoni, 1994 y Truyóls-Massoni \& García-Alcalde, 1994), citó diferentes formas del grupo discutido, sin figuración ni descripción formal, parte de las cuales, las pertenecientes al Devónico Medio, se ofrecerán en una publicación ulterior.

En este trabajo se avanza, de nuevo, en el conocimiento de los meristeloideos del Devónico Inferior, mediante:

a) La descripción de nuevas especies de Meristella Hall, 1859 y Camarium Hall, 1859 que constituyen, al propio tiempo, las primeras referencias documentadas de dichos géneros en la Cordillera Cantábrica.

b) La propuesta de un nuevo género, Saberaia, con especie-tipo $S$. truyolsae n.sp., uno de los homeomorfos externos del terebratúlido Terebratula Bordini Verneuil, en Prado \& Verneuil, 1850.

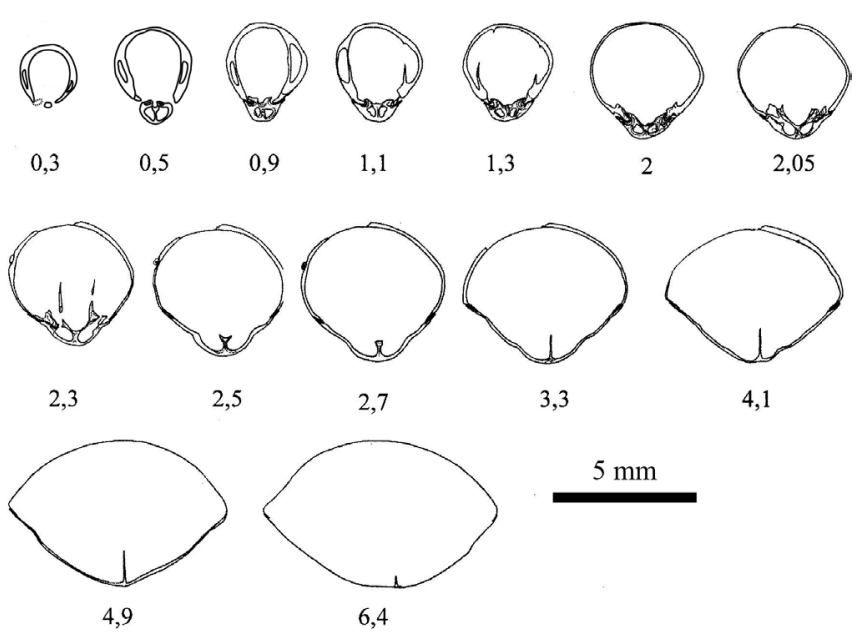

Figura 4. Meristella esbelta n.sp. DPO 39070, de Santa Lucía (León). Dibujos con cámara clara de secciones seriadas, perpendiculares al plano de simetría y al plano comisural. Braquidio destruido. Distancias medidas en $\mathrm{mm}$. al ápice ventral.

Meristella esbelta n.sp. DPO 39070, from Santa Lucía (León). Camera lucida drawings of serial sections, normal to both the symmetry and the commisural planes. Brachidium broken. Distances in $\mathrm{mm}$ measured to the ventral apex. 
c) La redescripción de Triathyris mucronata, a partir de numerosas secciones seriadas y observaciones sobre material relativamente abundante de la localidad tipo.

\section{SISTEMÁTICA}

Todo el material citado bajo las siglas DPO está depositado en las colecciones del Museo de Geología, Paleontología, de la Universidad de Oviedo.

Superfamilia Meristelloidea Waagen, 1883

Familia Meristellidae Waagen, 1883

Subfamilia Meristellinae Waagen, 1883

\section{Género Meristella Hall, 1859}

Especie-tipo: Atrypa laevis Vanuxem, 1842.

Diagnosis: Conchas impuntuadas, desigualmente biconvexas, casi siempre más largas que anchas. Concha lisa, no diferenciada, a veces con seno ventral y pliegue medio dorsal desarrollados cerca del margen anterior o afectando sólo a la comisura. Placas deltidiales visibles en los primeros estadios de desarrollo, ocultas en los ejemplares adultos por el fuerte recurvamiento del gancho ventral. Con o sin pliegue medio dorsal y seno ventral, los cuales pueden afectar sólo a la comisura anterior. Placas dentales cortas, obsolescentes. Campo muscular ventral abriéndose hacia delante. Septalio abierto, ancho y poco profundo, soportado por un septo medio que alcanza alrededor de la mitad de la longitud. Arco yugal agudo proyectándose hacia atrás en un largo tallo débilmente inclinado posteriormente, el cual se bifurca en lamelas yugales accesorias que tras describir sendos bucles se unen de nuevo al tallo. Capa terciaria presente.

Discusión: Meristella es un género cuyas especies son, principalmente, de fines del Silúrico, del Lochkoviense y del Praguiense en el Dominio Apalachense (Boucot et al., 1969). Las formas indudables del Emsiense y del Eifeliense se conocían, hasta ahora, sólo en Alemania y, quizás, en Nevada (EEUU). Las formas citadas por Barrois (1889), en el Emsiense superior de la Caliza de Erbray, en Francia: Meristella circe, M. recta, M. lata y M. biplicata, podrían también pertenecer al género, pero los dibujos proporcionados por Barrois (1889) muestran placas dentales muy desarrolladas en todas ellas, que no son propias del

Tabla 1. Meristella esbelta n.sp. Medidas de algunos ejemplares en mm (L, a, g: longitud, anchura y grosor). Meristella esbelta n.sp. Measurements of some specimens in mm (L, a, g: length, width, and thickness).

\begin{tabular}{|c|c|c|c|c|c|c|}
\hline Ejemplar & Localidad & $\mathbf{L}$ & $\mathbf{a}$ & g & $\mathbf{a} / \mathbf{L}$ & g/L \\
\hline Paratipo DPO 39041 & Argovejo & 19,1 & 17,0 & 9,0 & 0,89 & 0,47 \\
\hline Paratipo DPO 39042 & Argovejo & 15,5 & 13,8 & 8,0 & 0,89 & 0,52 \\
\hline Paratipo DPO 39043 & Argovejo & 15,4 & 12,7 & 7,0 & 0,82 & 0,45 \\
\hline DPO 39056 & Santa Lucía & 14,4 & 9,4 & 6,6 & 0,65 & 0,46 \\
\hline Paratipo DPO 39044 & Argovejo & 14,3 & 9 & 6,4 & 0,63 & 0,45 \\
\hline DPO 39054 & Santa Lucía & 14,2 & 12,9 & 7,3 & 0,91 & 0,51 \\
\hline DPO 39055 & Santa Lucía & 13,3 & 8,3 & 5,9 & 0,62 & 0,44 \\
\hline DPO 39059 & Moniello & 13,0 & 10,8 & 7,2 & 0,83 & 0,55 \\
\hline Holotipo DPO 39045 & Argovejo & 12,8 & 8,3 & 5,7 & 0,65 & 0,44 \\
\hline DPO 39061 & Moniello & 12,7 & 10 & 6,7 & 0,79 & 0,53 \\
\hline Paratipo DPO 39046 & Argovejo & 12,4 & 8,6 & 6,6 & 0,69 & 0,53 \\
\hline Paratipo DPO 39047 & Argovejo & 12,4 & 8,5 & 5,5 & 0,68 & 0,44 \\
\hline Paratipo DPO 39049 & Argovejo & 11,4 & 8,4 & 5,1 & 0,74 & 0,45 \\
\hline Paratipo DPO 39048 & Argovejo & 11,1 & 8,2 & 5,6 & 0,74 & 0,50 \\
\hline DPO 39060 & Moniello & 11 & 8,5 & 6 & 0,77 & 0,54 \\
\hline Paratipo DPO 39051 & Argovejo & 10,5 & 6,9 & 4,8 & 0,66 & 0,46 \\
\hline DPO 39057 & Santa Lucía & 9,5 & 7,3 & 4,7 & 0,77 & 0,49 \\
\hline Paratipo DPO 39052 & Argovejo & 9,2 & 6 & 4,3 & 0,65 & 0,47 \\
\hline DPO 39058 & Santa Lucía & 8,7 & 6 & 4,6 & 0,69 & 0,53 \\
\hline DPO 39053 & Santa Lucía & 4,3 & 3,9 & 2,3 & 0,91 & 0,53 \\
\hline DPO 39062 & Moniello & 4,3 & 2,7 & 2,4 & 0,63 & 0,56 \\
\hline
\end{tabular}




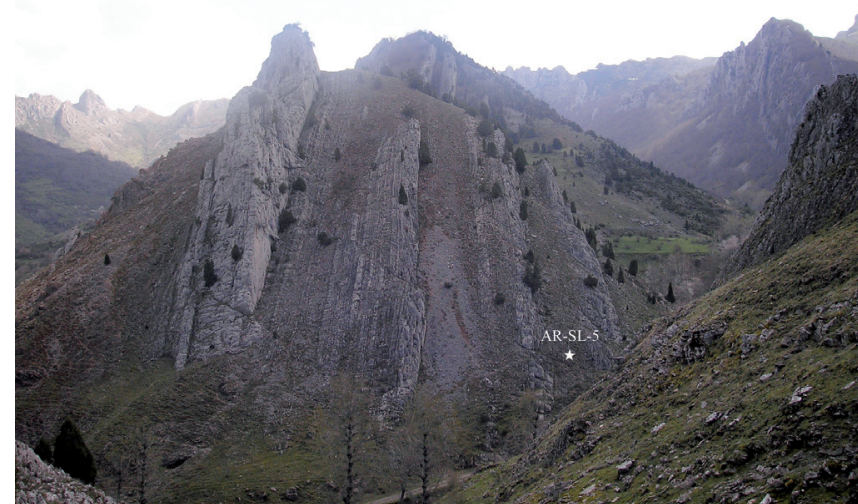

Figura 5. Localidad tipo de Meristella esbelta n.sp., a lo largo del Arroyo de La Trapa, en la ladera occidental de Peña Escricia, 500 m ESE de Argovejo (provincia de León),

Locus typicus of Meristella esbelta n.sp., track along the La Trapa creek, western slope of Peña Escricia, $500 \mathrm{~m}$ ESE of Argovejo, province of León.

género discutido. Meristella esbelta n.sp. sería, a nuestro conocimiento, la primera especie del género de la transición Emsiense-Eifeliense que se conoce en España.

\section{Meristella esbelta n.sp.}

Figs. 1-7, Tab. 1

Derivatio nominis: En castellano, esbelta: delgada: alude al contorno alargado y elegante de la especie en las fases juveniles y comienzos de la efébica.

Material: Treinta ejemplares, con diferente grado de conservación (Tab. 1). Holotipo DPO 39045 y 11 paratipos, DPO 39041-39044, 39046-39048, 39051-39052 procedentes de la localidad y estrato-tipo. Otros 7 ejemplares DPO 39063-39069 (39063 seccionado para cortes seriados, Fig. 3) y 39071 de la misma localidad, en mal estado de conservación. Siete ejemplares, DPO 39053-39058, 39070 (seccionado para cortes seriados, Fig. 4) de distintos niveles del Miembro III de la Formación Santa Lucía, en el corte del Arroyo del Puerto (ESE de Santa Lucía, prov. de León, N de España) (Fig. 1), Emsiense más alto o Eifeliense basal. Cuatro ejemplares, DPO 39059-39062 de la ensenada de Moniello (Luanco, Asturias, $\mathrm{N}$ de España) (Fig. 1), del miembro superior de la Fm. Moniello, Emsiense más alto.

Localidad y estrato tipo: La localidad tipo se encuentra en la pista a lo largo del arroyo de La Trapa, a unos 500 m al ESE del pueblo de Argovejo (Crémenes, Cistierna, provincia de León, $\mathrm{N}$ de España) (Fig. 5). El estrato tipo se encuentra en unas calizas arcillosas decimétricas gris oscuro, con finas intercalaciones pizarrosas, pertenecientes a la parte superior del Miembro III de la Formación Santa Lucía, nivel M-AR-SL-5 (Fig. 6) del Emsiense final, techo del Intervalo Faunístico 16 (García-Alcalde, 1996).

Diagnosis: Meristella pequeña, de contorno sub-romboidal a longitudinalmente ovalado; comisuras cortantes, comisura frontal recta o ligeramente arqueada en dirección dorsal; sin seno ventral ni pliegue medio dorsal. Foramen mesotírido a permesotírido, deltidio fuerte, siempre visible, ángulo apical promedio $64^{\circ}$. Placas dentales cortas pero bien singularizadas; septo medio dorsal muy largo, extendiéndose más allá de la mitad de la longitud.

Meristella small sized, sub-rhomboidal to longitudinally oval outline, commissures sharp, anterior commissure right to slightly arched dorsally, no ventral sinus nor median dorsal fold. Foramen mesothyrid to permesothyrid, deltidium strong, well visible, average apical angle $64^{\circ}$. Dental plates well-defined, short, very long median dorsal septum, prolonged anterior to mid-length.

Descripción: Conchas astróficas con charnela estrecha; palintropo muy pequeño limitado por aristas umbonales poco definidas, redondeadas. Tamaño pequeño para el género (menos de $20 \mathrm{~mm}$ de longitud; promedio 11,9 $\mathrm{mm}$ ), alargadas (promedio a/L: 0,74), bajas (promedio $\mathrm{g} / \mathrm{L}$ 0,49) (Fig. 7, Tab. 1), con la máxima anchura hacia los $2 / 3$ de la longitud; contorno sub-romboidal asimétrico a longitudinalmente ovalado, ventribiconvexas con el máximo grosor por detrás de la mitad de la longitud (el de la ventral hacia el $40 \%$ de $\mathrm{L}$ y el de la dorsal hacia el $46 \%$ de L). Gancho ventral curvado, suberecto a erecto, perforado por un foramen circular mesotírido a permesotírido, limitado basalmente por un deltidio convexo y fuerte, siempre visible; ángulo apical entre $50^{\circ}$ y $70^{\circ}$ (promedio $64^{\circ}$ ) (Tab. 1); gancho dorsal recurvado ocupando parte de la cavidad deltirial; regiones umbonales fuertemente convexas; valvas regularmente convexas en vistas anterior y posterior. Comisuras cortantes, la anterior rectimarginada o débilmente curvada dorsalmente, y las laterales rectas. Superficie de ambas valvas lisa, sin seno ventral ni pliegue medio dorsal, cubierta de finas líneas concéntricas de crecimiento, numerosas y regularmente distanciadas; las líneas evidencian un desarrollo ontogenético donde domina la componente longitudinal del crecimiento en las fases bréficas y la transversal en las efébicas.

Caracteres internos (apreciados en conchas desgastadas y en secciones seriadas) (Figs. 5-6): Placas dentales finas y cortas, pero bien definidas, limitando posterolateralmente el campo muscular, no reforzadas por placas mistroquiales u otros elementos esqueléticos; dientes relativamente menudos y largos. Campo muscular ventral 


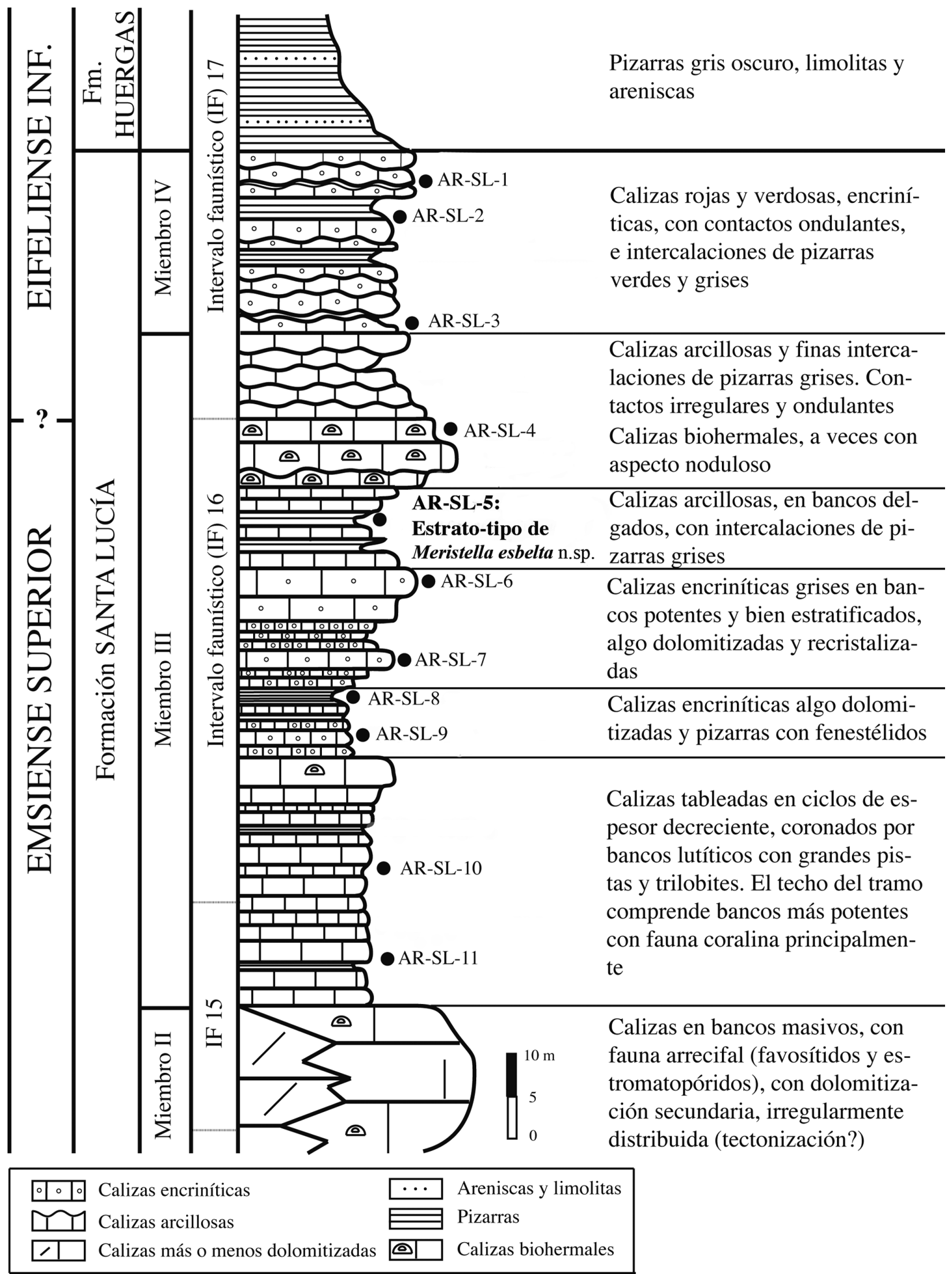

Figura 6. Estrato tipo de Meristella esbelta n.sp. en la la localidad anterior. El estrato tipo es el nivel AR-SL-5, en la parte alta del Miembro III y del Intervalo Faunístico 16 de la Formación Santa Lucía, Emsiense terminal.

Meristella esbelta n.sp., stratum typicum at the locus typicus above: Level AR-SL-5, upper part of the Member III and of the Fauna Interval 16, Santa Lucia Formation, latest Emsian. 
típico para el género, en forma de abanico ensanchándose débilmente hacia delante, poco marcado. Septo medio dorsal muy largo, terminando más allá de la mitad de la longitud, sin ningún tipo de placas de refuerzo. El septo soporta un septalio descubierto, ancho y poco profundo, ocupado en la parte posterior por una pequeña prominencia de concha secundaria; el septo es grueso y bajo, pero tiende a adelgazar y a aumentar la altura por delante de la plataforma cardinal hasta casi la mitad de la longitud de la concha, para luego perder, de nuevo, altura hacia su extremo distal; placas cardinales separadas y muy inclinadas hacia el plano medio de la valva. Cavidades glenoideas estrechas y profundas; crestas internas prominentes, articuladas con la base de los dientes. Cruras finos que en el mismo borde de la estructura septalial se curvan abruptamente en dirección ventral. Braquidio espiralado con espiras dirigidas lateralmente, mal conservado en los ejemplares seccionados, de manera que no se pudo apreciar la estructura yugal.

Discusión: La mayor parte de caracteres externos e internos acreditan la pertenencia de esta especie a los meristelinos, en particular a Meristella. Sin embargo, el tamaño pequeño, y la estructura apical, con deltidio siempre evidente, no responden a las típicas del género. Dichos caracteres no parecen suficientes, en todo caso, para proponer un nuevo género, máxime cuando existen formas descritas, como las subespecies de Meristella iconensis Struve, 1964, que comparten tales caracteres con la aquí presentada. Dichas subespecies (M. iconensis iconensis y M. iconensis permusculosa Struve, 1964), del Eifeliense inferior del Eifel (capas de Nohn), se diferencian de nuestra especie en que presentan siempre seno ventral y pliegue medio dorsal más o menos desarrollados, reflejados en la comisura frontal, claramente uniplegada, y en que el septo medio dorsal es más corto, alcanzando algo menos de la mitad de la longitud.

Meristella scalproides Struve, 1964, es equidimensional a transversa, y la comisura frontal es también uniplegada. De las especies citadas en el Emsiense superior de la Caliza de Erbray, por Barrois (1889), Meristella recta es comparable con la aquí presente por el tamaño, desarrollo del septo medio dorsal y parte media de ambas valvas no diferenciada, pero es prácticamente equidimensional, de contorno pentagonal redondeado con la anchura máxima hacia la mitad de la longitud o antes y ángulo apical mucho mayor. Algunas de las especies descritas y/o figuradas por Hall (1867) y Hall \& Clarke (1893), en especial, M. haskinsi, presentan ciertas semejanzas con la nuestra, pero son todas, invariablemente, más grandes, con valvas de convexidad similar, pliegue dorsal y/o seno ventral más marcados $\mathrm{y}$, por tanto, con comisura frontal uniplegada. $M$. rostrata, de pequeño tamaño como $M$. esbelta, tiene seno ventral bien marcado anteriormente y el frente de la concha suele estar débilmente invaginado. A pesar de no conocerse la estructura yugal, $M$. esbelta n.sp. tiene placas dentales muy cortas y campo muscular ventral poco marcado, lo que la separa de todas las formas de Meristina.

\section{Género Saberaia n.gen.}

Derivatio nominis: De Sabero (provincia de León, N de España, próxima a la localidad tipo del género, Colle).

Especie-tipo: Saberaia truyolsae n.sp., Emsiense superior, Cordillera Cantábrica ( $\mathrm{N}$ de España).

Diagnosis: Meristelino de tamaño pequeño a medio, alargado, de contorno subpentagonal; concha lisa, no diferenciada, o con seno y pliegue dorsal marcados sólo en la comisura, que se arquea débilmente en dirección dorsal. Foramen mesotírido a epitírido, limitado basalmente por
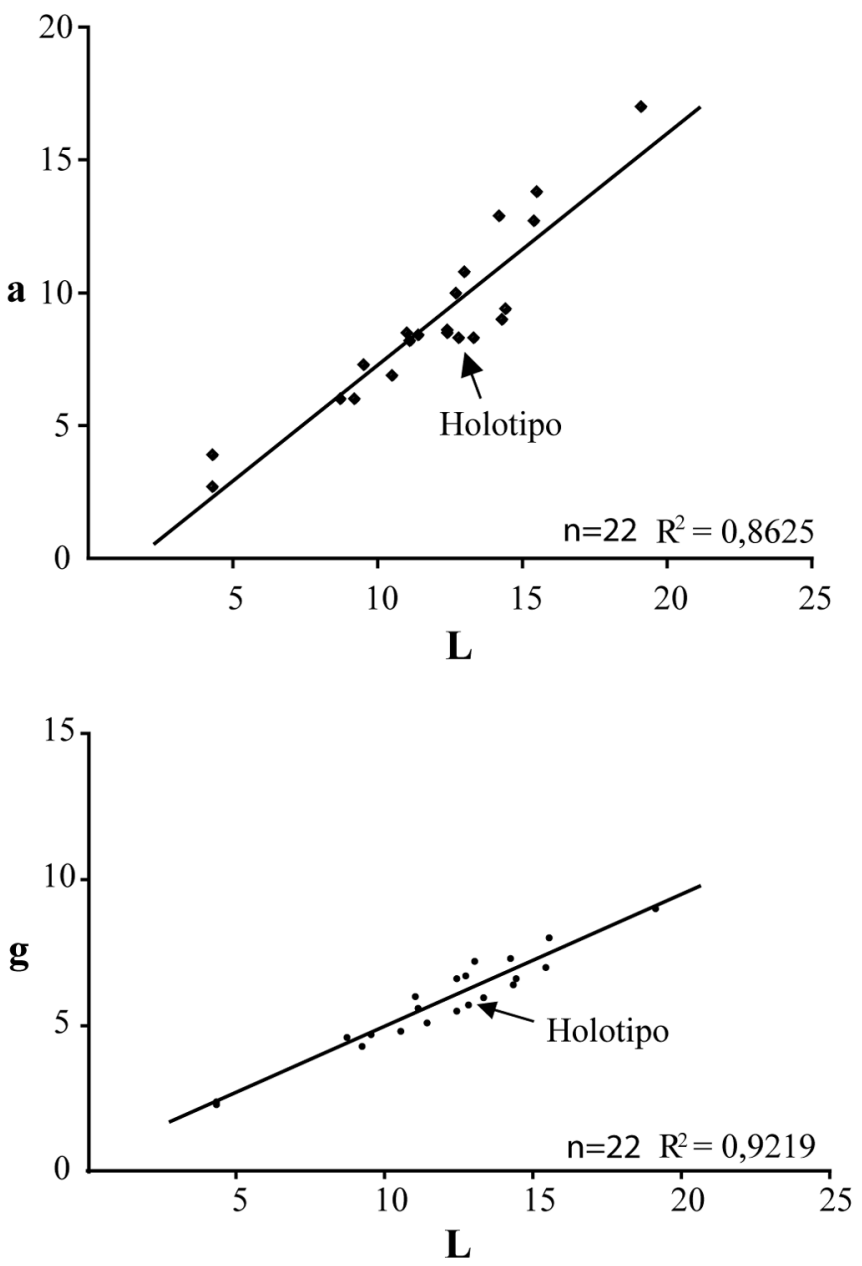

Figura 7. Diagramas de dispersión longitud/anchura (L/a) y longitud/grosor (L/g) de Meristella esbelta n.sp., incluyendo la posición del holotipo.

Meristella esbelta n.sp. length/width (L/a) and length/thickness $(\mathrm{L} / \mathrm{g})$ dispersion diagrams, including the setting of the holotype. 
un robusto deltidio, siempre visible. Placas dentales cortas, divergentes, limitando un campo muscular débil, atravesado por finas elevaciones radiales redondeadas que alcanzan el margen de la concha. Septalio descubierto, ancho y relativamente profundo, soportado por un septo medio fino, alto y largo, que parece atravesar, con frecuencia, el fondo de la cavidad septalial, formando una cresta media más o menos alta. Braquidio espiralado. Yugo con arco yugal proyectándose posteriormente en un tallo yugal bi- furcado en ramas yugales accesorias, frecuentemente espinosas, las cuales describen sendos bucles y se unen de nuevo al tallo yugal.

Meristelline small to mid-sized, longer than wide, subpentagonal outline, either not differentiated, smooth shell, or with a ventral sinus and dorsal fold developed at the commissure, that is faintly arched dorsally. Mesothyrid to epithyrid foramen, bounded basally for a robust, always visible deltidium. Dental plates short, divergent, bounding

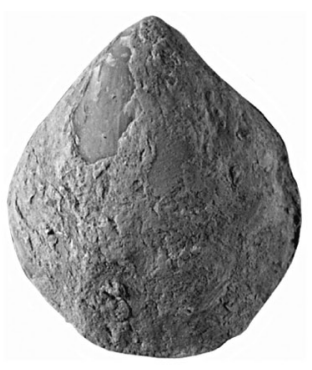

a1

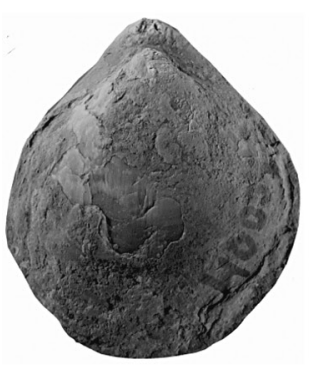

a2

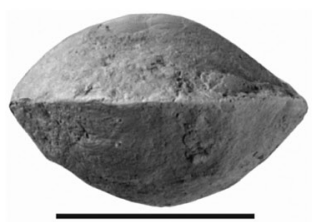

a3

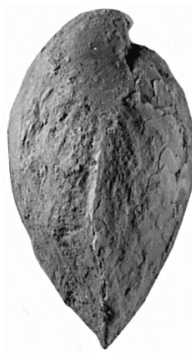

a4

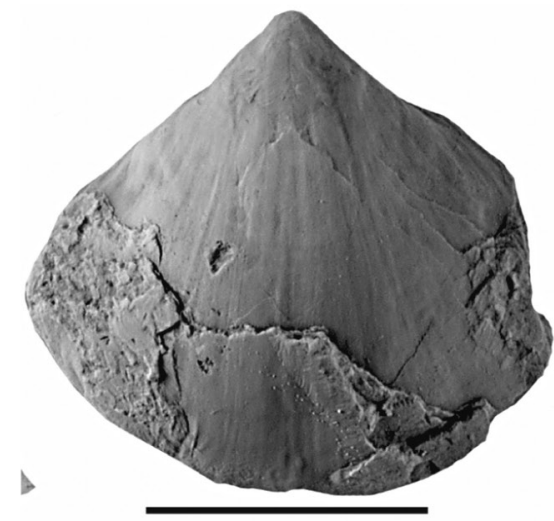

b

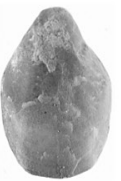

d1

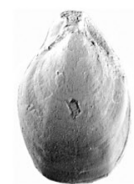

d3

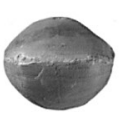

d4

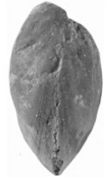

$\mathrm{d} 2$

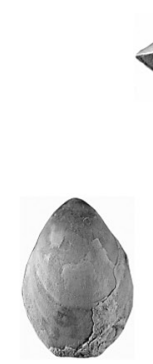

f1

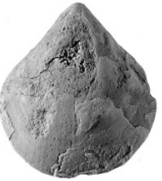

e1

e4

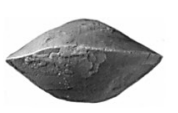

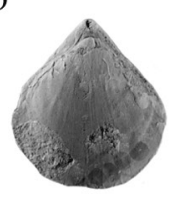

e2

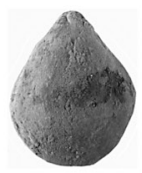

g1

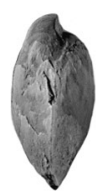

e3

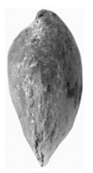

g2

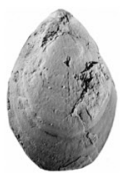

f2

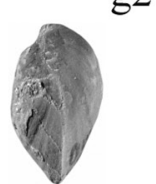

f3

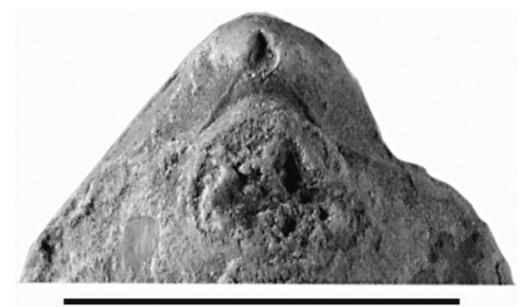

c
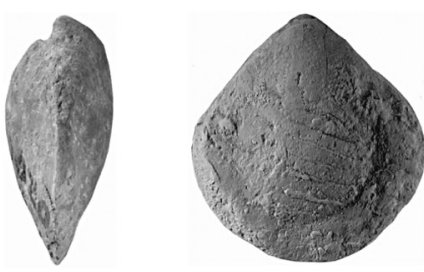

h1

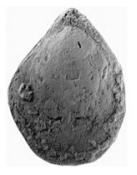

g3

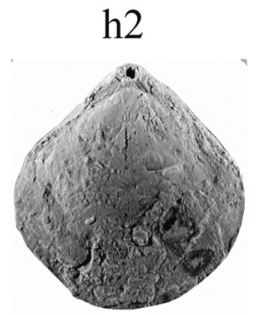

h3

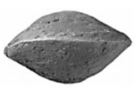

g4

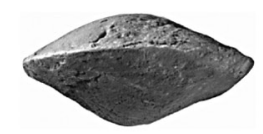

h4

Figura 8. Saberaia truyolsae n.gen. n.sp., de Colle (León). a1-a4: Holotipo DPO 40004, vistas ventral, dorsal, anterior y lateral. b: Paratipo DPO 40005. Vista ventral de un ejemplar desconchado mostrando el campo muscular y las finas elevaciones radiales atravesándolo. c: Paratipo DPO 40097, detalle de la región apical ventral, mostrando el deltidio completo. d1-d4: Paratipo DPO 40109, vistas ventral, lateral, dorsal y anterior. e1-e4: Paratipo DPO 40067, vistas ventral, dorsal, lateral y anterior. f1-f3: Paratipo DPO 40060, vistas ventral, dorsal y lateral. g1-g4: Paratipo DPO 40106, vistas ventral, lateral, dorsal y anterior. h1-h4: Paratipo DPO 40020, vistas lateral, ventral, dorsal y anterior. Barras de escala: $10 \mathrm{~mm}$. La barra más pequeña corresponde a todas las figura menos a b y c.

Saberaia truyolsae n.gen. n.sp., from Colle (León). a1-a4: Holotype DPO 40004, ventral, dorsal, anterior and lateral views. b: Paratype DPO 40005, fragmentary ventral internal mould showing the muscle field and fine radial ridges crossing it. c: Paratype DPO 40097, enlarged dorsal view of the shell apical region showing the complete deltidium. d1-d4: Paratype DPO 40109, ventral, lateral, dorsal and anterior views. e1-e4: Paratype DPO 40067, ventral, dorsal, lateral and anterior views. f1-f3: Paratype DPO 40060, ventral, dorsal and lateral views. g1-g4: Paratype DPO 40106, ventral, lateral, dorsal and anterior views. h1-h4: Paratype DPO 40020, lateral, ventral, dorsal and anterior views. Scale bars: $10 \mathrm{~mm}$. The smaller bar corresponds to all the figures excepting $\boldsymbol{b}$ and $\boldsymbol{c}$. 
a very faint muscle field, crossed by round and fine radial ridges that reach the shell margins. Septalium open, wide, and relatively deep, supported by a median septum high, long and thin, that usually penetrates the septalial cavity forming a more or less high median crest. Well-developed spiralium and jugum; jugal arch projecting posteriorly in a jugal stem bifurcated distally, giving rise to frequently fimbriate accessory jugal branches, that diverge and curve into complete loops joined again to the jugal stem.

Discusión: Saberaia se separa de la mayoría de meristelinos conocidos, en el carácter indiferenciado de la concha, tamaño, contorno, grosor, estructuras apicales, con gancho relativamente curvado y deltidio fuerte, siempre visible, placas dentales cortas pero bien individualizadas, campos musculares muy poco marcados y septalio bien desarrollado apoyado en un septo medio alto, fuerte y largo.

García-Alcalde (2001b) interpretó, con dudas, el material tipo del nuevo género como perteneciente a Charionoides Boucot, Johnson \& Staton, 1964, una forma apalachense de la misma edad, con ciertos rasgos similares: concha no muy gruesa con gancho ventral poco curvado y deltidio fuerte y visible, placas dentales cortas y campo muscular ventral poco marcado. Dicho género se diferencia, sin embargo, en la posesión de un palintropo ventral muy extenso, un seno ventral y un pliegue dorsal desarrollados en buena parte de la concha que originan una comisura anterior fuertemente arqueada en dirección dorsal, $\mathrm{y}$ un septalio sesil posteriormente, apoyado hacia delante en un corto septo medio.

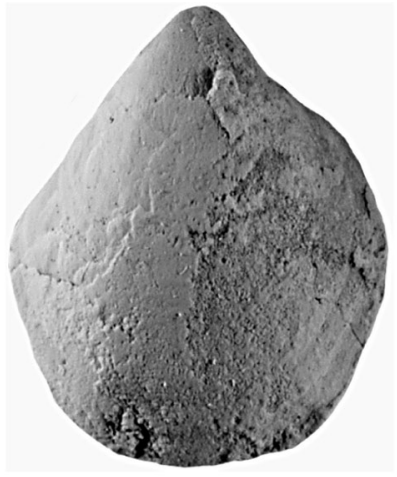

a1

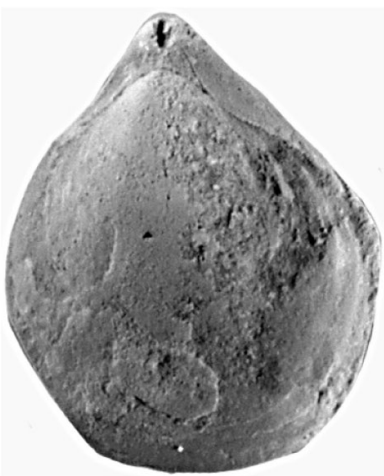

a2

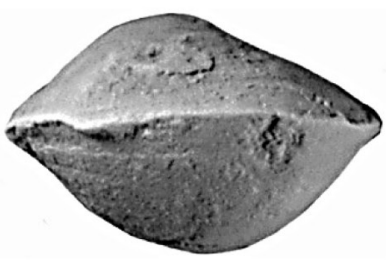

a3

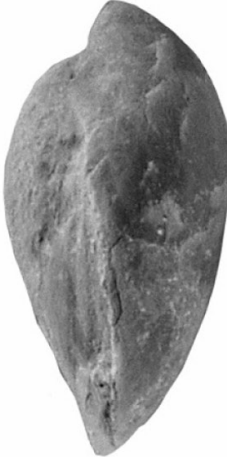

$\mathrm{a} 4$

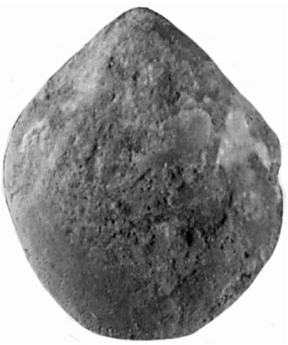

b1

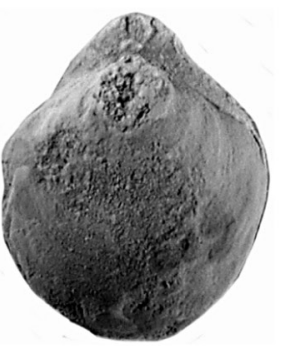

b3

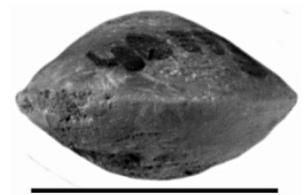

b4
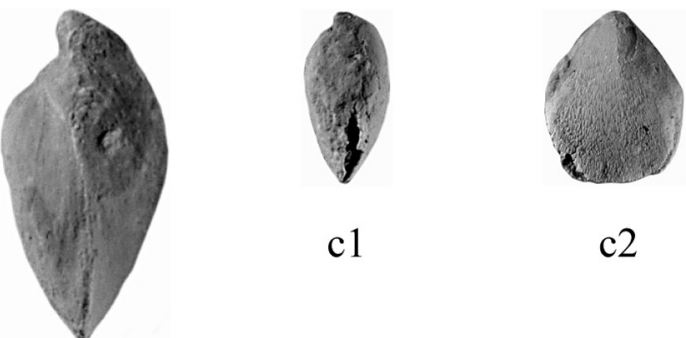

c1

c2
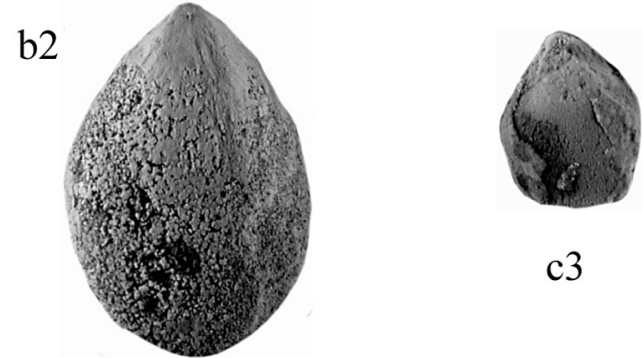

c3

d1
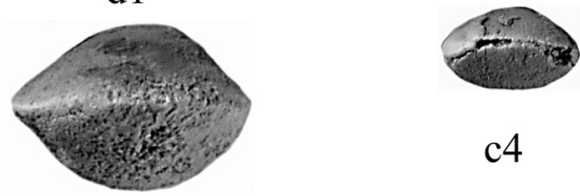

c4

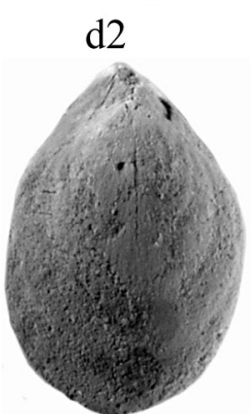

d3

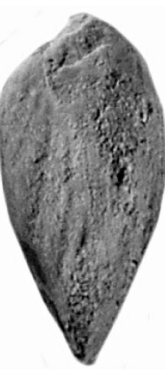

d4

Figura 9. Saberaia truyolsae n.gen. n.sp., de Colle (León). a1-a4: Paratipo DPO 40055, vistas ventral, dorsal, anterior y lateral. b1b4: Paratipo DPO 40113, vistas ventral, lateral, dorsal y anterior. c1-c4: Paratipo DPO 40089, ejemplar juvenil, vistas lateral, ventral, dorsal y anterior. d1-d4: Paratipo DPO 40059, vistas ventral, anterior, dorsal y lateral. Barra de escala: $5 \mathrm{~mm}$. Saberaia truyolsae n.gen. n.sp. a1-a4: Paratype DPO 40055, ventral, dorsal, anterior and lateral views. b1-b4: Paratype DPO 40113, ventral, lateral, dorsal and anterior views. c1-c4: Paratype DPO 40089, young specimen, lateral, ventral, dorsal and anterior views. d1-d4: Paratype DPO 40059, ventral, anterior, dorsal and lateral views. Scale bar: $5 \mathrm{~mm}$. 
Especies asignadas: Sólo la especie tipo.

\section{Saberaia truyolsae n.sp.}

Figs. 8-17, Tab. 2

? 1850 Terebratula Bordini, n.sp.; Verneuil (en Prado \& Verneuil), p. 36 (pars), non pl. I, Fig. 8a, b (Cimicinella bordini $=$ Cimicinella schulzi).

? 1892 Terebratula (Cryptonella) Bordiu, Vern.; Mallada, p. 47 (pars).

? 1938 Triathyris bordiu Verneuil; Comte, p. 45 (pars), non Pl. IV, Fig. 17 (=Lectotipo de Cimicinella bordini $=$ C. schulzi).

? 1959 Triathyris bordui, Verneuil; Comte, p. 218 (pars).
? 1959 Triathyris bordiu; Comte, pp. 307 (pars), 247, Tab. II (suite) (pars).

? 1959 Triathyris bordiu Verneuil; Comte, p. 406 (pars).

v. 2001b Charionoides? sp. A; García-Alcalde, Fig. 1.

Derivatio nominis: Dedicada a Montserrat Truyols Massoni, profesora titular de la Universidad de Oviedo, compañera, amiga queridísima y colaboradora fiel.

Material: Un total de 261 ejemplares, frecuentemente deformados pero conservando estructuras internas bien preservadas. Holotipo DPO 40004 y 89 paratipos DPO 3411334114, 39919, 40001-40003 y 40005-40057, 40059-40067,

Tabla 2. Saberaia truyolsae n.gen. n.sp., de Colle (León). Medidas de algunos ejemplares en mm. (L, a, g y $\alpha$ : longitud, anchura, grosor y ángulo apical).

Saberaia truyolsae n.gen. n.sp., from Colle (León). Measurements of some specimens in mm (L, a, g, $\alpha$ : length, width, thickness, and apical angle).

\begin{tabular}{|c|c|c|c|c|c|c|}
\hline Ejemplar & $\mathbf{L}$ & $\mathbf{a}$ & g & $\mathbf{a} / \mathbf{L}$ & $g / L$ & $\alpha$ \\
\hline Holotipo DPO 40004 & 17,4 & 15,0 & 9,7 & 0,86 & 0,56 & 77 \\
\hline DPO 34114 & 15,6 & 13,4 & 7,7 & 0,86 & 0,49 & 90 \\
\hline DPO 40090 & 16,6 & 14,7 & 7,4 & 0,88 & 0,44 & 77 \\
\hline DPO 40091 & 15,6 & 13,0 & 7,0 & 0,83 & 0,45 & \\
\hline Paratipo DPO 40232 & 15,5 & 13,5 & 7,5 & 0,88 & 0,49 & 79 \\
\hline DPO 40092 & 15,5 & 12,7 & 7,8 & 0,82 & 0,50 & \\
\hline Paratipo DPO 40233 & 15,4 & 14,6 & 7,0 & 0,95 & 0,45 & 75 \\
\hline DPO 40093 & 15,0 & 12,6 & 7,1 & 0,84 & 0,47 & 91 \\
\hline Paratipo DPO 40234 & 14,9 & 13,6 & 6,7 & 0,91 & 0,45 & \\
\hline DPO 40094 & 14,0 & 11,4 & 6,5 & 0,81 & 0,46 & \\
\hline Paratipo DPO 40236 & 13,6 & 11,3 & 6,9 & 0,83 & 0,51 & 65 \\
\hline Paratipo DPO 40235 & 13,2 & 11,1 & 6,2 & 0,84 & 0,47 & 77 \\
\hline DPO 40012 & 12,5 & 10,0 & 6,8 & 0,80 & 0,54 & 88 \\
\hline DPO 40018 & 11,9 & 9,4 & 5,5 & 0,79 & 0,46 & 77 \\
\hline DPO 40260 & 11,8 & 9,6 & 6,1 & 0,81 & 0,52 & 70 \\
\hline DPO 40099 & 11,5 & 9,0 & 5,3 & 0,78 & 0,46 & 83 \\
\hline DPO 40027 & 10,7 & 8,8 & 5,8 & 0,82 & 0,54 & \\
\hline DPO 40262 & 10,2 & 8,6 & 5,0 & 0,84 & 0,49 & 57 \\
\hline DPO 40102 & 10,2 & 8,5 & 5,5 & 0,83 & 0,54 & \\
\hline DPO 40034 & 10,2 & 8,3 & 5,4 & 0,81 & 0,53 & 79 \\
\hline DPO 40037 & 10,1 & 8,5 & 5,1 & 0,84 & 0,50 & 77 \\
\hline DPO 40044 & 10,0 & 8,0 & 4,7 & 0,80 & 0,47 & 76 \\
\hline DPO 40045 & 8,8 & 7,4 & 4,9 & 0,84 & 0,56 & 78 \\
\hline DPO 40048 & 8,7 & 7,2 & 4,2 & 0,83 & 0,48 & \\
\hline DPO 40061 & 7,5 & 6,2 & 4,0 & 0,83 & 0,53 & 69 \\
\hline DPO 40066 & 7,2 & 6,0 & 3,7 & 0,83 & 0,51 & 73 \\
\hline DPO 40070 & 6,5 & 5,6 & 3,6 & 0,86 & 0,55 & 58 \\
\hline DPO 40075 & 5,4 & 4,6 & 2,9 & 0,85 & 0,54 & 67 \\
\hline DPO 40084 & 4,3 & 3,6 & 2,0 & 0,84 & 0,46 & 65 \\
\hline DPO 40089 & 3,3 & 2,7 & 1,7 & 0,82 & 0,51 & 70 \\
\hline DPO 40085 & 3,2 & 2,7 & 1,5 & 0,84 & 0,47 & \\
\hline
\end{tabular}


40069-40071, 40073-40087, 40089 (Figs. 8-9), bastante bien conservados, del estrato tipo y de la localidad tipo (ejemplares DPO 34113-34114, 39119, 40007, 40015, seccionados, Figs. 10-14); otros 168 ejemplares topotípicos, DPO 40090-40116, 40118-40257, en peor estado de conservación. Siete ejemplares, DPO 40258-40264, de Villayandre (Crémenes, prov. de León) (Fig. 1), yac. I-141, del mismo nivel estratigráfico que el material tipo, Grupo de La Vid, Formación Coladilla, Emsiense superior.

Localidad y estrato tipo: Colle $(5 \mathrm{~km}$ al Oeste de Sabero, prov. de León, $\mathrm{N}$ de España), ladera septentrional de la colina sobre la que se asienta la iglesia del pueblo (Fig. 15). Calizas y calcoesquistos finamente estratificados, amarillentos, verdosos y rojizos de la parte alta del Grupo de La Vid, mitad inferior de la Fm. Coladilla, nivel 28 (Fig. 16), Emsiense superior, Intervalo Faunístico 12 (García-Alcalde, 1996), probablemente parte alta de la zona de conodontos Polygnatus inversus/P. laticostatus ( $c f$. García-López \& Sánz-López, 2002).

Diagnosis: Saberaia de tamaño pequeño a medio, alargada, subpentagonal, lisa y no diferenciada, o con seno y pliegue dorsal débiles, indicados en la comisura. Máxima anchura situada en la mitad anterior de la longitud.

Saberaia small to mid-sized, longer than wide, subpentagonal outline, either smooth, not differentiated shell, or with a faint median ventral sinus and dorsal fold, developed at the commissure. Greatest width anterior to mid-length.

Descripción: Concha impuntuada, de tamaño pequeño a medio (promedio L 9,8 mm para 107 medidas; Lmáx 19 mm; Lmin $3 \mathrm{~mm}$ ), astrófica con charnela corta e interárea ventral poco desarrollada que se encuentra limitada por aristas umbonales subangulosas. Contorno subpentagonal con la máxima anchura en la mitad anterior de la longitud, ligeramente ventribiconvexa y poco espesa (promedio $\mathrm{g} / \mathrm{L}$ 0,50, para 107 medidas). La máxima convexidad de las valvas se encuentra en la región umbonal. Concha más larga que ancha (promedio a/L 0,84, para 107 medidas) (Fig. 17, Tab. 2). La concha no suele estar diferenciada, salvo en los adultos que tienden a desarrollar un seno medio ventral estrecho y muy poco profundo cerca del margen. Las valvas son suave y regularmente convexas en vistas anterior y lateral. El gancho ventral es prominente, suberecto a erecto en las conchas adultas, perforado por un foramen circular mesotírido a epitírido, limitado basalmente por un deltidio completo y convexo, a veces plegado en su parte media (Fig. 8c1). El gancho dorsal está oculto bajo el deltidio. Ángulo apical agudo, en torno a $72^{\circ}$. Comisuras laterales y anterior cortantes. Comisura anterior recta en los ejemplares juveniles, tendiendo a curvarse dorsalmente de manera suave en algunos adultos. Lamelas de crecimiento finas y numerosas, muy apretadas. Concha lisa, carente de elementos macro y microornamentales.

Caracteres internos (observados mediante secciones seriadas, Figs. 10-14): Placas dentales cortas, divergentes, con caras internas cóncavas que soportan dientes cardinales finos, a veces denticulados, formando una articulación robusta complementada, a veces, por la prolongación de las placas cardinales externas que encajan en la base de los dientes; en ciertos ejemplares parece existir una cápsula peduncular fina y angosta; cavidades apicales laterales libres y bien desarrolladas. Septalio descubierto, ancho y relativamente profundo, que se extiende hasta el

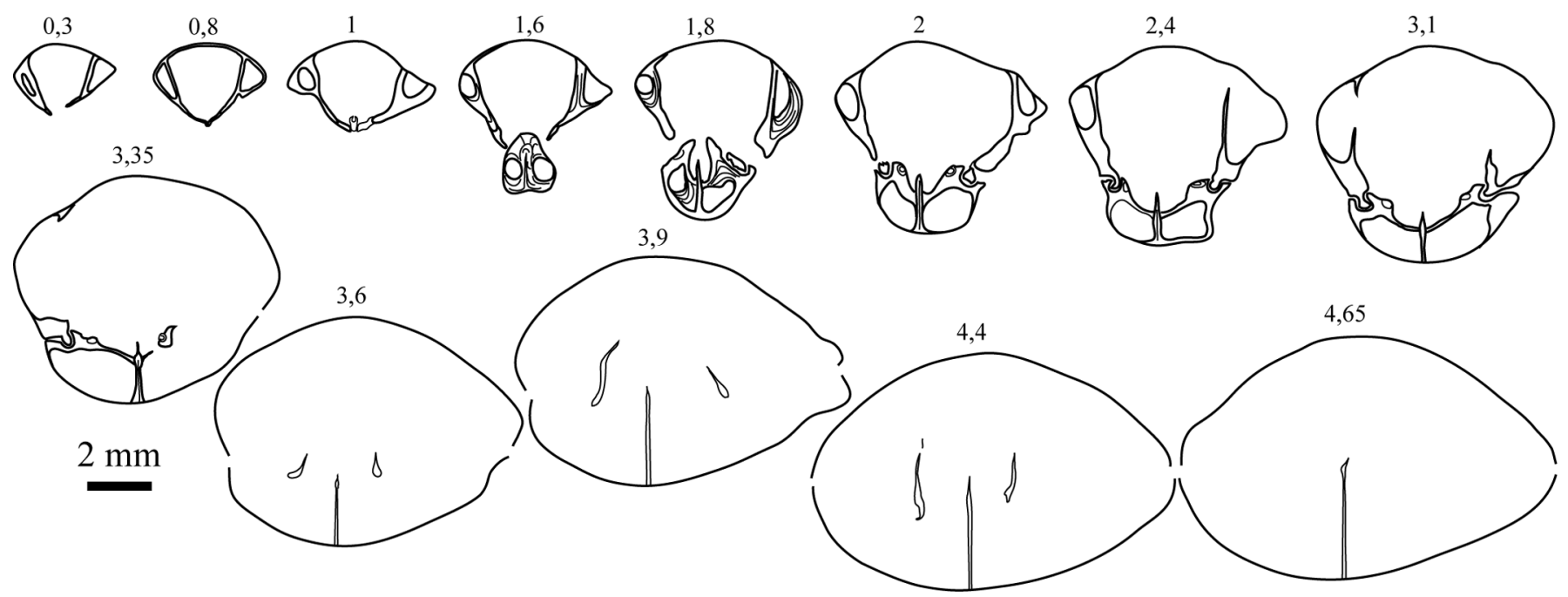

Figura 10. Saberaia truyolsae n.g. n.sp. Paratipo DPO 34113, de Colle (León). Dibujos con cámara clara de secciones seriadas, perpendiculares al plano de simetría y al plano comisural. Distancias medidas en mm. al ápice ventral. Saberaia truyolsae n.gen. n.sp. Paratipo DPO 34113, from Colle (León). Camera lucida drawings of serial sections, normal to both the symmetry and the commisural planes. Distances in mm measured from the shell apex. 
límite de la articulación de la concha, soportado por un septo medio alto y fino que se prolonga hasta cerca de la mitad de la longitud de la concha. Placas septaliales finas unidas lateralmente al septo medio, el cual suele descollar mucho del fondo del septalio, formando una especie de partición media del mismo (Fig. 10); cruras que se proyectan inicialmente en el plano de la comisura para doblarse luego ventralmente hasta unirse a las lamelas primarias del braquidio. Braquidio espiralado, conos espirales con 9-10 espiras, a veces fimbriadas en la región distal. Yugo complejo con ramas yugales laterales que parten de las lamelas primarias y forman un arco yugal del que se proyecta posteroventralmente un fino tallo yugal bifurcado a la altura de la unión de los crura con las lamelas primarias, en sendas ramas yugales accesorias que describen bucles, dirigidos dorsal, anterior y anteroventralmente que suelen unirse de nuevo al tallo yugal, en la forma habitual para Meristella y Triathyris mucronata (ver luego, Figs. 25-26). Ramas yugales accesorias espinosas, sobre todo cerca del punto de bifurcación del tallo yugal (Figs. 12-13). Campos musculares apenas impresos en el fondo de las valvas, atravesados por finas y bajas elevaciones longitudinales que alcanzan el frente de la concha (Fig. 8b).

Discusión: Teniendo en cuenta que Cimicinella bordini (Verneuil, en Prado \& Verneuil, 1850) (con toda probabilidad una forma corta de C. schulzi) es una forma rara en la Cordillera Cantábrica, ya que sólo se conoce el lectotipo en la Colección Verneuil, es probable que muchas de las referencias a la especie, en especial las de Mallada (1892) y Comte $(1938,1959)$, con las grafías Terebratula (Cryptonella) Bordiu, Triathyris bordiu y T. bordui se refieran, en realidad, a Saberaia truyolsae n.sp., que es muy abundante en su localidad tipo, donde coexiste con C. schulzi. Como ya se comentó antes, las homeomorfías entre Triathyris mucronata, Cimicinella bordini, C. schulzi y Saberaia truyolsae, son probablemente las causantes de que Comte (1938) las incluyese en un único género atiridáceo, Triathyris. Es más, el comentario de Verneuil (en Prado \& Verneuil, 1850, p. 172) en la descripción de Terebratula Bordini, "Coquille subpentagone, à test lisse et très finement perforé. Ces perforations, toutefois, paraissent n'appartenir qu'à la partie superficielle du test, et ne se voient pas quand la coquille est usée ou dépouillée", parece indicar que se mezclaron observaciones del ejemplar que luego se convirtió en el lectotipo del terebratúlido C. bordini, donde se aprecian con claridad los endopuntos, y de ejemplares no terebratúlidos de nuestro nuevo taxon, Saberaia truyolsae, en diferentes grados de desgaste los cuales, en efecto, carecen de tales perforaciones.

S. truyolsae n.sp. se diferencia fácilmente de T. $m u$ cronata, en la ausencia de microornamentación costulada, en el contorno subpentagonal y en la ausencia de carenas medias y espolón anterior en los adultos. De Cimicinella bordini $(=C$. schulzi), se separa en la ausencia de endopuntuación y en las estructuras internas; en particular $S$. truyolsae tiene un septo medio dorsal muy desarrollado, que se aprecia en todos los ejemplares con un mínimo desgaste, mientras que las especies de Ciminella carecen del mismo y en su lugar presentan una estructura en arco (doppeltrog) con largas bases crurales submedias, visibles también en ejemplares algo erosionados. Nuestra especie se separa de Meristella esbelta n.sp., en el contorno subpentagonal, menor grado de alargamiento, gancho ventral más recurvado, ángulo apical mayor.
0,1

0,9

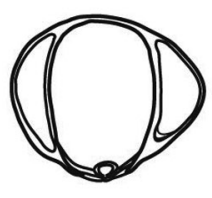

1,75
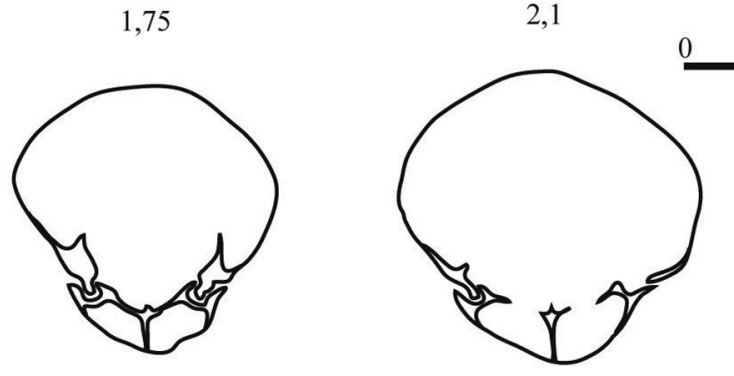

1,2

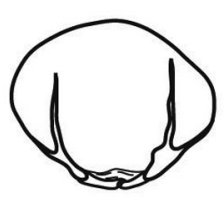

1,4

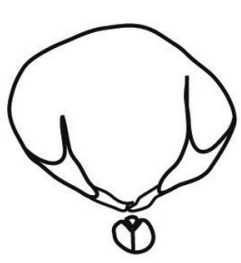

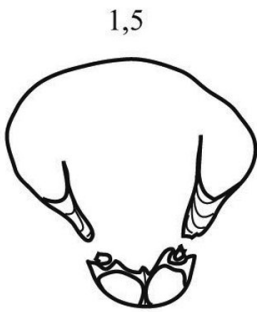

2,3

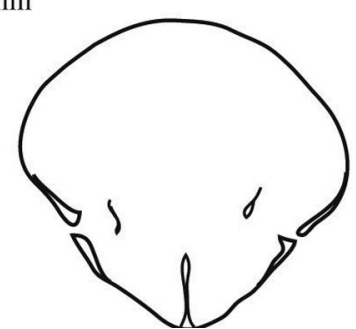

2,7

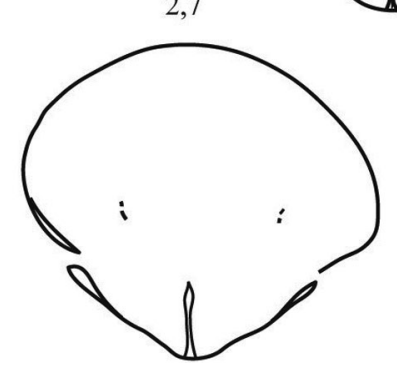

Figura 11. Saberaia truyolsae n.g. n.sp. Paratipo DPO 34114, de Colle (León). Dibujos con cámara clara de secciones seriadas, perpendiculares al plano de simetría y al plano comisural. Distancias medidas en mm. al ápice ventral.

Saberaia truyolsae n.gen. n.sp. Paratipo DPO 34114, from Colle (León). Camera lucida drawings of serial sections, normal to both the symmetry and the commisural planes. Distances in mm measured from the shell apex. 


\section{Familia Triathyrididae Álvarez, Rong \& Boucot, 1998}

Observaciones: Álvarez et al. (1998) propusieron que la nueva Familia Triathyrididae comprendía dos subfamilias, Triathyridinae (género-tipo: Triathyris) y Septathyridinae (género-tipo: Septathyris), asimismo nuevas, diferenciadas en el tipo de microornamentación costulada, la primera descrita como "ornament of delayed costation progressively developed medially", y la segunda como "ornament of fine lines folded in a chevron like pattern with the angles directed in posteroanterior direction" (op. cit., p. 836).

Pero la microornamentación de Triathyris comprende, en realidad, dos sistemas de estrías subradiales que se cortan, uno de ellos más completo que el otro, pero que tienden a formar una reticulación en chevron, esencialmen-
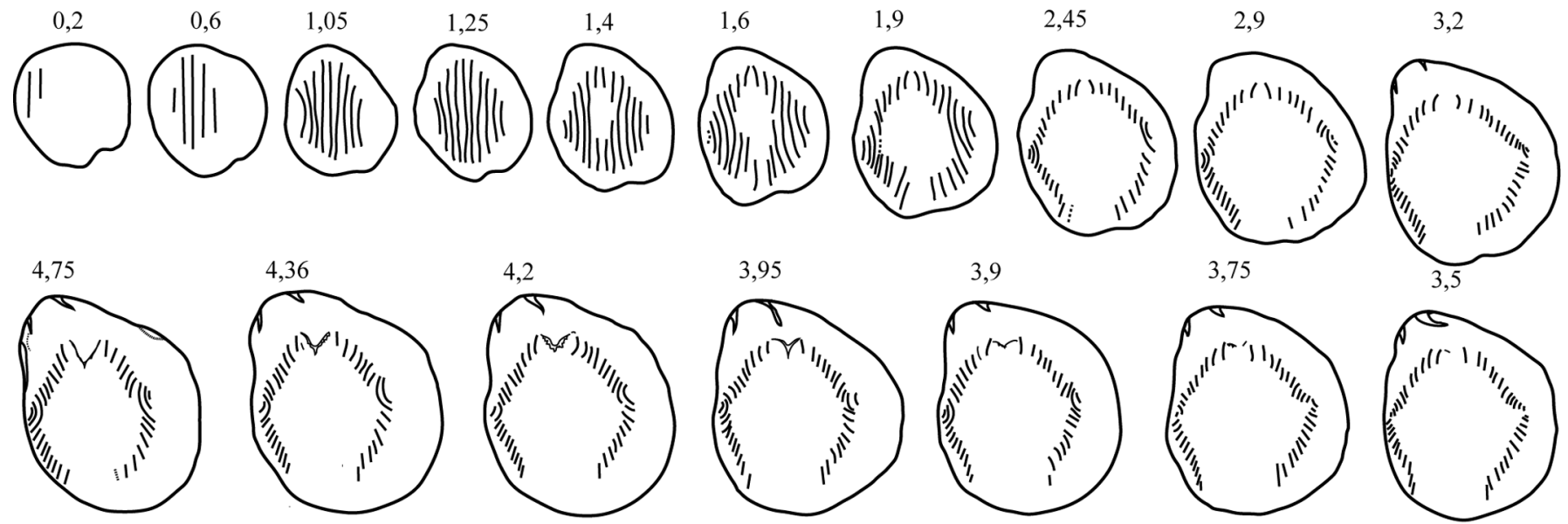

3,75
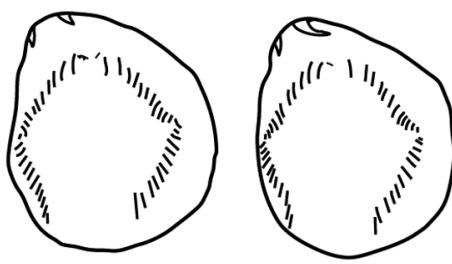

5,05

5,15

5,2

5,35

5,52

5,6

5,9

6
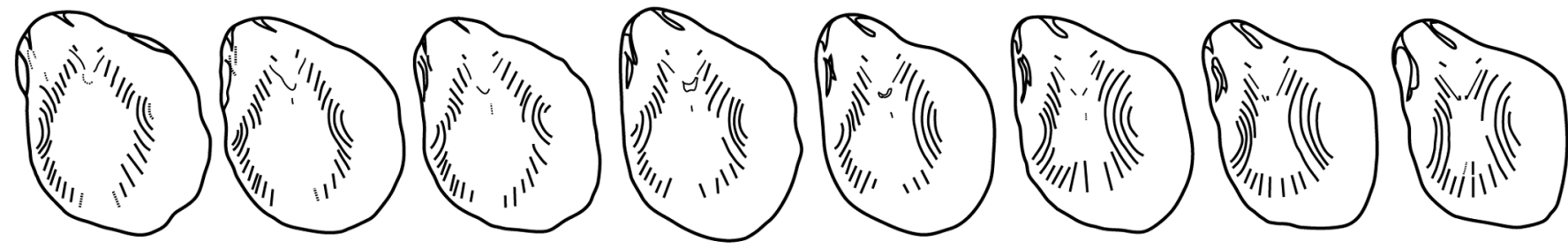

6,3

6,4

6,6

6,65

6,8

7,1

7,15

7,1

7,15
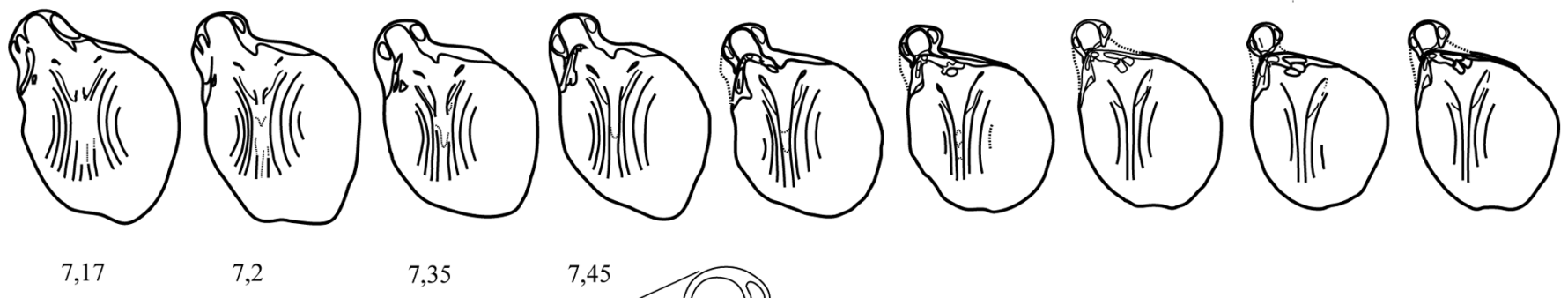

7,2
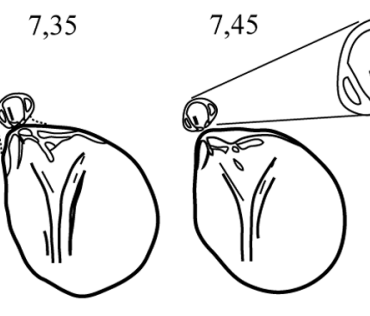

$0 \quad 2 \quad 4 \mathrm{~mm}$
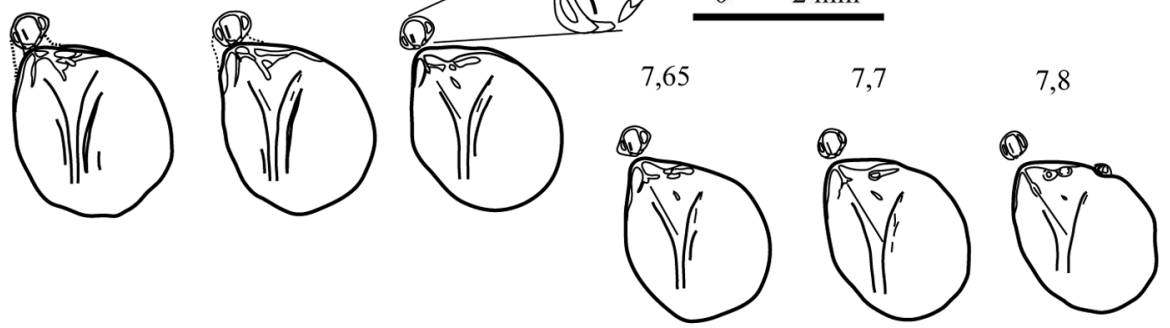

7,83

7,9
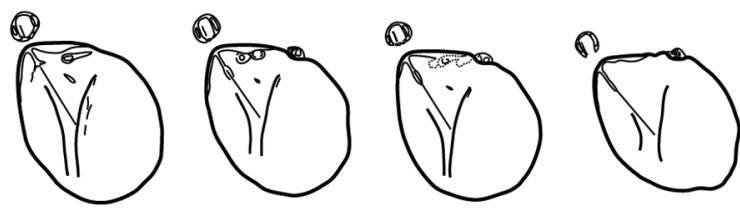

Figura 12. Saberaia truyolsae n.g. n.sp. Paratipo DPO 39919, de Colle (León). Dibujos con cámara clara de secciones seriadas, paralelas al plano de la comisura en sentido ventro-dorsal. Distancias en mm. medidas desde el plano tangente de la valva ventral.

Saberaia truyolsae n.gen. n.sp. Paratipo DPO 34113, from Colle (León). Camera lucida drawings of ventro-dorsally serial sections, parallel to the plane of commissure. Distances in $\mathrm{mm}$ from the tangent plane to the ventral valve. 
te similar a la de Septathyris (Figs. 18-19), por lo que la distinción de dos subfamilias basada sólo en la microornamentación de dichos géneros no resulta suficientemente motivada. Este tipo de microornamentación ya fue más o menos apercibido por Comte (1938), quién indicó que se parecía a la disposición reticulada de Pradoia, género con finas bases de espinas al tresbolillo (García-Alcalde, 1971, 1986), disposición que, en definitiva, puede considerarse como un chevron discontinuo.

En este trabajo visualizamos Triathyrididae Álvarez, Rong \& Boucot, 1998 como un taxon no subdividido que comprende, por el momento, los géneros Triathyris Comte, 1938 (Le Maître, 1952) y Septathyris Boucot, Johnson \& Staton, 1964. Ambos taxones están relacionados por el tipo de ornamentación y estructura interna, y ciertos ejemplares de Triathyris tienden a desarrollar, además, una de- presión media en ambas carenas (Fig. 19c1-c2), formando pares de pliegues que se encuentran en el margen anterior de la concha, similares a los de Septathyris.

\section{Género Triathyris Comte, 1938 (Le Maître, 1952)}

Diagnosis (enmendada): Concha de tamaño moderado, equidimensional a alargada, normalmente de contorno romboidal, ventribiconvexa; charnela corta, astrófica; foramen ventral mesotírido; deltirio cubierto por un deltidio fuerte y completo; comisura frontal recta a débilmente arqueada en dirección dorsal. Los ejemplares neánicos tienden a desarrollar carenas medias redondeadas en ambas valvas que, en los efébicos, se convierten en pliegues subangulo-
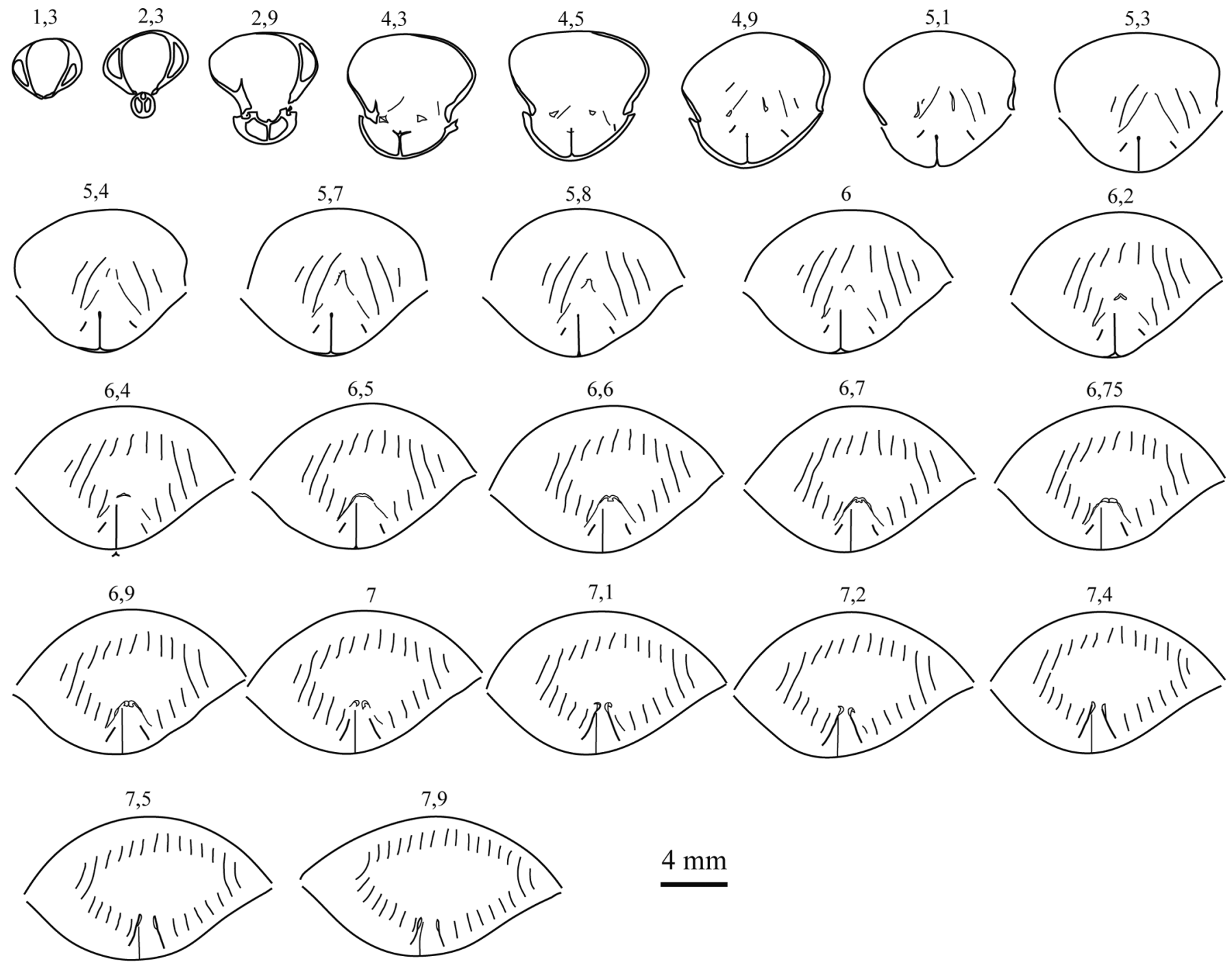

$4 \mathrm{~mm}$

Figura 13. Saberaia truyolsae n.g. n.sp. Paratipo DPO 40007, de Colle (León). Dibujos con cámara clara de secciones seriadas, perpendiculares al plano de simetría y al plano comisural. Distancias medidas en mm. al ápice ventral.

Saberaia truyolsae n.gen. n.sp. Paratipo DPO 40007, from Colle (León). Camera lucida drawings of serial sections, normal to both the symmetry and the commisural planes. Distances in mm measured from the shell apex. 
sos, prolongados en un espolón anterior. Microornamentación básicamente divaricada con finas cóstulas subradiales cubriendo la concha, que intersectan en la línea media de ambas valvas, cortadas por otro sistema discontinuo de microcóstulas, que forma con el anterior una estructura en chevron, visible, sobre todo, cerca de la parte media de ambas valvas y de la comisura anterior. Placas dentales cortas, delgadas, medianamente cóncavas. Septo medio
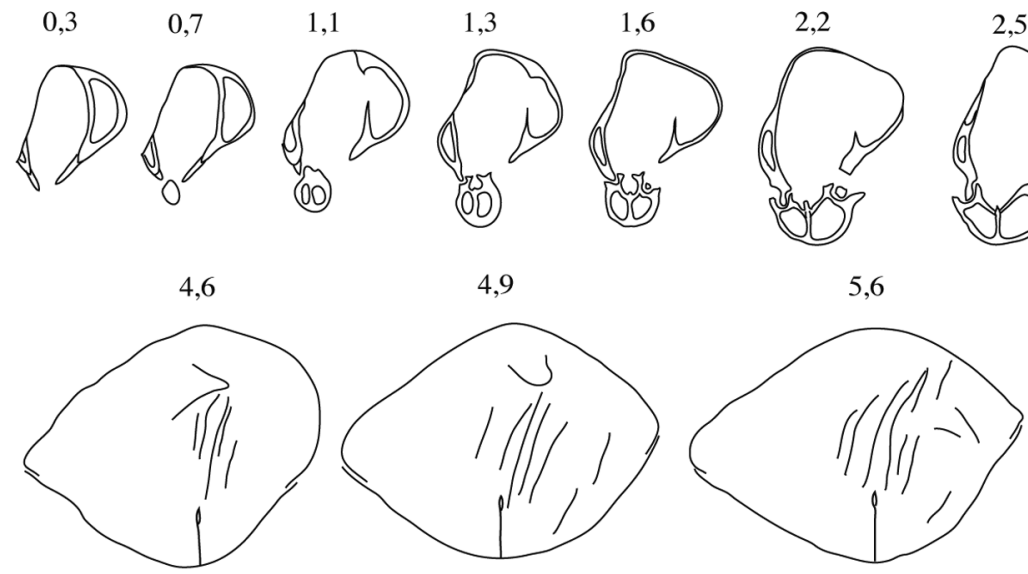

9,1

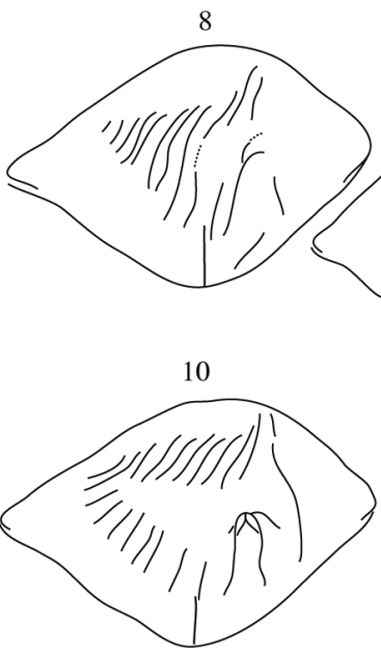

11,8

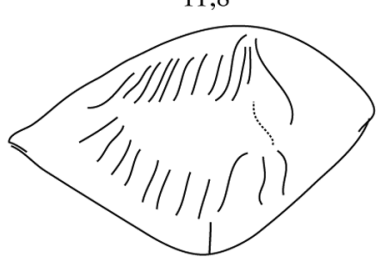

14,5
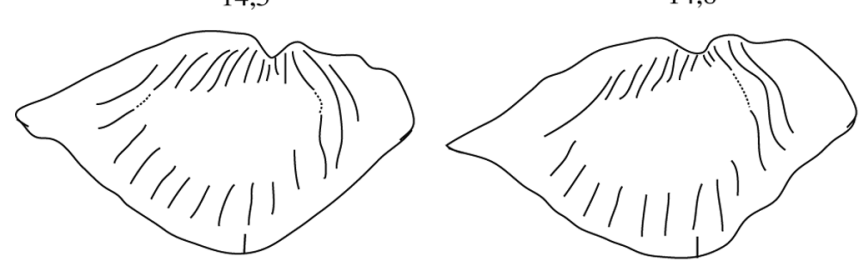
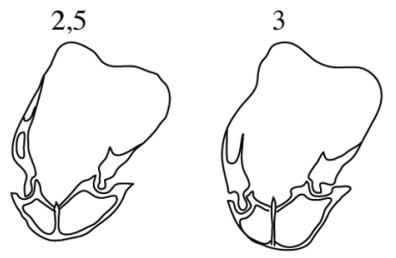

6,5
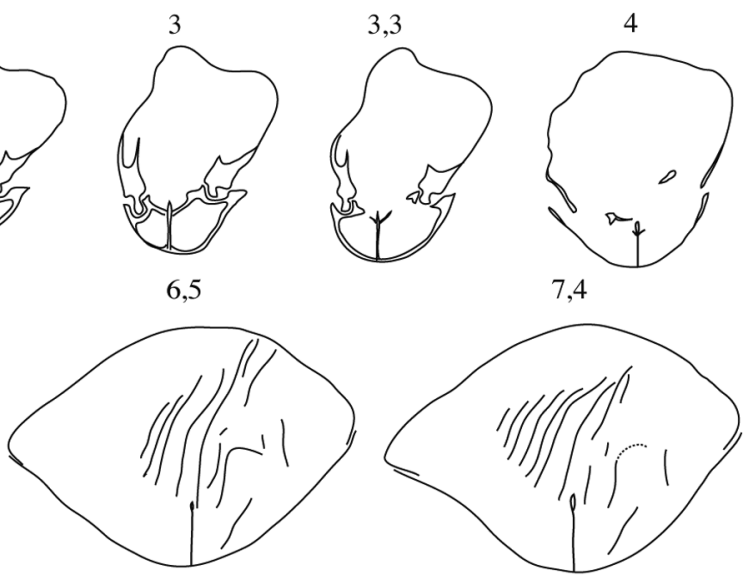

7,4

9,7
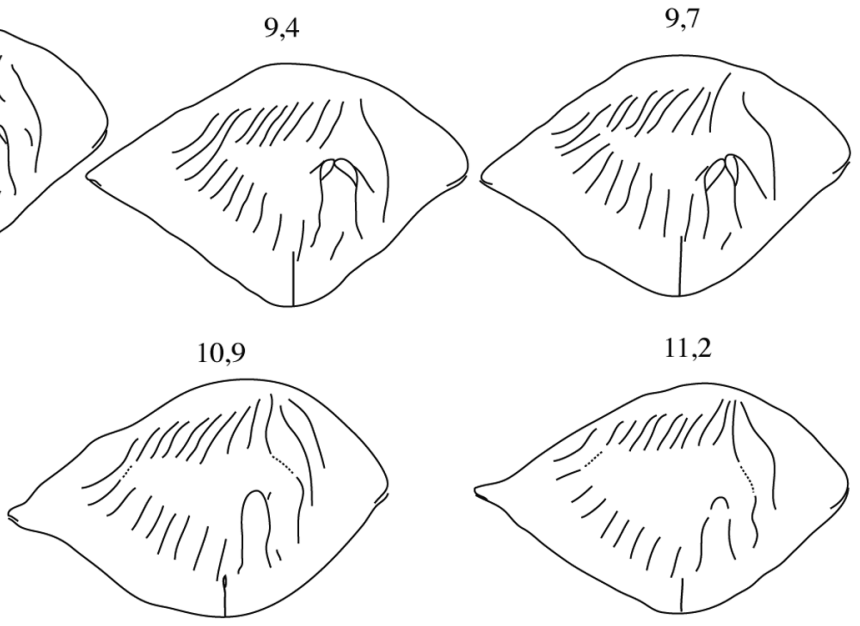

13

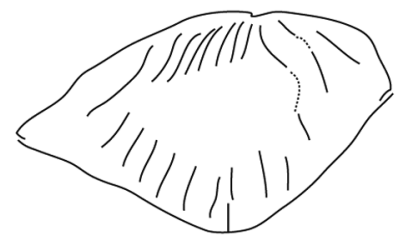

15,2

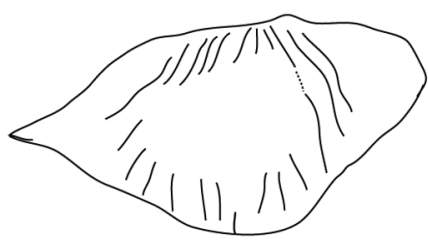

Figura 14. Saberaia truyolsae n.g. n.sp. Paratipo DPO 40015, de Colle (León). Dibujos con cámara clara de secciones seriadas, perpendiculares al plano de simetría y al plano comisural. Braquidio dañado pero mostrando un yugo meristelino, con tallo yugal y ramas accesorias uniéndose hacia delante al arco yugal. Distancias medidas en mm al ápice ventral.

Saberaia truyolsae n.gen. n.sp. Paratipo DPO 40015, from Colle (León). Camera lucida drawings of serial sections, normal to both the symmetry and the commisural planes. The damaged and broken brachidium shows a meristelline jugum with a jugal stem and accesory jugal branches joining to the jugal arch. Distances in mm measured from the shell apex. 


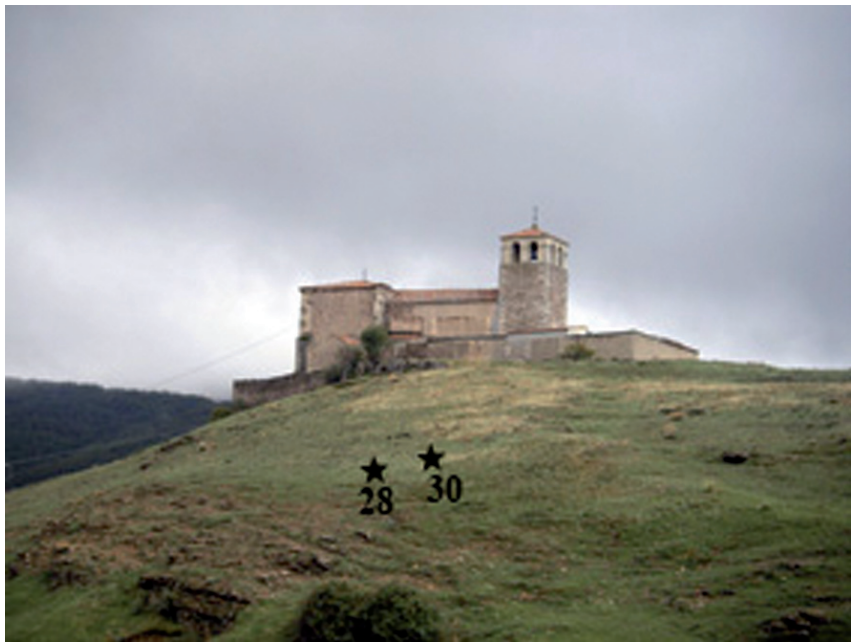

Figura 15. Localidad tipo de Saberaia truyolsae n.g. n.sp. y Triathyris mucronata (Verneuil, en Prado \& Verneuil, 1850), en la ladera septentrional de la donde se asienta la iglesia de Colle.

Locus typicus of Saberaia truyolsae n.g. n.sp. and Triathyris mucronata (Verneuil, in Prado \& Verneu$i l, 1850)$ in the northern slope of the hill where the Colle Church sets up.

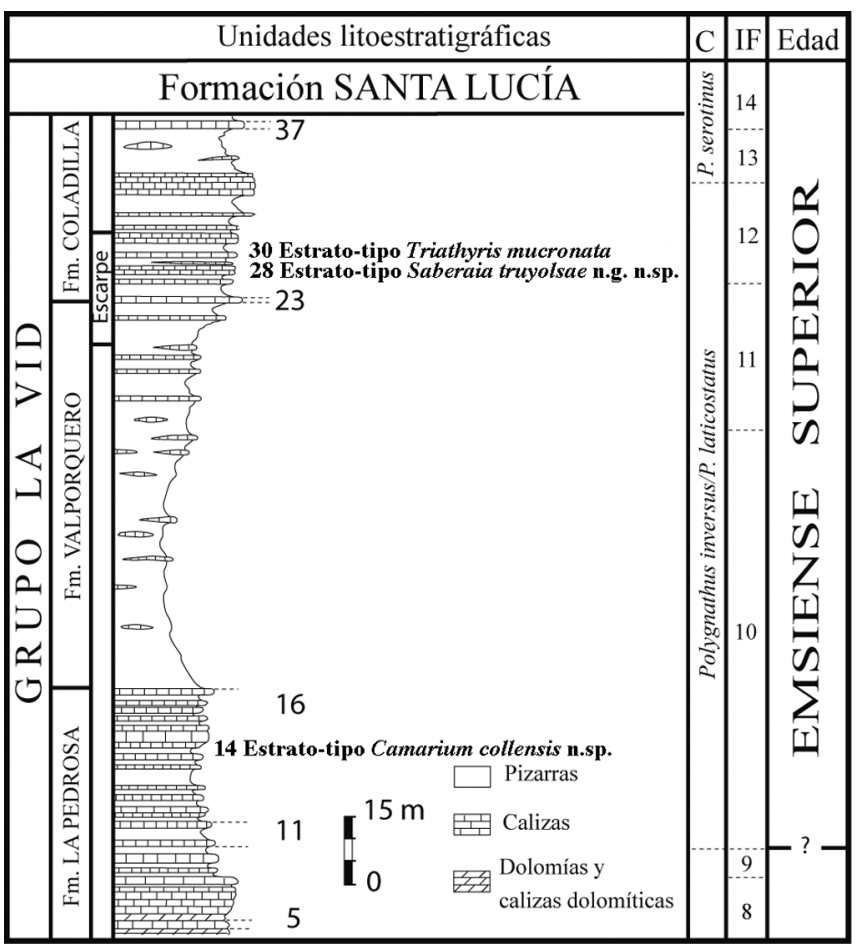

Figura 16. Situación de los estratos tipo de Saberaia truyolsae n.gen. n.sp., Triathyris mucronata (Verneuil, en Prado \& Verneuil, 1850) (ver Fig. 15) y Camarium collensis n.sp. cerca de Colle (provincia de León) (Ver Fig. 29).

Strata typica of Saberaia truyolsae n.gen.n.sp., Triathyris mucronata (Verneuil, in Prado \& Verneuil, 1850) (see Fig. 15) and Camarium collensis n.sp., near Colle (province of Leon) (see Fig. 29). dorsal alto, soportando un septalio no cubierto, ancho y profundo. Campos musculares débilmente impresos, recorridos por finas y bajas elevaciones radiales que alcanzan el margen de la concha. Braquidio espiralado; yugo bien desarrollado con tallo yugal prolongado posteriormente en lamelas yugales accesorias que forman volutas yugales unidas de nuevo hacia delante al tallo yugal.

Shell medium sized, as long as wide to longer than wide, outline usually rhomboidal, ventri-biconvex, hinge short, astrophic, ventral foramen mesothyrid, delthyrium covered by a strong, complete deltidium, anterior commissure right to faintly arched dorsally. The neanic specimens show tendency to develop rounded median carinae in both valves that in adult specimens transform into
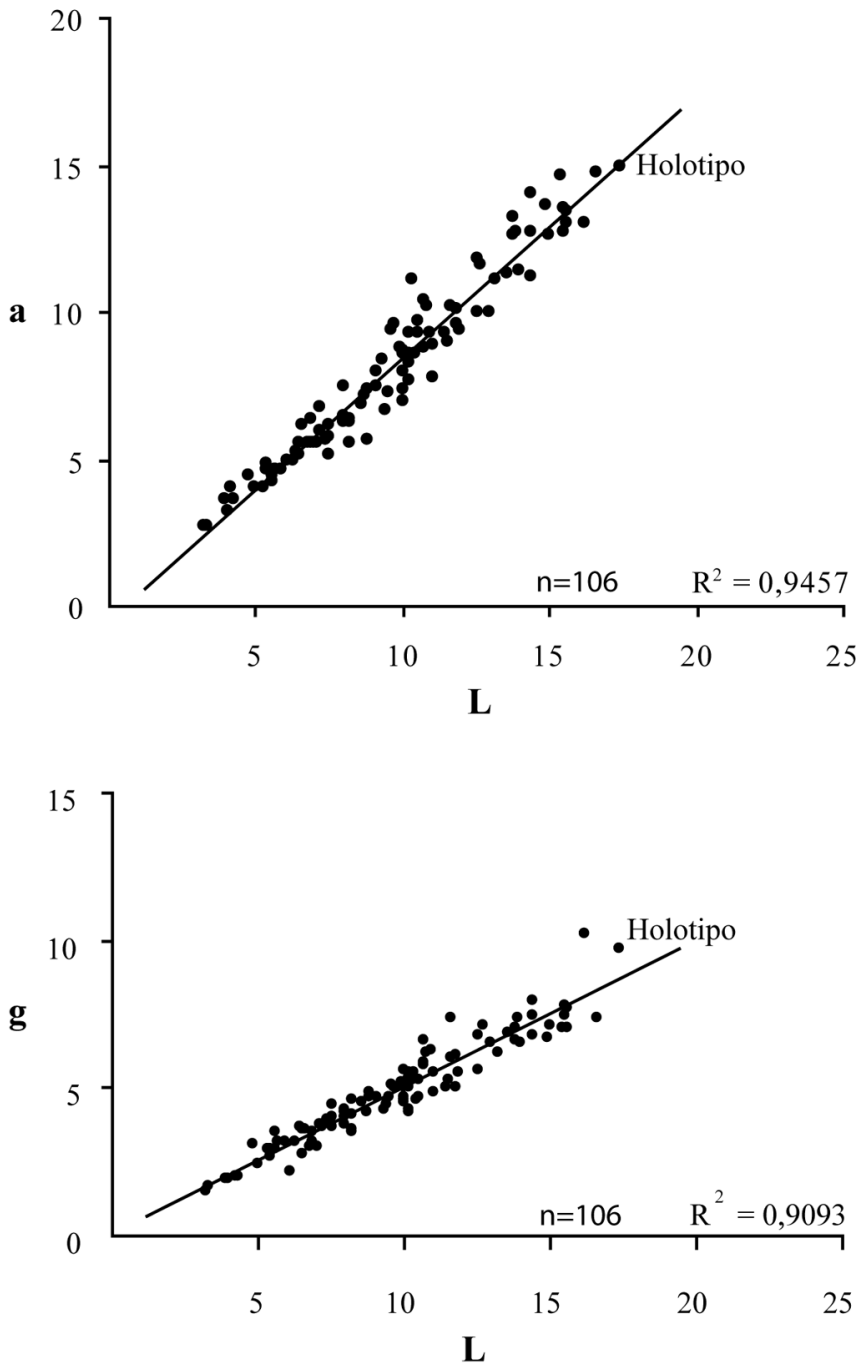

Figura 17. Diagramas de dispersión longitud/anchura (L/a) y longitud/grosor (L/g) de Saberaia truyolsae n.gen. n.sp., incluyendo la posición del holotipo.

Saberaia truyolsae n.gen. n.sp., length/width (L/a) and length/thickness $(\mathrm{L} / \mathrm{g})$ dispersion diagrams, including the setting of the holotype. 


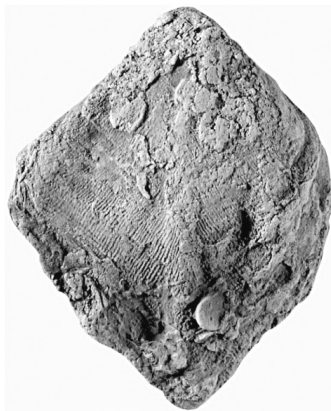

al

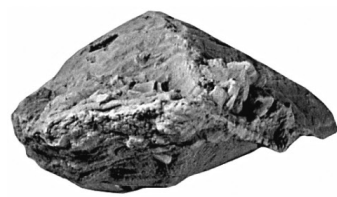

a4

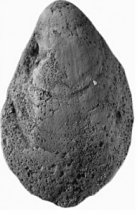

d1

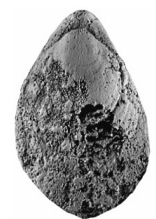

d3

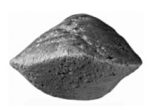

d4

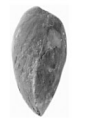

e3

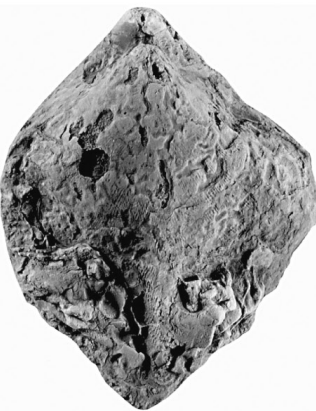

a2

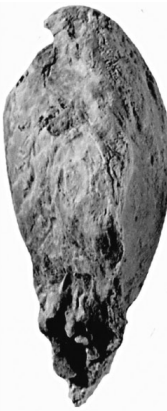

a3

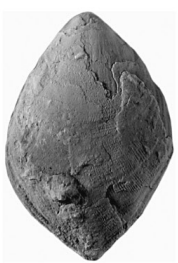

b1

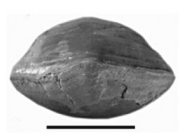

b4

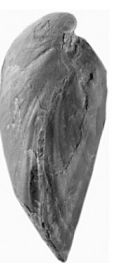

b2

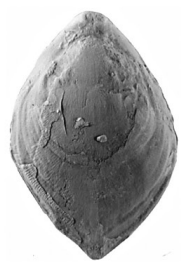

b3

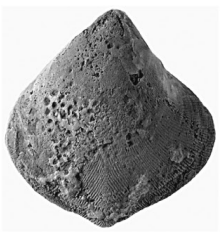

c1

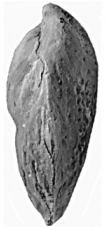

c2

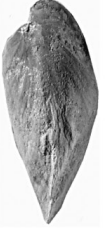

f2

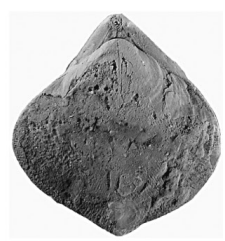

c3

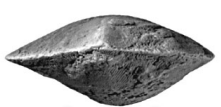

c4

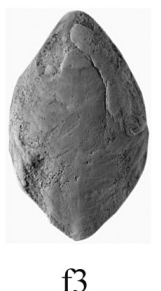

f3

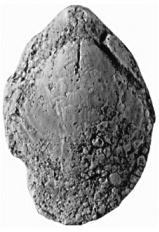

h

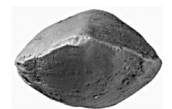

f4

Figura 18. Triathyris mucronata (Verneuil, en Prado \& Verneuil, 1850), todas de Colle (León) salvo c1-c5 de Caldas de Luna (León). a1-a4: DPO 40268, vistas ventral, dorsal, lateral y anterior, mostrando la microornamentación costulada. b1-b4: DPO 40365, vistas ventral, lateral, dorsal y anterior. c1-c5: DPO 40383, vistas ventral, lateral, dorsal, anterior y ampliación de la valva ventral mostrando la microornamentación costulada esencialmente divaricada, con chevron incompletos. d1-d4: DPO 40354, vistas ventral, lateral, dorsal y anterior. e1-e4: DPO 40367, vistas anterior, ventral, lateral y dorsal. f1-f4: DPO 40352, vistas ventral, lateral, dorsal y anterior. g1: DPO 40289, vista ventral de una concha deformada mostrando la microornamentación costulada divaricada con chevron incompletos. h: DPO 40319, vista dorsal de un homeomorfo externo de Cimicinella schulzi. Barras de escala: $10 \mathrm{~mm}$. La barra más pequeña corresponde a todas las figuras salvo c5 y g. Triathyris mucronata (Verneuil, in Prado \& Verneuil, 1850). All specimens from Colle (Leon) excepting c1-c5, from Caldas de Luna (Leon). a1-a4: DPO 40268, ventral, dorsal, lateral and anterior views, showing the costulate micro-ornamentation. b1-b4: DPO 40365, ventral, lateral, dorsal and anterior views. c1-c5: DPO 40383, ventral, lateral, dorsal, anterior views and enlargement of the ventral valve showing an essentially divaricate, costulate micro-ornamentation, and incomplete chevrons. d1-d4: DPO 40354, ventral, lateral, dorsal and anterior views. e1-e4: DPO 40367, anterior, ventral, lateral and dorsal views. f1-f4: DPO 40352, ventral, lateral, dorsal and anterior views. $\mathrm{g}$ : DPO 40289, ventral view of a distorted shell showing a divaricate costulate micro-ornamentation with incomplete chevron. $\boldsymbol{h}$ : DPO 40319, dorsal view of an external homeomorph of Cimicinella schulzi. Scale bars: $10 \mathrm{~mm}$. The smaller bar corresponds to all figures excepting $\mathbf{c} 5$ and $\mathbf{g}$. 


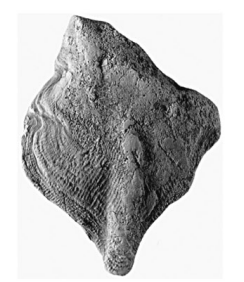

a1

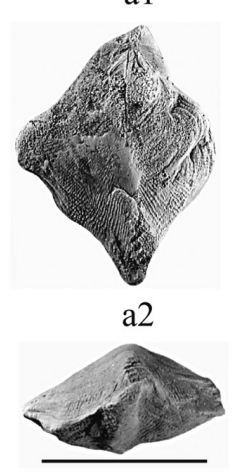

a3

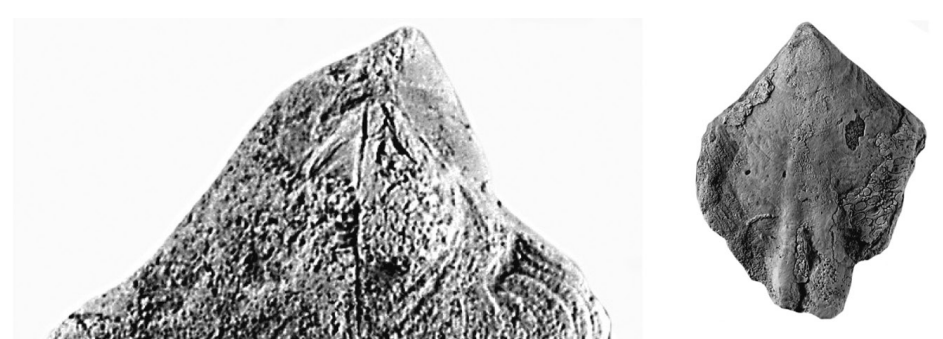

c1

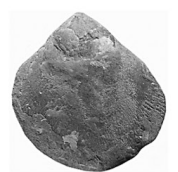

d1

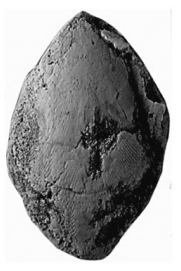

e1

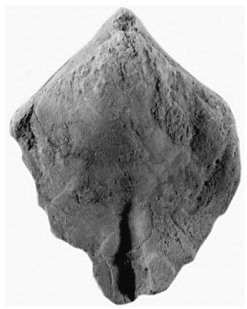

c2

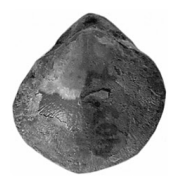

d2

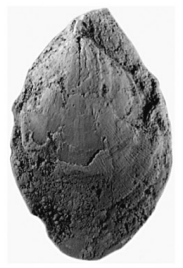

e2

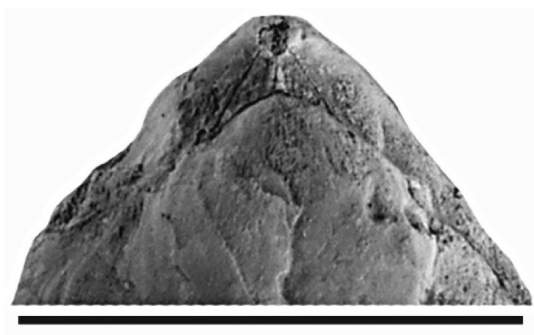

f

Figura 19. Triathyris mucronata (Verneuil, en Prado \& Verneuil, 1850). a1-a4: DPO 40343, de Colle (León), vistas ventral, dorsal y anterior de un ejemplar deforme y ampliación de la valva dorsal, mostrando la microornamentación costulada con sistemas de cóstulas entrecruzados formando chevron particularmente cerca de los bordes de la valva. b: DPO 40381, de Santa Lucía (León), vista dorsal mostrando la microornamentación costulada con sistemas de cóstulas entrecruzados formando chevron particularmente cerca de los bordes de la valva. c1-c2: DPO 40376, de Villayandre (León), vistas ventral y dorsal de un ejemplar con la carena media dividida. d1-d2: DPO 40387, de Caldas de Luna (León), vistas ventral y dorsal, de un ejemplar juvenil, mostrando microornamentación costulada. e1-e2: DPO 40366, de Colle (León), vistas ventral y dorsal de un homeomorfo externo de C. schulzi. f: DPO 40280, detalle de la región apical ventral mostrando un seudodeltidio completo, plegado en su parte media. Barras de escala: $10 \mathrm{~mm}$. La barra más pequeña corresponde a todas las figuras salvo a4, b y f.

Triathyris mucronata (Verneuil, in Prado \& Verneuil, 1850). a1-a4: DPO 40343, from Colle (León), ventral, dorsal and anterior views of a distorted specimen, and enlargement of the dorsal view showing the costulate micro-ornamentation with chevron crossing costules developed particularly near the valve margins. b: DPO 40381, from Santa Lucía (León), dorsal view showing the costulate micro-ornamentation with chevron crossing costules developed particularly near the valve margins. c1-c2: DPO 40376, from Villayandre (Leon), ventral and dorsal views of a specimen with divided median carinae. d1-d2: DPO 40387, from Caldas de Luna (León), ventral and dorsal views of a young specimen showing the costulate micro-ornamentation. e1-e2: DPO 40366, from Colle (León), ventral and dorsal views of an external homeomorph of C. schulzi. $f$ : DPO 40280, enlarged apical ventral region showing a medially folded complete pseudodeltidium. Scalebars: $10 \mathrm{~mm}$. The smaller bar corresponds to all the figures excepting $\boldsymbol{a} 4, \boldsymbol{b}$ and $\boldsymbol{f}$. 
subangular folds prolonged anteriorly in a short, sharp spur. Micro-ornamentation mostly divaricate, with fine sub-radial costules intertwining slightly along the median line of both valves, that are crossed by another discontinuous microcostulate system developing chevron patterns specially along the carinae and near of the shell margins. Dental plates short, thin, medially concaves. High median dorsal septum that supports an open, wide and deep septalium. Muscle fields faint, crossed by fine, low, round radial ridges that reach the shell margins. Spiralium and jugum developed; jugum complex with a jugal stem prolonged posteriorly in accessory jugal lamellae that rejoin anteriorly the stem.

Observaciones: Por haberlo publicado después de 1930, Comte (1938) tendría que haber designado especie-tipo para su género Triathyris a fin de que el nombre estuviese disponible en el sentido del Código (art. 13. CINZ, 2000). Al no hacerlo así, la autoría del nombre pasa a la persona que lo publicó por primera vez satisfaciendo los criterios de disponibilidad (art. 50.1, CINZ, 2000). Álvarez et al. (1998, p. 836) y Álvarez \& Rong (2002, p. 1576) entienden que fueron Boucot, Johnson \& Staton (1965, p. H663) quiénes realizaron la primera designación válida de especie-tipo para el género. Pero, de hecho, el mérito recae en Le Maître (1952, p. 146) (García-Alcalde \& Álvarez, 1976, p. 42), quién estableció, hablando de Triathyris: "T. mucronata qui a un appareil brachial spiralé peut être pris comme type du genre Triathyris", designación que parece inequívoca en el sentido del art. 67.5 y válida en el del art. 69 del Código Internacional de Nomenclatura Zoológica (CINZ, 2000).

Especies asignadas: Sólo la especie-tipo.
0,05

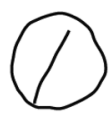

0,4

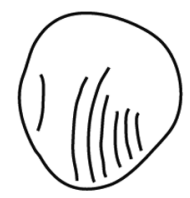

0,6

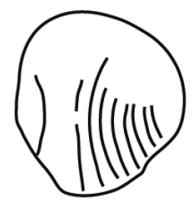

0,7

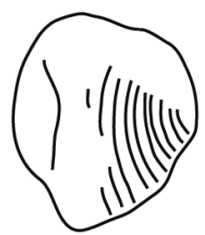

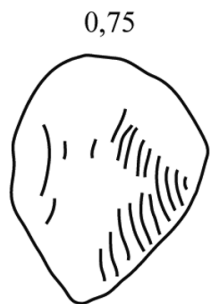
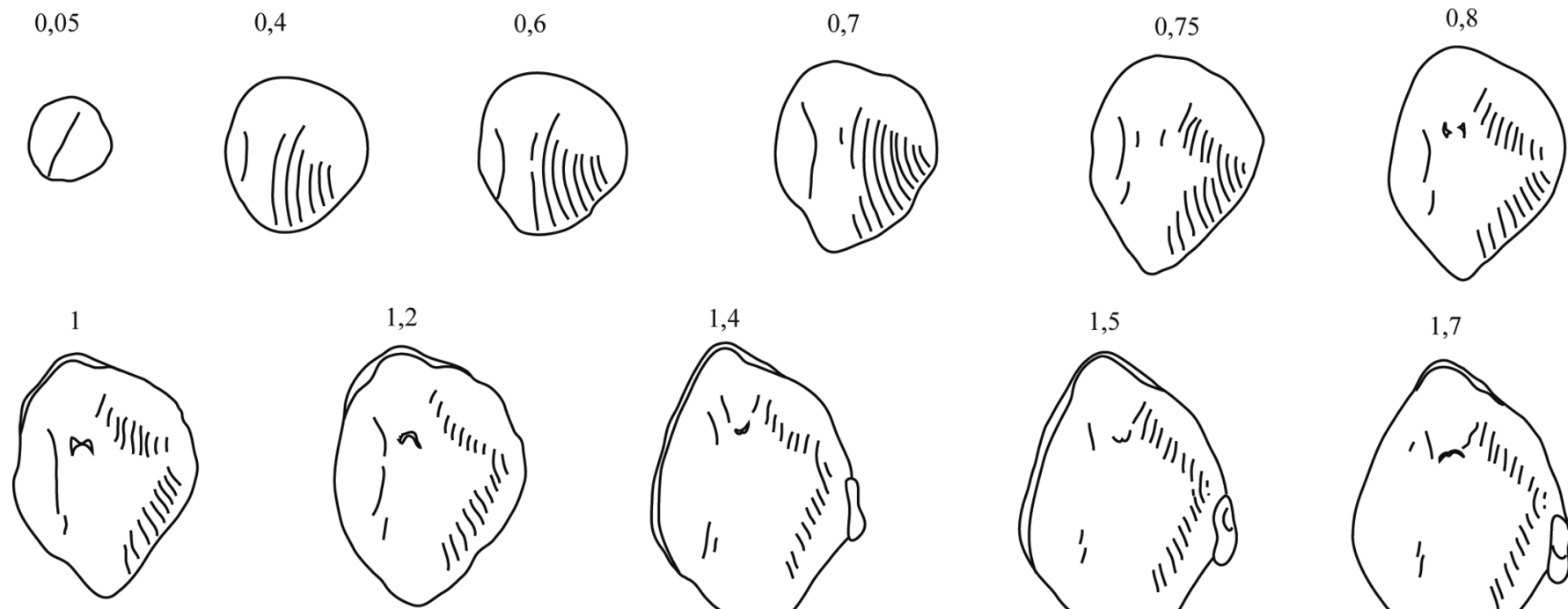

0

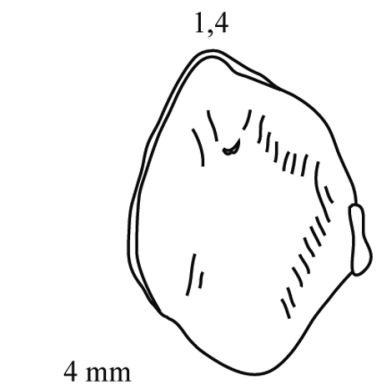

2,3
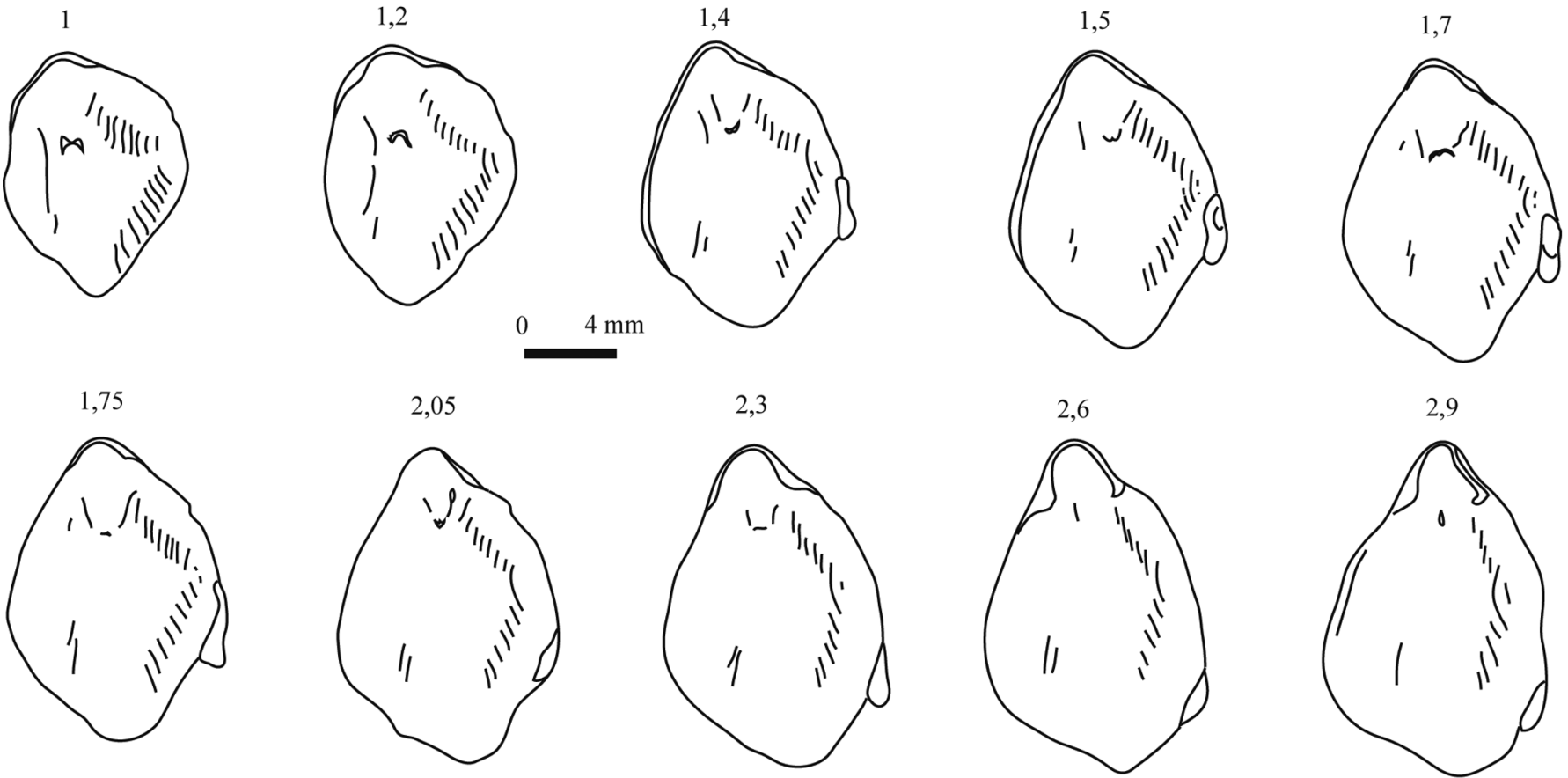

Figura 20. Triathyris mucronata (Verneuil, en Prado \& Verneuil, 1850). DPO 38567, de Colle (León), nivel 28. Dibujos con cámara clara de secciones seriadas, paralelas al plano de la comisura en sentido ventro-dorsal. Espiralio roto y yugo incompleto. Distancias en mm. medidas al plano tangente de la valva ventral paralelo al de comisura.

Triathyris mucronata (Verneuil, in Prado \& Verneuil, 1850). DPO 38567, from Colle (León), level 28. Camera lucida drawings of ventro-dorsally serial sections, parallel to the plane of commissure. Broken spiralia, incomplete jugum. Distances in $\mathrm{mm}$. from the plane tangent to the ventral valve. 


\section{Triathyris mucronata}

(Verneuil, en Prado \& Verneuil, 1850)

Figs. 18-27, Tab. 3

v. *1850 Terebratula mucronata, n.sp.; Verneuil (en Prado \& Verneuil, 1850), p. 172, pl. 1, Fig. 6.

- 1875 S. ? mucronata, Vern. (sp).=Retzia mucronata, Vern. (sp). = Terebratula mucronata, Vern.; Mallada, p. 65
1875 Spirigera mucronata, Vern.; Mallada, Devoniano, Lám. 7, Fig. 2.

- 1892 Athyris ? mucronata, Vern.sp.; Mallada, p. 45.

v. 1938 Triathyris mucronata Verneuil; Comte, p. 45, Pl. 4, Fig. 16.

- 1952 T. mucronata; Le Maître, p. 146.

- 1959 T. mucronata Verneuil; Comte, p. 247, Tab. 2.

- 1959 Triathyris mucronata Verneuil; Comte, p. 406, Tab. II (p. 247).

Tabla 3. Triathyris mucronata (Verneuil, en Prado \& Verneuil, 1850). Medidas de algunos ejemplares en mm (L, a, g: longitud, anchura y grosor).

Triathyris mucronata (Verneuil, in Prado \& Verneuil, 1850). Measurements of some specimens in mm (L, a, g: length, width, and thickness).

\begin{tabular}{|c|c|c|c|c|c|}
\hline Ejemplar & $\mathbf{L}$ & $\mathbf{a}$ & $\mathbf{g}$ & $a / L$ & $\mathrm{~g} / \mathrm{L}$ \\
\hline DPO 40268a & 23,2 & 18,7 & 9,3 & 0,81 & 0,40 \\
\hline Lectotipo & 22,4 & 22,7 & 11 & 1,01 & 0,49 \\
\hline DPO 40377 & 18,2 & 16,2 & 10 & 0,89 & 0,55 \\
\hline DPO 40342 & 16,6 & 15,8 & 7,8 & 0,95 & 0,47 \\
\hline DPO 40343 & 16,0 & 12,2 & 6,4 & 0,76 & 0,40 \\
\hline DPO 38567 & 15,8 & 11,3 & 6,3 & 0,71 & 0,40 \\
\hline DPO 40344 & 14,4 & 10,9 & 5,8 & 0,76 & 0,40 \\
\hline DPO 40372 & 14,2 & 10,6 & 6,4 & 0,75 & 0,45 \\
\hline DPO 40297 & 13,5 & 12,9 & 5,7 & 0,95 & 0,42 \\
\hline DPO 40365b & 13,4 & 9,1 & 5,8 & 0,68 & 0,43 \\
\hline DPO 40352 & 13,3 & 8,2 & 5,7 & 0,62 & 0,43 \\
\hline DPO 40270a & 13,2 & 11,7 & 7,2 & 0,89 & 0,54 \\
\hline DPO 40382 & 12,7 & 11,6 & 6,6 & 0,91 & 0,52 \\
\hline DPO 40383 & 12,6 & 12,0 & 5,4 & 0,95 & 0,43 \\
\hline DPO 40271 & 12,5 & 10,1 & 5,1 & 0,81 & 0,41 \\
\hline DPO 39918 & 12,2 & 10,8 & 5,6 & 0,88 & 0,46 \\
\hline DPO 40348 & 12,2 & 10,0 & 6,3 & 0,82 & 0,52 \\
\hline DPO 40273 & 12,1 & 10,5 & 4,8 & 0,87 & 0,40 \\
\hline DPO 40353 & 11,9 & 7,6 & 5,2 & 0,64 & 0,44 \\
\hline DPO 40354 & 11,7 & 7,6 & 4,9 & 0,65 & 0,42 \\
\hline DPO 40349 & 11,1 & 9,1 & 4,6 & 0,82 & 0,41 \\
\hline DPO 40356 & 10,7 & 7,0 & 4,9 & 0,65 & 0,46 \\
\hline DPO 40276 & 10,0 & 9,0 & 5,0 & 0,90 & 0,50 \\
\hline DPO 40350 & 9,7 & 9,9 & 5,3 & 1,02 & 0,55 \\
\hline DPO 40282 & 9,3 & 9,0 & 4,2 & 0,97 & 0,45 \\
\hline DPO 40358 & 9,2 & 5,7 & 4,6 & 0,62 & 0,50 \\
\hline DPO 40389 & 8,5 & 8,3 & 3,8 & 0,98 & 0,45 \\
\hline DPO 40360 & 8,4 & 5,9 & 4,6 & 0,70 & 0,55 \\
\hline DPO 40387 & 8,3 & 8,1 & 3,9 & 0,97 & 0,50 \\
\hline DPO 40361 & 8,3 & 7,0 & 4,5 & 0,84 & 0,54 \\
\hline DPO 40323 & 7,5 & 7,1 & 4,0 & 0,95 & 0,53 \\
\hline DPO 40280 & 7,5 & 6,3 & 3,2 & 0,84 & 0,43 \\
\hline DPO 40365a & 6,6 & 4,4 & 3,0 & 0,67 & 0,45 \\
\hline DPO 40336 & 6,5 & 4,5 & 3,2 & 0,69 & 0,49 \\
\hline DPO 40369b & 6,3 & 5,2 & 3,3 & 0,82 & 0,52 \\
\hline DPO 40368b & 5,8 & 4,8 & 3,2 & 0,83 & 0,55 \\
\hline DPO 40335 & 5,7 & 4,6 & 3,2 & 0,81 & 0,56 \\
\hline
\end{tabular}


v. 1965 T. mucronata (DE VERNEUIL); Boucot et al., p. H663, Fig. 538, 1a,b.

v. 1976 Terebratula mucronata VERN.; García-Alcalde \& Álvarez, pp. 42-43, Lám. 2, Figs. 4-12.

v. 1976 Triathyris mucronata (VERN.); García-Alcalde \& Álvarez, Pl. 2, Figs. 4-12.

v. 1990 Triathyris mucronata; García-Alcalde (en Truyols et al.), Fig. 1. v. 1995 Triathyris mucronata; García-Alcalde, Fig. 6.

v. 1996 Triathyris mucronata; García-Alcalde, Fig. 2.

- 1998 Triathyris mucronata (Verneuil, 1850); Álvarez et al., Fig. 7.

v. 2001b Triathyris mucronata; García-Alcalde, Fig. 1.

v. 2002 T. mucronata (DE VERNEUIL); Álvarez \& Rong, p. 1574, Fig. 1073.
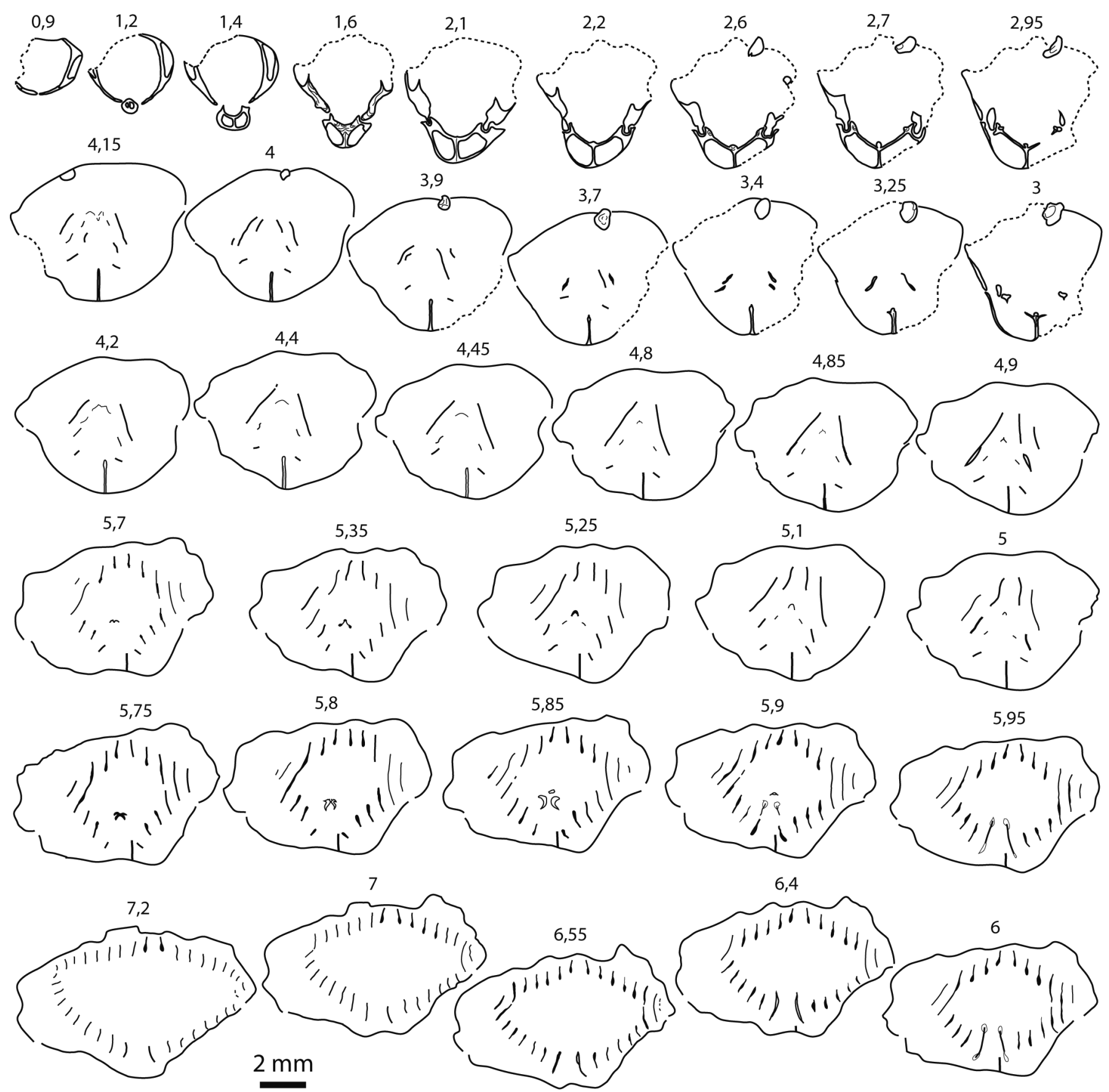

Figura 21. Triathyris mucronata (Verneuil, en Prado \& Verneuil, 1850). DPO 38568 de Colle (León), nivel 29. Dibujos con cámara clara de secciones seriadas, perpendiculares al plano de simetría y al plano comisural. Distancias medidas en mm al ápice ventral. Triathyris mucronata (Verneuil, in Prado \& Verneuil, 1850). DPO 38568 from Colle (León), level 29. Camera lucida drawings of serial sections, normal to both the symmetry and the commisural planes. Distances in mm measured from the shell apex. 

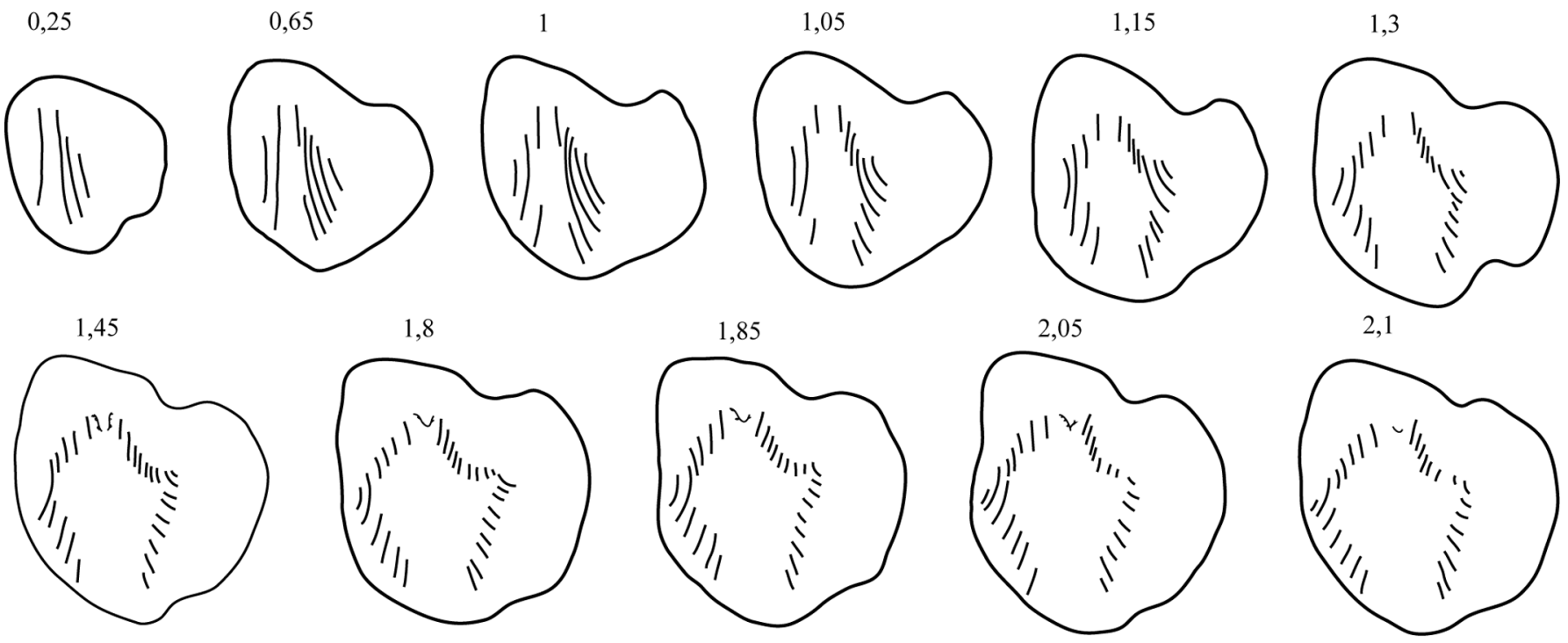

2,1

2,15
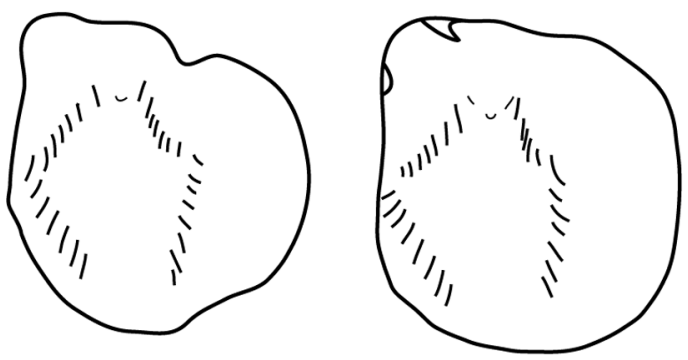

2,65

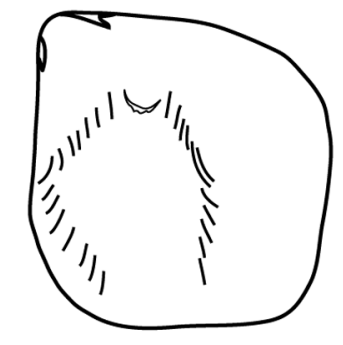

2,75

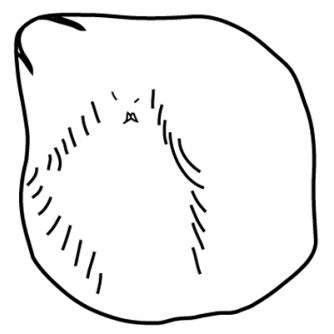

3,37

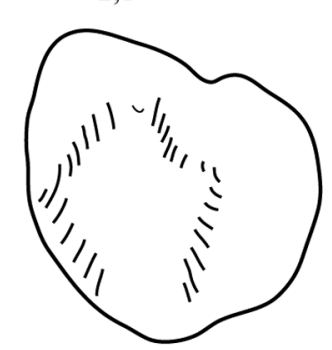

2,95
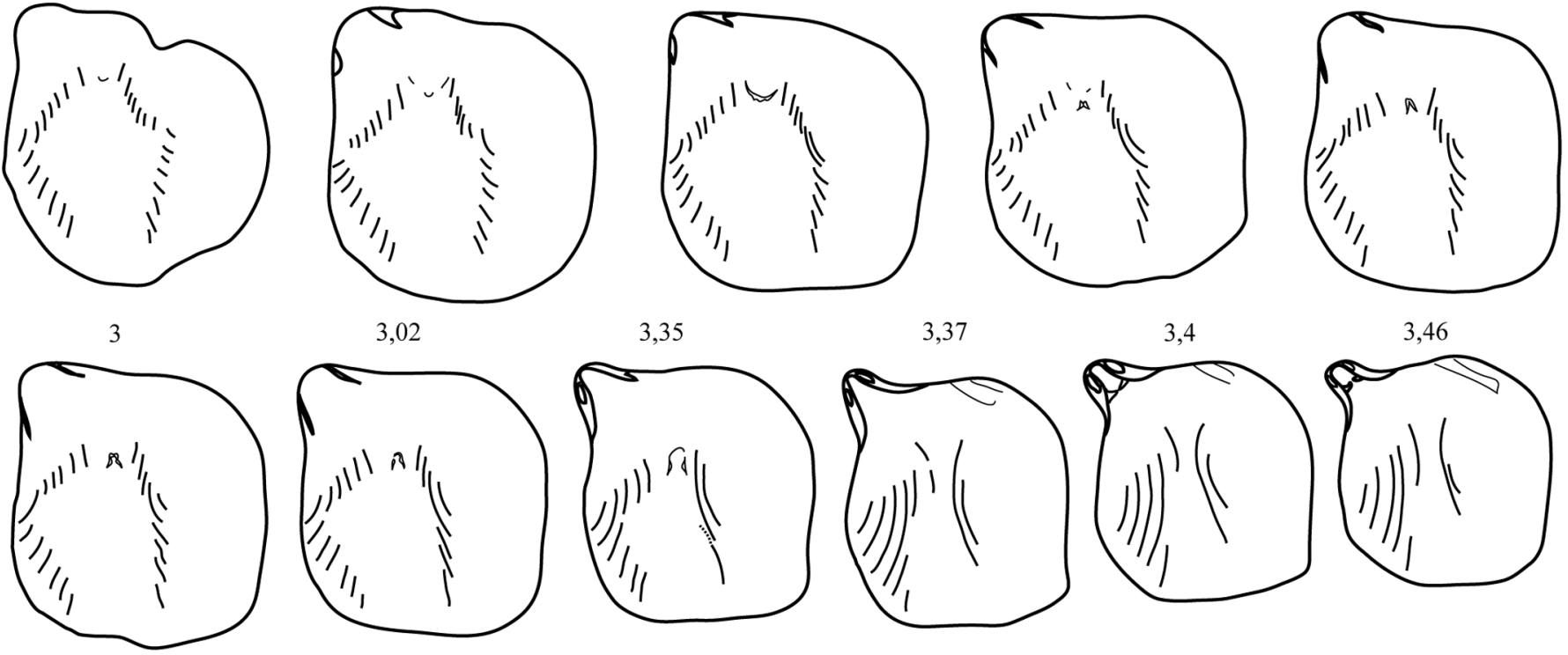

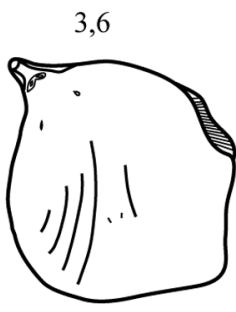

4,8

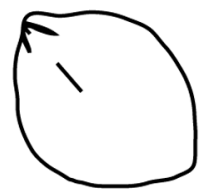

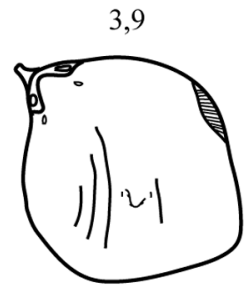

4,96

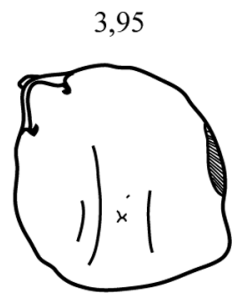

5

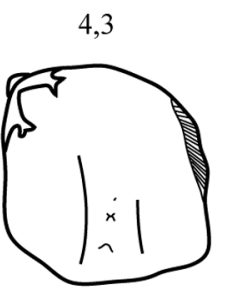

5,1
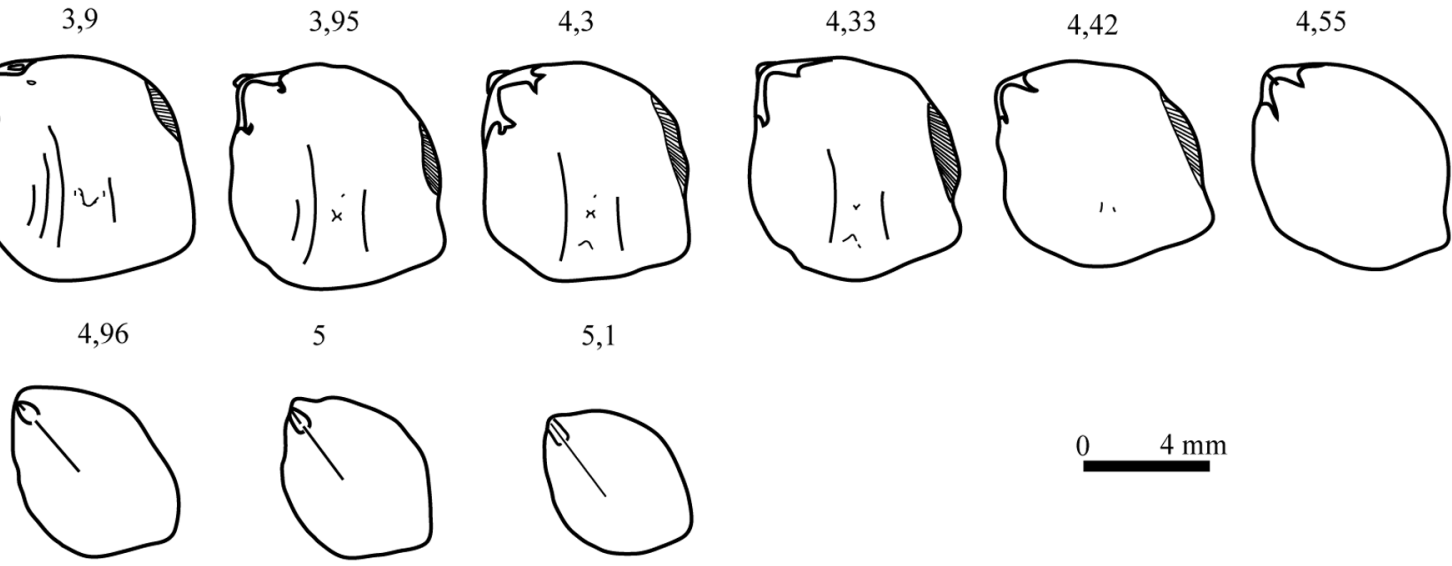

Figura 22. Triathyris mucronata (Verneuil, en Prado \& Verneuil, 1850). DPO 39918, de Colle (León), nivel 29. Dibujos con cámara clara de secciones seriadas, paralelas al plano de la comisura en sentido ventro-dorsal. Distancias en mm medidas al plano tangente de la valva ventral paralelo al de comisura.

Triathyris mucronata (Verneuil, in Prado \& Verneuil, 1850). DPO 39918, from Colle (León), level 29. Camera lucida drawings of ventro-dorsally serial sections, parallel to the plane of commissure. Distances in mm from the plane tangent to the ventral valve. 


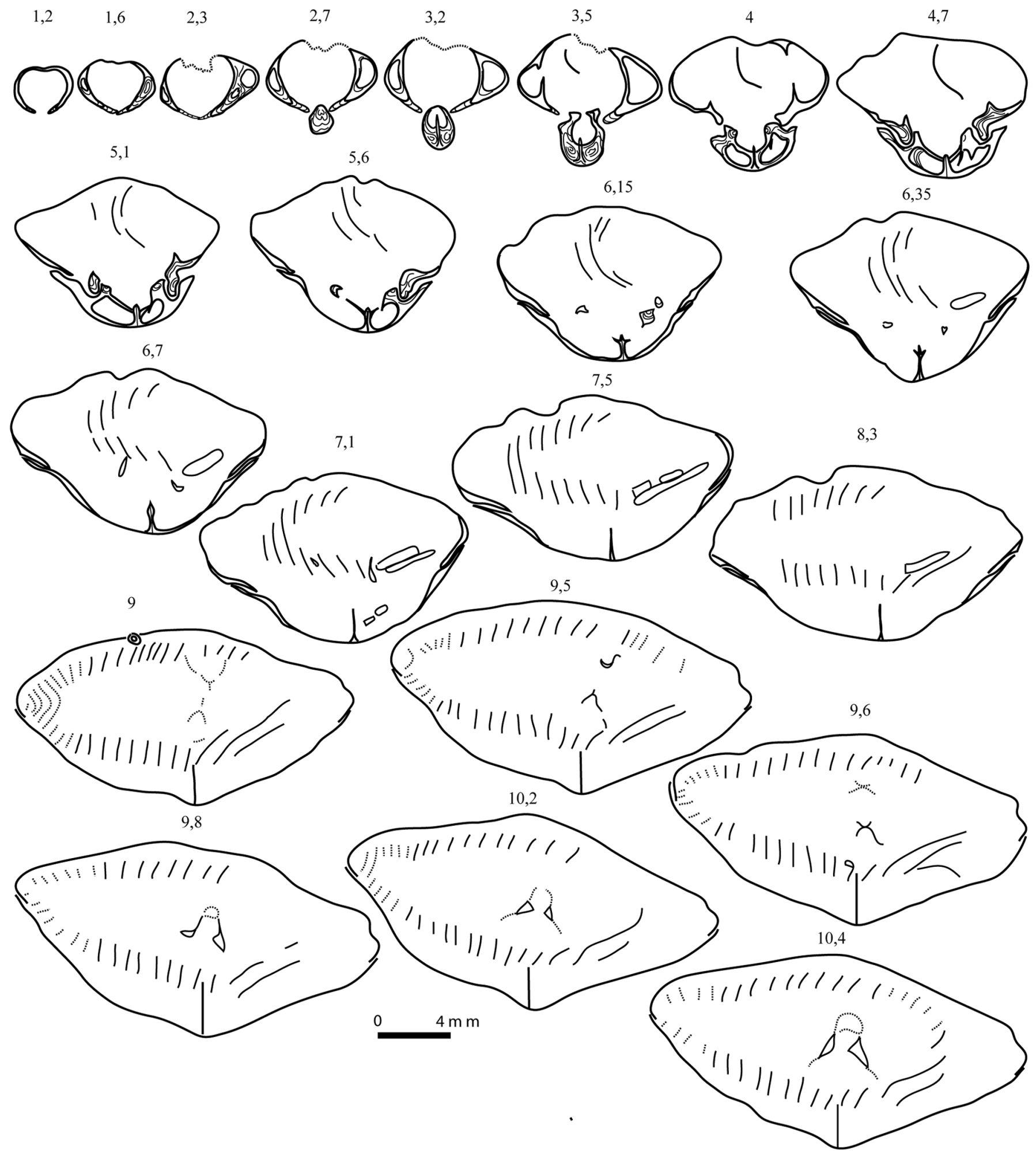

Figura 23. Triathyris mucronata (Verneuil, en Prado \& Verneuil, 1850). DPO 40265 de Colle (León), nivel 30. Dibujos con cámara clara de secciones seriadas, perpendiculares al plano de simetría y al plano comisural. Espiralio roto, yugo incompleto Distancias medidas en $\mathrm{mm}$ al ápice ventral.

Triathyris mucronata (Verneuil, in Prado \& Verneuil, 1850). DPO 40265 from Colle (León), level 30. Camera lucida drawings of serial sections, normal to both the symmetry and the commisural planes. Broken spiralium, incomplete jugum. Distances in mm measured from the shell apex. 
Lectotipo: Ejemplar D868 de la colección de la Facultad de Ciencias de Orsay, designado por Comte, como "Type" (1938, pl. IV, Fig. 16), bivalvo, con carenas medias bien desarrolladas. Este ejemplar lo reencontraron el autor y otros colegas de la Universidad de Oviedo en la Facultad de Ciencias de Orsay (Francia), donde formaba parte de la colección Verneuil en 1975, y fue figurado por García-
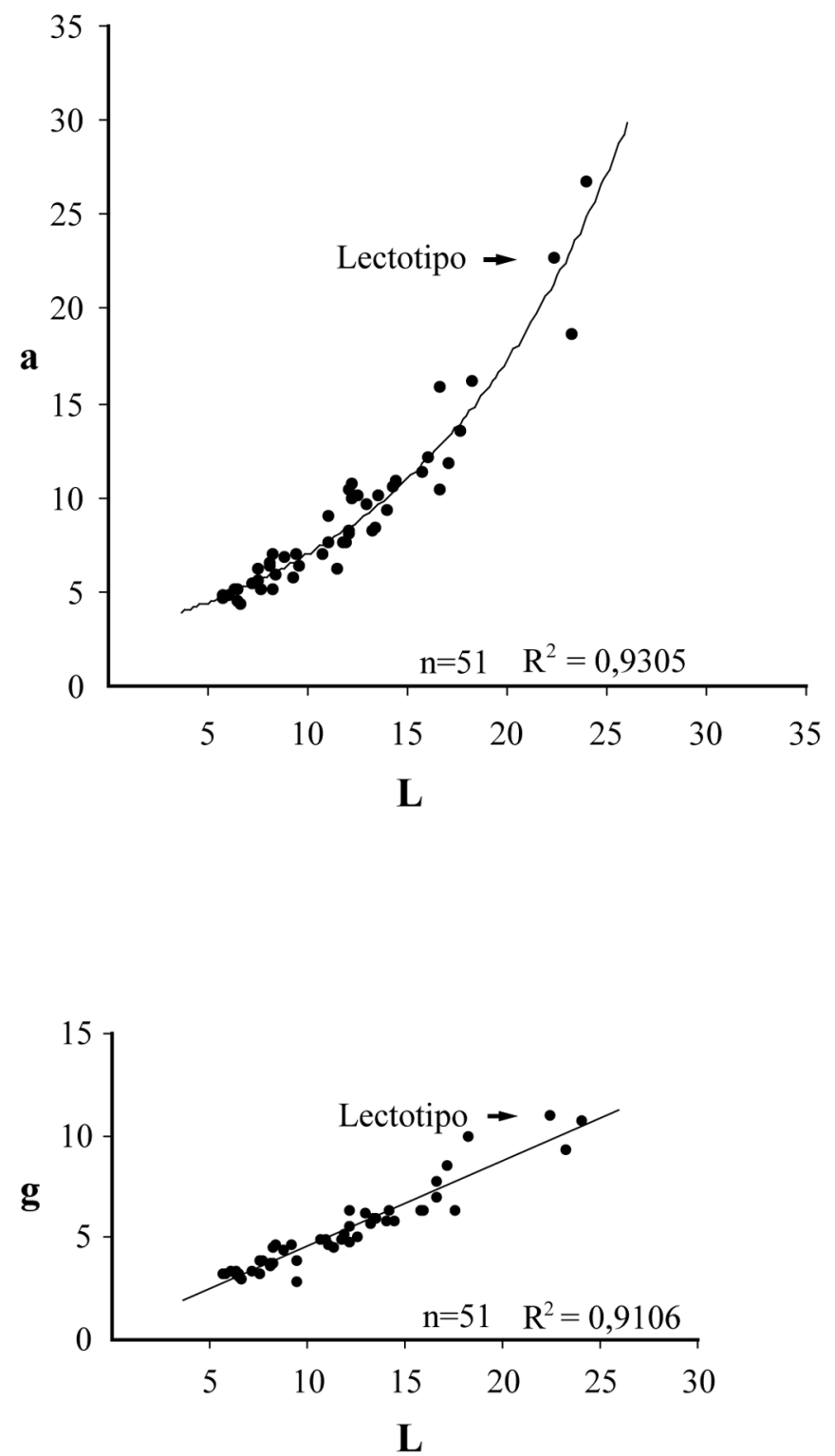

Figura 24. Diagramas de dispersión longitud/anchura (L/a) y longitud/grosor (L/g) de Triathyris mucronata (Verneuil, en Prado \& Verneuil, 1850), incluyendo la posición del lectotipo (Colección Verneuil, cf. GarcíaAlcalde \& Álvarez, 1976).

Triathyris mucronata (Verneuil, in Prado \& Verneuil, 1850). Length/width (L/a) and length/thickness (L/g) dispersion diagrams, including the setting of the lectotype (Coll. Verneuil, cf. Garcia-Alcalde \& Álvarez, 1976).
Alcalde \& Álvarez (1976, lám. 2, Figs. 4-7), junto con los paralectotipos D869 y D871 (op. cit. Lám. 2, Figs. 8-12).

Localidad y estrato-tipo: Como repetidas veces se ha arguido (Comte, 1959; García-Alcalde \& Álvarez, 1976; Álvarez \& Brime, 1990; García-Alcalde, 1996, 1999, 2008, 2011), la mayoría de formas devónicas, Triathyris тисronata inclusive, citadas por Verneuil (en Prado \& Verneuil, 1850) de Sabero, proceden de la aldea de Colle (unos $5 \mathrm{~km}$ al Oeste de Sabero). En particular, García-Alcalde \& Álvarez (1976, Fig. 2), señalaron como estrato tipo de la especie que se discute, un paquete de unos $2 \mathrm{~m}$ de potencia de pizarras pardo-rojizas y calizas arcillosas plagado de artejos de crinoideos, correspondiente a la parte alta del Grupo La Vid, 30 m por debajo de la base de la Formación Santa Lucía. Dicho nivel corta el camino que asciende hacia la iglesia de Colle, unos $40 \mathrm{~m}$ al Este de la misma (Fig. 15). En términos actuales, el estrato tipo se localizaría en el nivel 30 de la sección de Colle, perteneciente al Grupo de La Vid, mitad inferior de la Formación Coladilla (Fig. 16), Intervalo Faunístico 12 de García-Alcalde (1998), parte alta de la zona de conodontos Polygnathus inversus/P. laticostatus (cf. García-López \& Sánz-López, 2002).

Material del autor: Un total de 121 ejemplares, casi siempre algo deformados, en particular los individuos de mayor edad, pero que conservan bastante bien las estructuras internas. De éstos, 104 ejemplares DPO 38567-38568, 39918, 40265-40375 (Figs. 18-19) provienen de la localidad tipo, niveles 25 a 32 (DPO 38567, 38568, 39918, 40265, seccionados, Figs. 20-23). Otros 17 ejemplares, de diferentes localidades leonesas (Fig. 1) de parecido nivel

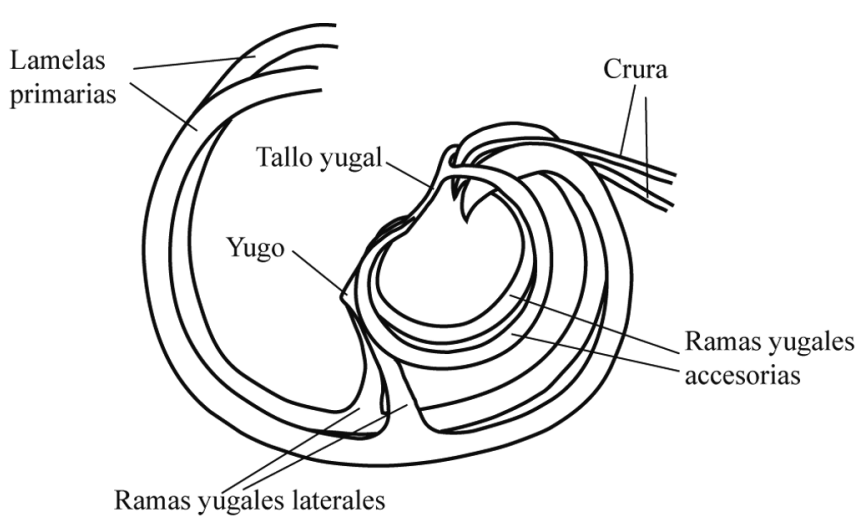

Figura 25. Triathyris mucronata (Verneuil, en Prado \& Verneuil, 1850). Reconstrucción idealizada del yugo a partir de las secciones seriadas anteriores (conos espirales suprimidos). Vista lateral. No a escala.

Triathyris mucronata (Verneuil, in Prado \& Verneu$i l, 1850)$. Idealized reconstruction of the jugum from the serial sections above (spiralia supressed). Lateral view. Not to scale. 
estratigráfico dentro del Grupo La Vid: DPO 40376-40379, de Villayandre, yac. I-141, DPO 40380-40381, de Santa Lucía, yac. I-29 y DPO 40382-40392, de Caldas de Luna, yac. M-CAL-15.

Descripción: Concha impuntuada, de tamaño medio (promedio L 11,5, para 64 medidas, Lmax $24 \mathrm{~mm}$ ), ventribiconvexa y poco espesa (promedio g/L 5,2, para 64 medidas), equidimensional a alargada (promedio a/L 9,1, para 64 medidas) (Fig. 24, Tab. 3), de contorno romboidal, astrófica, con charnela corta e interárea ventral poco desarrollada, limitada por aristas umbonales subangulosas. Gancho ventral prominente, erecto a curvado, perforado por un foramen circular mesotírido a epirítido, limitado basalmente por un fuerte deltidio completo y convexo (Figs. 19f). Gancho dorsal oculto bajo el deltidio. Ángulo apical en torno a $90^{\circ}$. Comisuras laterales y anterior cortantes. Comisura anterior recta o algo curvada en dirección

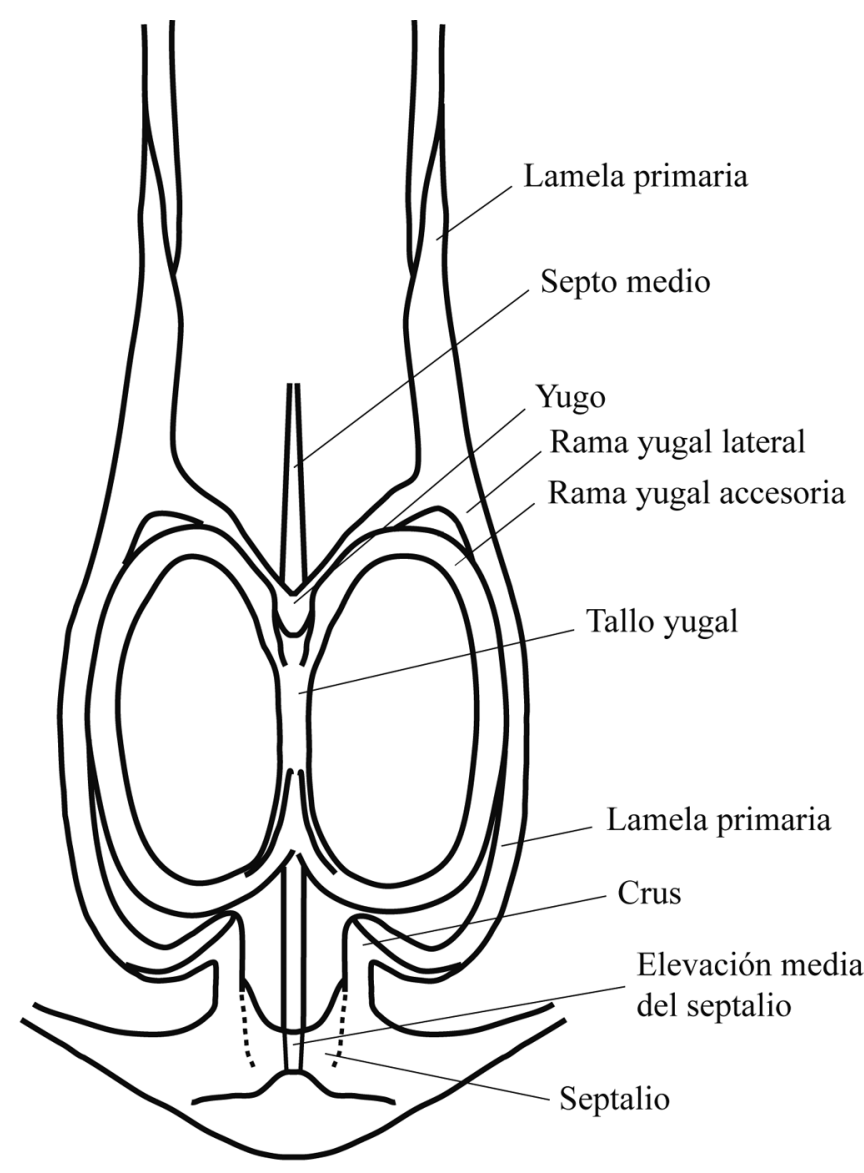

Figura 26. Triathyris mucronata (Verneuil, en Prado \& Verneuil, 1850). Reconstrucción idealizada del yugo a partir de las secciones seriadas anteriores (conos espirales suprimidos). Vista ventral. No a escala.

Triathyris mucronata (Verneuil, in Prado \& Verneuil, 1850). Idealized reconstruction of the jugum from the serial sections above (spiralia supressed). Ventral view. Not to scale. dorsal, bastante fuerte y aguda en los ejemplares adultos. Lamelas de crecimiento bien desarrolladas y numerosas, más apretadas cerca de los márgenes. Algunas de ellas son más fuertes que las otras y forman relieves redondeados sobre todo cerca de los bordes laterales (Figs. 19a1-a2). En los ejemplares juveniles se insinúa una débil carena media redondeada en ambas valvas, que se acusa con la edad; las carenas se convierten en el estadio efébico en pliegues subangulosos que se prolongan hacia delante en una especie de corto espolón agudo, muy característico (ver "Desarrollo Ontogenético", más abajo). Rara vez, las carenas de ambas valvas muestran sendas depresiones medias, originando hacia delante pliegues redondeados que se encuentran en la comisura (Fig. 19c1-c2). La concha está ornamentada por un sistema divaricado de finísimas cóstulas subradiales, redondeadas y muy apretadas, en número de 20-30 por $3 \mathrm{~mm}$ cerca del frente, que aparecen a lo largo de las carenas medias y suelen curvarse posterolateralmente en los extremos distales. Las cóstulas de cada flanco se cortan en la parte media, formando un sistema chevron que puede prolongarse hacia los márgenes merced a la presencia de otro sistema de cóstulas discontinuas, aún más finas que las anteriores (Figs. 18-19).

Caracteres internos (observados en ejemplares desgastados y en secciones seriadas, Figs. 20-23): Campos musculares muy débiles atravesados por elevaciones radiales finas, bajas y redondeadas que alcanzan el borde de las valvas. Placas dentales cortas, cóncavas, proximalmente divergentes y distalmente convergentes. Dientes cardinales robustos, provistos a veces de uno o más dentículos complementarios. Cavidades dentales profundas, frecuentemente denticuladas; rebordes internos bien desarrollados, insertos en cavidades de la base de los dientes, formando una articulación complementaria (Figs. 21, 23). Articulación alcanzando el margen anterior del septalio. Septalio no cubierto, ancho y relativamente profundo. Las placas septaliales se unen lateralmente al septo medio, el cual sobresale, a veces bastante, del fondo de la cavidad septalial (Fig. 23). Septo medio, alto, delgado y muy largo, alcanzando la mitad de la longitud o más. Bases crurales desarrolladas en el límite entre las placas septaliales y los rebordes internos de las cavidades dentales resolviéndose, por delante del eje cardinal, en sendos crura delgados y cortos; los crura se disponen al principio de manera oblicua, convergentes ventralmente y se verticalizan luego hasta unirse a las lamelas primarias. Braquidio espiralado, con conos dirigidos lateralmente provistos de 9-12 espiras cada uno, con frecuencia fimbriadas (Fig. 21). Yugo complejo con ramas yugales laterales que se destacan de las lamelas primarias y forman un arco yugal del que se proyecta posteroventralmente un tallo yugal acanalado, dividido a la altura de la unión de los crura y lamelas primarias en sendas ramas accesorias que se dirigen posteroventral y anterodorsalmente, entre las dos primeras espiras del braquidio, para terminar uniéndose a la base del tallo yugal, 

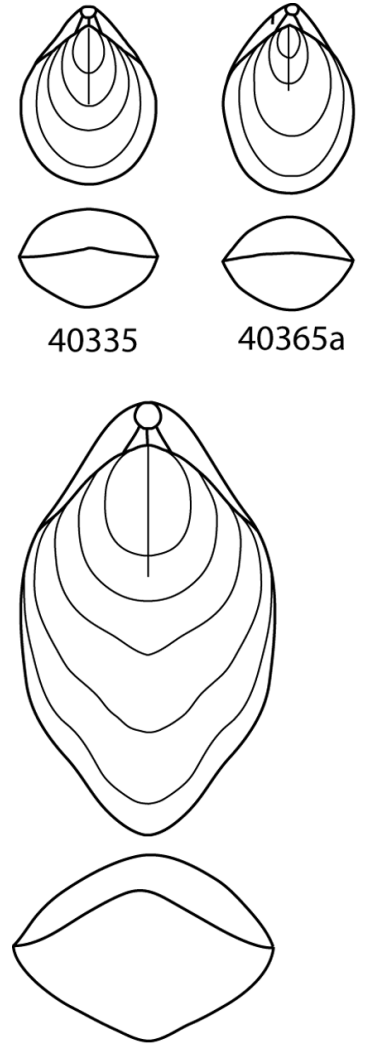

40352
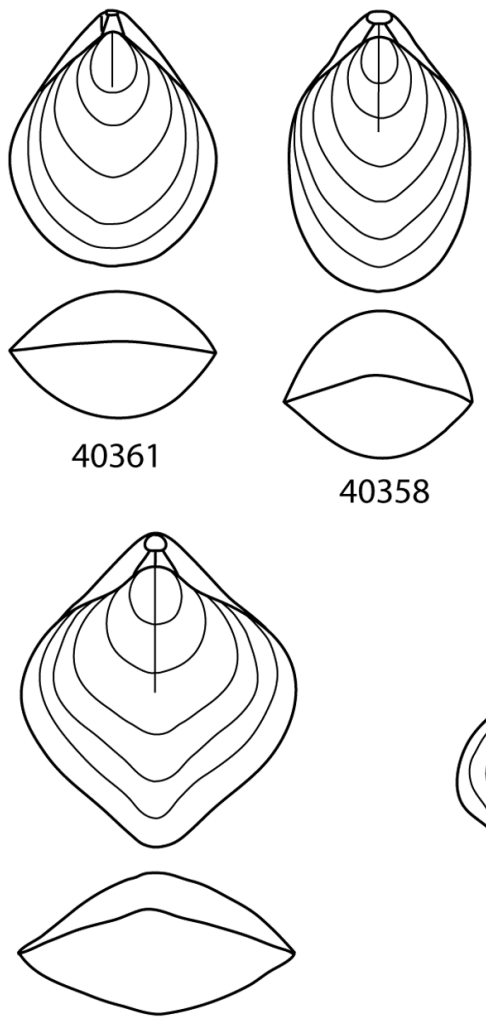

40349

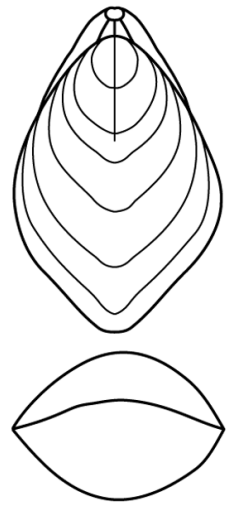

40356
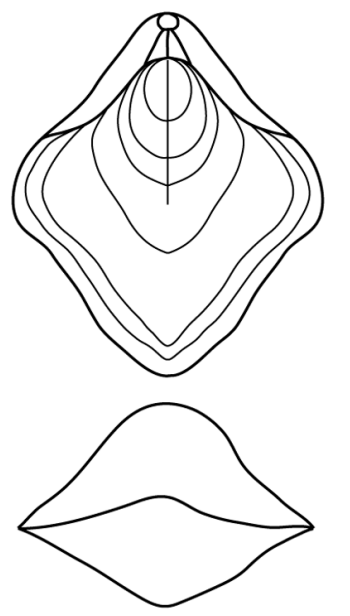

40348
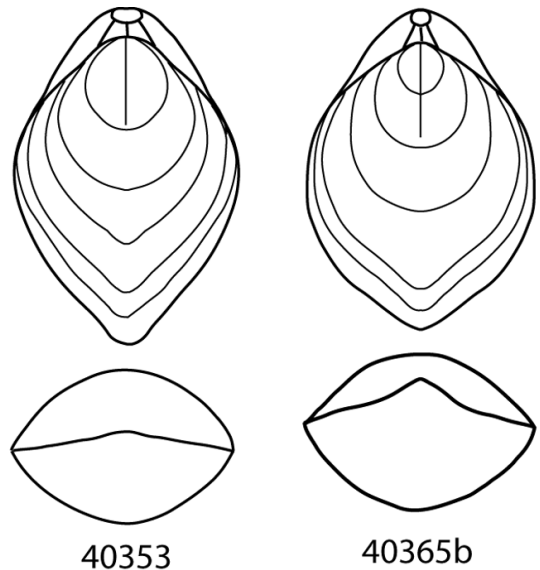

$40365 b$
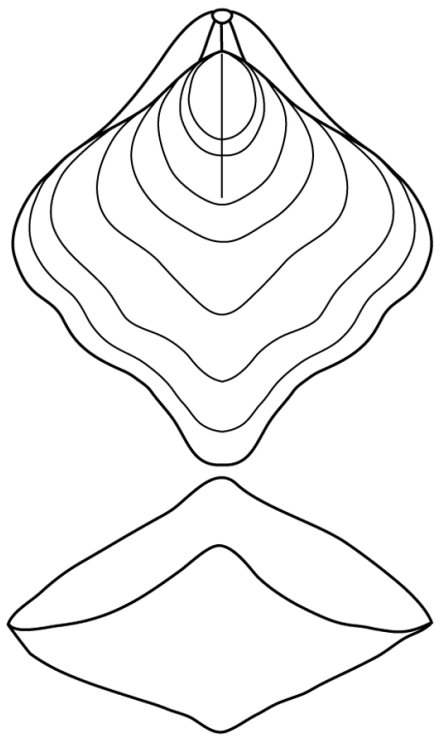

40343

$5 \mathrm{~mm}$

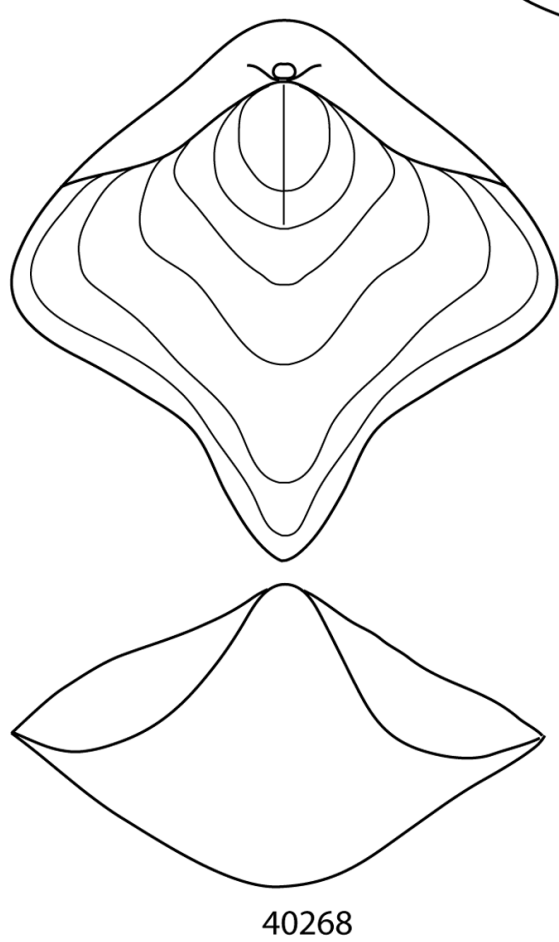

Figura 27. Dibujos esquemáticos con cámara clara, algo idealizados, de una serie ontogenética de Triathyris mucronata (Verneuil, en Prado \& Verneuil, 1850). Obsérvese la relación alométrica L/a (ver también Fig. 24).

Triathyris mucronata (Verneuil, in Prado \& Verneuil, 1850). Camera lucida schematic drawings a little idealized of a Triathyris mucronata (Verneuil, in Prado \& Verneuil, 1850) ontogenetic series. See L/a allometric relation (see also Fig. 24). 
formando sendas volutas, más o menos circulares (Figs. 25-26), similares a las de Meristella y otros meristelinos. Dichas volutas son espinosas, especialmente en la bifurcación del tallo yugal (Fig. 22)

Desarrollo ontogenético: El crecimiento de T. mисronata es marcadamente alométrico, con las fases bréfica y efébica inicial dominadas por la componente longitudinal mientras que la efébica lo está por la transversal (Figs. 24, 27). Las formas bréficas de la especie son bastante alargadas, de contorno elíptico a subpentagonal, con la máxima anchura situada por detrás de la mitad de la longitud, la comisura anterior rectimarginada o sólo débilmente arqueada en dirección dorsal y no tienen carenas en las valvas (Fig. 27), mimetizando las formas juveniles de otras

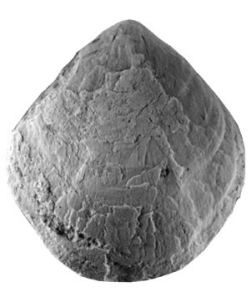

a1

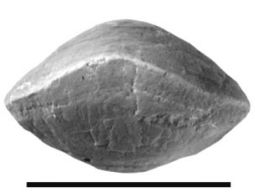

a2

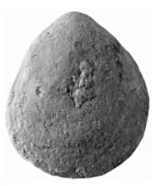

d1

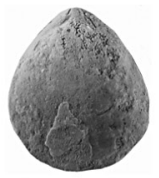

d3

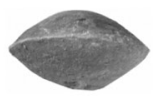

d4

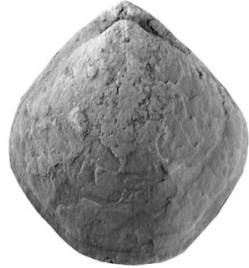

a3

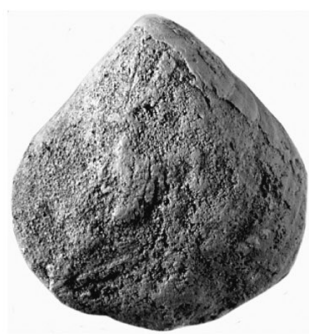

e1

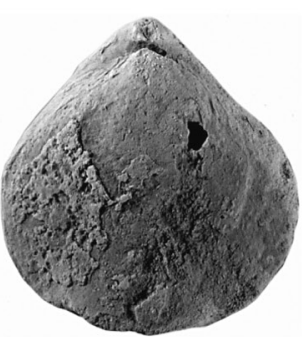

e3

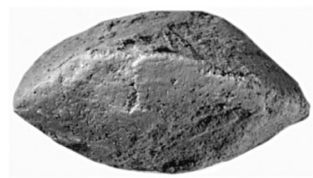

e4

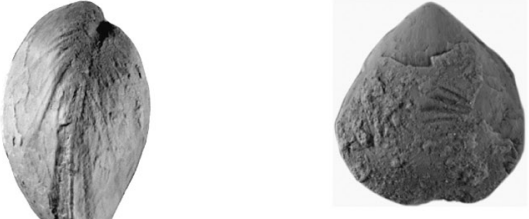

b1

a4

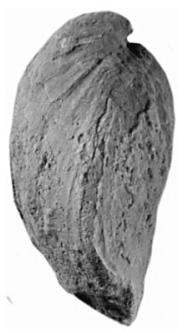

e2

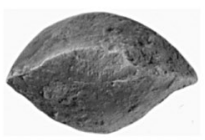

b3

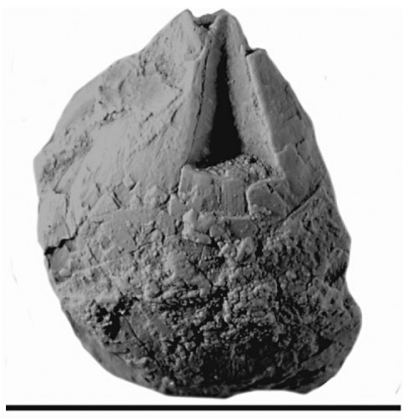

f

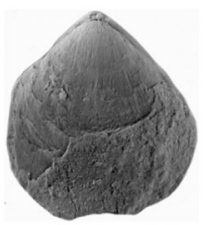

b2

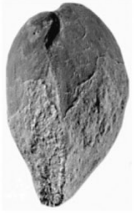

b4

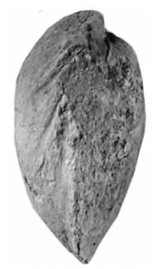

c2

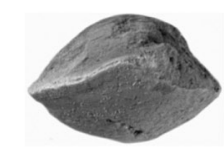

c4

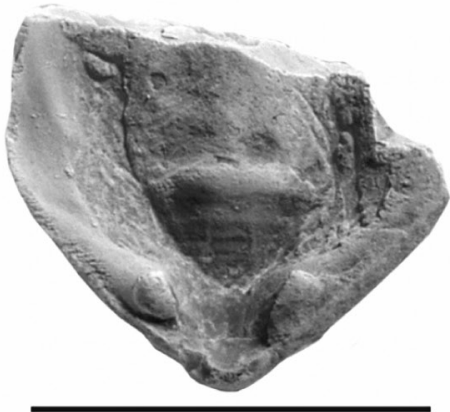

g

Figura 28. Camarium collensis n.sp., de Colle (León). a1-a4: Holotipo DPO 127929, vistas ventral, anterior, dorsal y lateral. b1b4: Paratipo DPO 127933, vistas ventral, dorsal, anterior y lateral. c1-c4: Paratipo DPO 127930, vistas ventral, lateral, dorsal y anterior. d1-d4: DPO 127941, vistas ventral, lateral, dorsal y anterior. e1-e4: DPO 127938, vistas ventral, lateral, dorsal y anterior. f: DPO 127946, Valva ventral rota, mostrando el arco de la placa calzador (shoelifter process). g: DPO 127936, valva ventral fragmentaria orientada con el ápice hacia abajo, mostrando la estructura interna, incluida la placa calzador (shoelifter process) bien desarrollada. Barras de escala: $10 \mathrm{~mm}$. La barra más pequeña corresponde a todas las figuras, salvo $\mathbf{f} \mathbf{y} \mathbf{g}$.

Camarium collensis n.sp., from Colle (León). a1-a4: Holotype DPO 127929, ventral, anterior, dorsal and lateral views. b1-b4: Paratype DPO 127933, ventral, dorsal, anterior and lateral views. c1-c4: Paratype DPO 127930, ventral, lateral, dorsal and anterior views. d1-d4: DPO 127941, ventral, lateral, dorsal and anterior views. e1-e4: DPO 127938, ventral, lateral, dorsal and anterior views. $f$ : DPO 127946, broken ventral valve showing the shoelifter process arch. $\mathrm{g}$ : DPO 127936, fragmentary ventral valve oriented with the apex below, showing the internal structure, including a welldeveloped shoelifter process. Scale bars: $10 \mathrm{~mm}$. The smaller bar corresponds to all the figures excepting $\boldsymbol{f}$ and $\boldsymbol{g}$. 


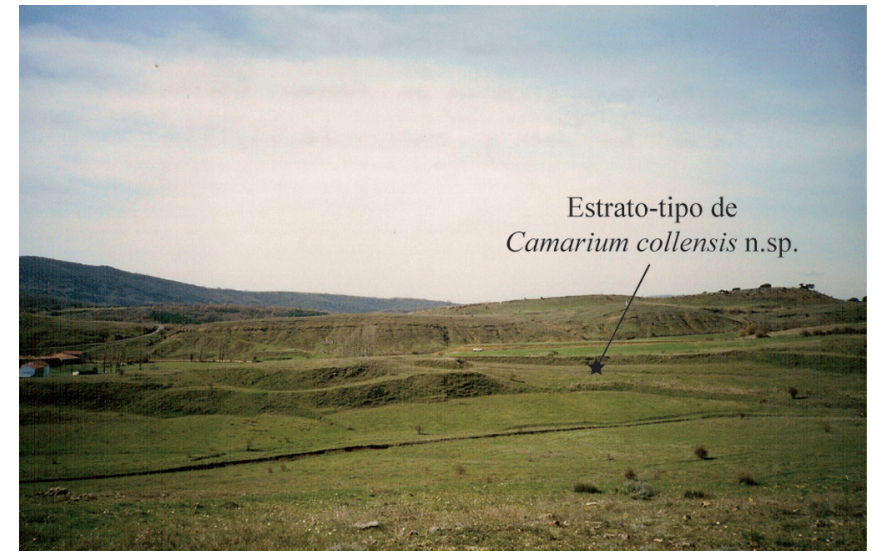

Figura 29. Localidad tipo de Camarium collensis n.sp. al NO del pueblo de Colle (León) (casas a la izquierda de la foto). Foto orientada $250^{\circ} \mathrm{SO}$.

Camarium collensis n.sp., from Colle (León). Locus typicus NW Colle (province of Leon) (houses to left hand of the picture). Photo oriented $250^{\circ} \mathrm{SW}$.

especies que coexisten con ellas, como el meristelino $\mathrm{Sa}$ beraia truyolsae n.gen. n.sp. (Figs. 18e1-e4, 19d1-d2) y el terebratúlido Cimicinella schulzi-C. bordini (Fig. 18d1-d4, 19e1-e2). Hacia L=5,5 mm, se produce la transición bréfico-efébica, con la aparición de sendas carenas redondeadas cerca del frente de las valvas, mientras el contorno de la concha tiende a hacerse romboidal. Las carenas se vuelven cada vez más fuertes con el crecimiento y se prolongan anteriormente en un corto espolón, al tiempo que la comisura frontal se curva en dirección dorsal, sobre todo en la posición del espolón (Fig. 27) y la máxima anchura tiende a desplazarse hacia la mitad de la longitud o algo por delante. En las fases ontogenéticas tardías las conchas son moderadamente alargadas, casi equidimensionales, de contorno netamente romboidal, con bordes posteriores paralelos a los anteriores, las carenas son subangulosas a angulosas con un espolón evidente, más o menos largo, y la comisura frontal forma un pliegue agudo dirigido hacia la valva dorsal en la región del espolón (Figs. 19a1-a4, 27).
Discusión: T. mucronata es una especie inconfundible debido al contorno romboidal y presencia de carenas medias en ambas valvas en los ejemplares efébicos y al característico tipo de microornamentación costulada, presente en todos los estadios de crecimiento. Las especies de Septathyris Boucot, Johnson \& Staton, 1964, muestran un modelo ornamental similar, algo más elaborado, con finas líneas quebradas, que forman una trama en chevron abriéndose anteriormente, pero dicho género comprende especies equidimensionales a claramente transversas, mientras que T. mucronata es alargada a muy alargada.

Comte (1938) integró en Triathyris tres especies, Terebratula mucronata, T. schulzi (non T. schultzi, Comte, 1938, nombre vano, $c f$. García-Alcalde 1998, p. 172) у T. bordini (non T. Bordiu, T. bordiu o T. bordui; Mallada, 1875, 1892, Comte, 1938, nombres vanos, cf. GarcíaAlcalde \& Álvarez, 1976, p. 43; García-Alcalde, 1998, p. 173). T. mucronata fue elegida como tipo del género por Le Maître (1952, p. 146) y las otras dos especies, no tienen nada que ver con ella. En efecto, Terebratula schulzi Verneuil (en Prado \& Verneuil, 1850) es una forma endopuntuada del género Cimicinella Schmidt, 1946 (ver más arriba). Por su parte, el tipo de T. Bordini Verneuil, en Prado \& Verneuil, 1850, es también endopuntuado, y representa, casi con toda seguridad, una variante poco alargada, de Cimicinella schulzi (Garcia-Alcalde \& Álvarez, 1976, p. 43; García-Alcalde, 1998, p. 170, 173).

El error de Comte al considerar las tres especies que incluyó en Triathyris como provistas de braquidio espiralado (Comte, 1938, p. 45) se debe, probablemente, a las homeomorfías que existen entre ellas. En efecto, como ya se dijo más arriba, los juveniles de T. mucronata son alargados y recuerdan a los maduros de $C$. schulzi y las variantes menos alargadas de la especie (del tipo de $C$. bordini), se parecen al meristeloideo que describimos antes, Saberaia truyolsae n.g. n.sp.

Familia Meristidae Hall \& Clarke, 1893

Subfamilia Meristinae Hall \& Clarke, 1893

Género Camarium Hall, 1859
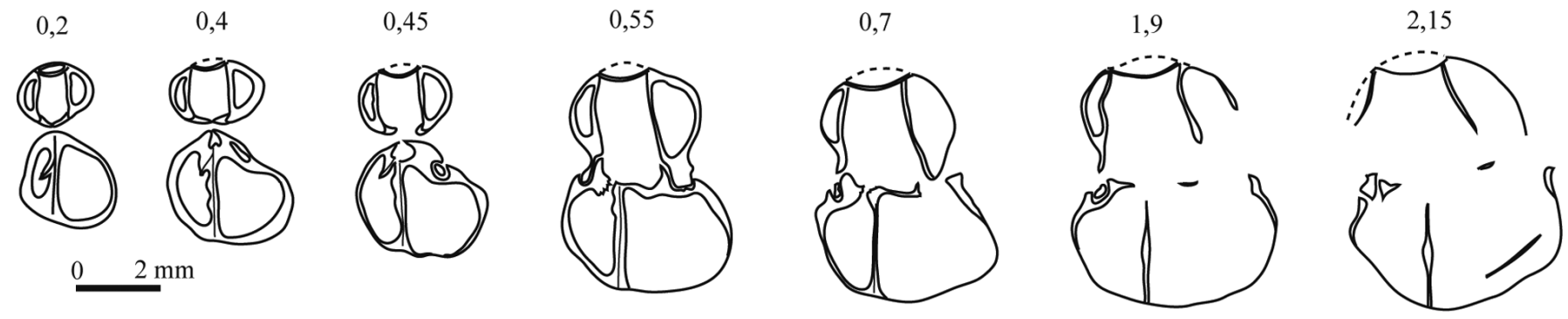

Figura 30. Camarium collensis n.sp. DPO 127931 de Colle (León), nivel 14. Dibujos con cámara clara de secciones seriadas, perpendiculares al plano de simetría y al plano comisural. Distancias medidas en mm. al ápice ventral.

Camarium collensis n.sp. DPO 127931 from Colle (León), level 14. Camera lucida drawings of serial sections, normal to both the symmetry and the commisural planes. Distances in mm measured from the shell apex. 


\section{Camarium collensis n.sp.}

Figs. 28-31, Tab. 4

Derivatio nominis: De la localidad tipo de la especie, en Colle (Sabero, provincia de León).

Material: Veinte ejemplares en diferentes estados de conservación. Holotipo DPO 127929 y 5 paratipos DPO 127930-127931 (Fig. 28), 127933, 127935 y 127949 procedentes del estrato y localidad tipo (DPO $127931 \mathrm{y}$ 127949 seccionados, Figs. 30-31). Otros dos ejemplares, DPO 127932 y 127934 , de la misma procedencia, en mal estado. Ocho ejemplares de la misma localidad, pero del nivel 18 (Fig. 16), DPO 127936-127943, cuatro ejemplares en mal estado, de la misma localidad, pero del nivel 21 (Fig. 16), DPO 127944-127947. Un ejemplar del pueblo de La Vid (Fig. 1), DPO 127948, del nivel M-LV-36/37.

Localidad y estrato típicos: La localidad tipo se sitúa al NNO de Colle (distrito de Sabero, prov. de León), cerca del arroyo de Colle (Fig. 29). El estrato tipo correponde al Grupo La Vid, parte alta de la Formación La Pedrosa, nivel 14 (Fig. 16), Intervalo Faunístico 9 (García-Alcalde, 1996), tercio inferior del Emsiense superior.

Diagnosis: Camarium de pequeño tamaño para el género. Seno ventral y pliegue medio dorsal débiles, apreciables sólo cerca del margen anterior de la concha. Placas dentales con bases prolongadas en los márgenes de la placa calzador (shoelifter process), sin placas mistroquiales.

Camarium small-sized. Ventral sinus and dorsal fold faint, only visible near to the shell margin. Dental plates with bases prolonged lateral to a well-developed shoelifter process. No mistrochial plates.
Descripción: Concha astrófica, impuntuada, lisa, de tamaño pequeño (Tab. 4), contorno ovalado a subpentagonal, algo más larga que ancha (promedio a/L 0,88, para 11 medidas), con la máxima anchura en la mitad anterior de la longitud, ventribiconvexa, poco engrosada (promedio $\mathrm{g} / \mathrm{L}$ 0,56, para 11 medidas) con el máximo grosor en la mitad posterior de la concha, seno ventral y pliegue medio dorsal indiferenciados, marcándose prácticamente sólo en la comisura anterior, la cual forma un arco amplio y redondeado en dirección dorsal (muy suave en los juveniles). Superficie de la concha surcada por líneas de crecimiento distantes, irregularmente distribuidas, de las cuales 3 a 5 son algo más fuertes y evidentes que las otras. Valva ventral perforada por un foramen apical circular, mesotírido, que trunca a un gancho curvo, limitado basalmente por un deltidio fuerte, generalmente visible bajo el gancho; ángulo apical entre 82 y $93^{\circ}$ (promedio $86^{\circ}$, para 9 medidas). Valva dorsal, con gancho oculto bajo el deltidio.

Características internas (visibles por transparencia y mediante secciones seriadas, Figs. 30-31): Placas dentales altas, verticales, relativamente cortas, sin placas mistroquiales, apoyadas en los extremos de una lámina arqueada, bastante larga (placa calzador, shoelifter process) (Figs. 28f, g, 30-31), que se ensancha y crece en altura hacia delante, hasta más allá de la zona de articulación; bases de las placas dentales divergentes, prolongadas hacia delante hasta la mitad de la longitud o más allá, en los extremos del shoelifter. Dientes cardinales fuertes, encajados en cavidades dentales profundas y simples; las crestas internas se acoplan a la base de los dientes formando una articulación complementaria (Figs. 30-31). Campo muscular débil situado por delante del shoelifter, atravesado por elevaciones radiales que alcanzan el margen de la concha. Valva dorsal provista de un septo medio fino, alto y muy

Tabla 4. Camarium collensis n.sp. Medidas de algunos ejemplares en mm. (L, a, g, $\alpha$ : longitud, anchura, grosor y ángulo apical) Camarium collensis n.sp. Measurements of some specimens in $\mathrm{mm}$ ( $L, a, g$, $\alpha$ : length, width, thickness, and apical angle)

\begin{tabular}{|c|c|c|c|c|c|c|c|}
\hline Ejemplar & Localidad & $\mathbf{L}$ & $\mathbf{a}$ & $\mathbf{g}$ & $\mathbf{a} / \mathbf{L}$ & $\mathbf{g} / \mathbf{L}$ & $\alpha$ \\
\hline Holotipo DPO 127929 & Colle F-162 & 12,6 & 11,6 & 7,3 & 0,92 & 0,58 & $90^{\circ}$ \\
\hline Paratipo DPO 127930 & Colle F-162 & 11,9 & 9,0 & 6,3 & 0,76 & 0,53 & $86^{\circ}$ \\
\hline Paratipo DPO 127931 (Seccionado) & Colle F-162 & 11,1 & 9,7 & 6,9 & 0,87 & 0,62 & $86^{\circ}$ \\
\hline Paratipo DPO 127933 & Colle F-162 & 9,8 & 9,0 & 6,0 & 0,92 & 0,61 & $87^{\circ}$ \\
\hline Paratipo DPO 127935 & Colle F-162 & 9,6 & 7,6 & 5,7 & 0,79 & 0,59 & $83^{\circ}$ \\
\hline Paratipo DPO 127949 (Seccionado) & Colle F-162 & 14,4 & 12,2 & 8,5 & 0,85 & 0,59 & - \\
\hline DPO 127937 & Colle, nivel 20/21 & 12,1 & 11,0 & 6,5 & 0,91 & 0,54 & $93^{\circ}$ \\
\hline DPO 127938 & Colle, nivel 20/21 & 15,1 & 14,4 & 8,2 & 0,95 & 0,54 & $87^{\circ}$ \\
\hline DPO 127939 & Colle, nivel 20/21 & 13,5 & 11,7 & 7,8 & 0,87 & 0,58 & $81^{\circ}$ \\
\hline DPO 127940 & Colle,nivel 20/21 & 15,4 & 12,5 & 9,3 & 0,81 & 0,60 & $85^{\circ}$ \\
\hline DPO 127941 & Colle, nivel 18 & 7,9 & 6,8 & 3,8 & 0,86 & 0,48 & $82^{\circ}$ \\
\hline DPO 127942 & Colle, nivel 18 & 9,7 & 9,1 & 4,6 & 0,94 & 0,47 & - \\
\hline DPO 127948 & La Vid, M-LV-36/37 & 13,6 & 13,0 & 7,5 & 0,96 & 0,55 & - \\
\hline
\end{tabular}


largo, con el extremo distal algo engrosado, que alcanza más de la mitad de la longitud, y soporta posteriormente un septalio descubierto, ancho y poco profundo. Sin shoelifter dorsal. Bases crurales proyectándose en el límite entre las placas cardinales externas e internas con un resalte agudo dirigido lateralmente. Campo muscular muy poco marcado. Braquidio espiralado con conos espirales dirigidos posterolateralmente, con 6-7 espiras cada uno,
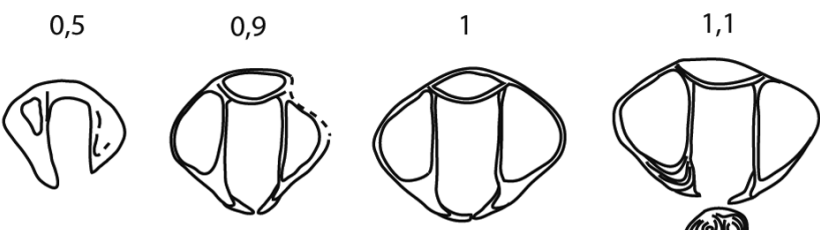

(20)
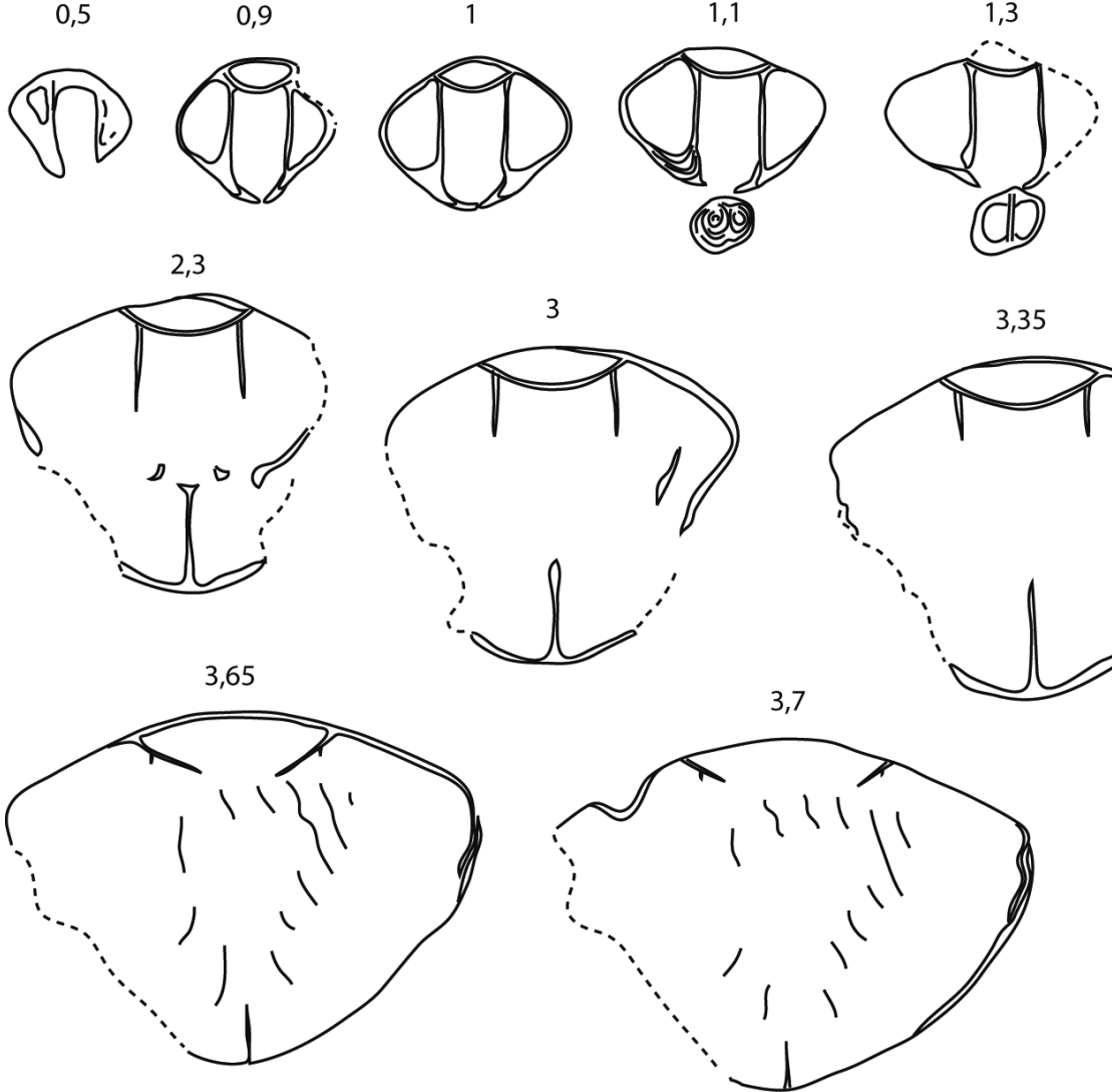

3,35
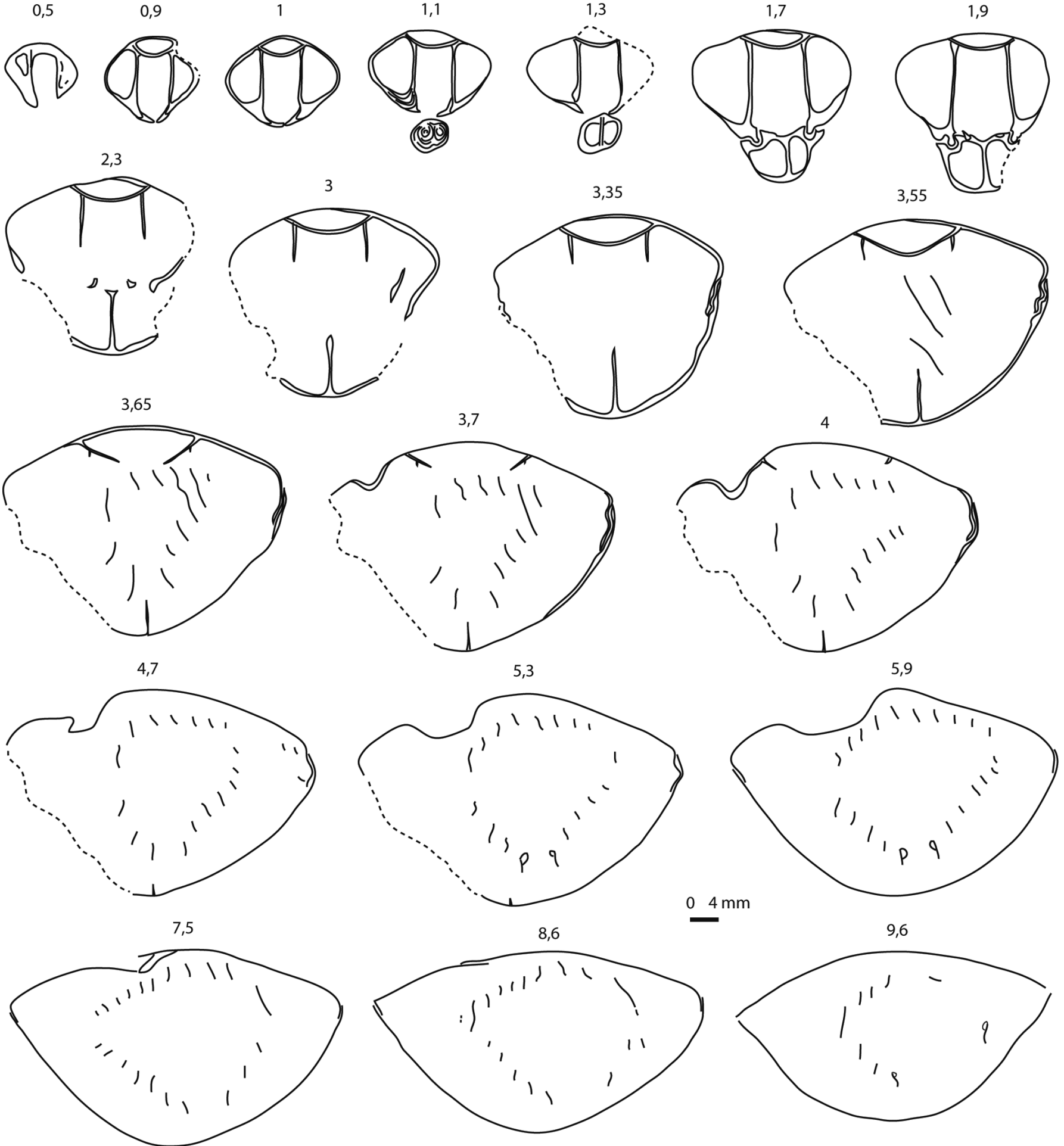

$-4 \mathrm{~mm}$

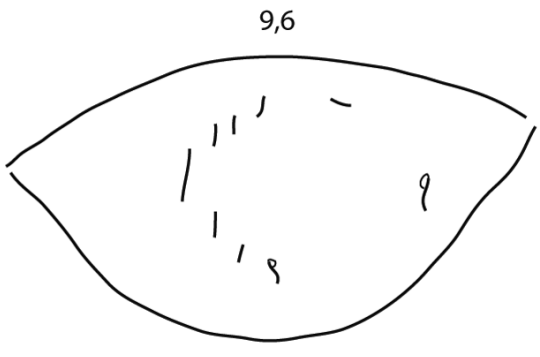

Figura 31. Camarium collensis n.sp. DPO 127949 de Colle (León), nivel 14. Dibujos con cámara clara de secciones seriadas, perpendiculares al plano de simetría y al plano comisural. Espiralio y yugo rotos. Distancias medidas en mm al ápice ventral. Camarium collensis n.sp. DPO 127949 from Colle (León), level 14. Camera lucida drawings of serial sections, normal to both the symmetry and the commisural planes. Broken spiralium and jugum. Distances in mm measured from the shell apex. 
bastante dañado en los dos ejemplares seccionados. Yugo desconocido, probablemente destruído también en el material disponible. Por delante de la charnela las valvas se acoplan mediante un mecanismo squama-glotta con el borde de la valva dorsal solapando el de la ventral (Fig. 31).

Discusión: La asignación de la especie al género Camarium Hall, 1859 se basa en la presencia de shoelifter ventral, carencia de placas mistroquiales ventrales y dorsales, desarrollo de las placas dentales y septalio poco profundo. Nuestra especie se diferencia de la tipo C. typum Hall, 1859, en el menor tamaño y grosor, seno ventral y pliegue dorsal marcados sólo en el borde de la concha y arqueamiento dorsal de la comisura anterior mucho menos acusado.

\section{AGRADECIMIENTOS}

Este trabajo es parte de los proyectos PICG 499 "Evolution of the ecosystems and climates during the Devonian" y PICG 596 "Climate change and biodiversity patterns in the Mid-Palaeozoic (Early Devonian to Late Carboniferous)" y fue subvencionado por el proyecto MEC-05-CGL 2005-03715 "Fases de desarrollo de asociaciones de corales y estromatoporoideos en el Devónico inferior de la Cordillera Cantábrica (NO de España) y relación de estos sucesos con eventos geo-biológicos" (ya concluido) y fondos FEDER. Agradecemos la labor de revisión efectuada por Peter Isaacson, de la Universidad Estatal de Idaho (EEUU) y por los editores de la Revista, Francisco J. Rodríguez-Tovar (editor principal) y Matías Reolid (editor adjunto), que mejoraron considerablemente el original.

\section{BIBLIOGRAFÍA}

Álvarez, F. \& Brime, C. 1990. Reencuentro con los "fósiles de Sabero". Comunicaciones de la Reunión sobre Tafonomía y Fosilización, 13-22.

Álvarez, F. \& Brime, C. 2000. Type specimens of Athyridid brachiopods from the James Hall collection. University of Kansas Paleontological Contributions, 12, 1-15.

Álvarez, F. \& Rong, J.-Y. 2002. Athyridida. En: Kaesler, R.L. (ed.), Treatise on Invertebrate Paleontology, part $\mathrm{H}$, Brachiopoda (revised), vol. 4, Rhynchonelliformea, 1476-1601.

Álvarez, F., Rong, J.-Y. \& Boucot, A.J. 1998. The classification of Athyridid brachiopods. Journal of Paleontology, 72 (5), 827-855.

Amsden, T.W. 1968. Articulate brachiopods of the St. Clair Limestone (Silurian), Arkansas and the Clarita Formation (Silurian), Oklahoma. Journal of Paleontology, 43 (3), supplement, 1-117.

Barrois, C. 1882. Recherches sur les terrains anciens des Asturies et de la Galice. Mémoires de la Société Géologique du Nord, 2 (1), 1-630.

Barrois, C. 1889. Faune du calcaire d'Erbray (Loire inférieure). Mémoires de la Société Géologique du Nord, 3, 1-348.
Binnekamp, J.G. 1965. Lower Devonian brachiopods and stratigraphy of North Palencia (Cantabrian Mountains, Spain). Leidse Geologische Mededelingen, 33, 1-62.

Boucot, A.J., Johnson, J.G. \& Staton, R.D. 1964. On some atrypoid, retzioid and athyridoid Brachiopoda. Journal of Paleontology, 38, 805-822.

Boucot, A.J., Johnson, J.G. \& Staton, R.D. 1965. Suborders Retziidina and Athyrididina. En: R.C. Moore (ed.), Treatise on Invertebrate Paleontology, Part $\mathrm{H}$, Brachiopoda, Geological Society of America and University of Kansas Press, 2, 649-667.

Boucot, A.J., Johnson, J.G. \& Talent, J.A. 1969. Early Devonian Brachiopod Zoogeography. The Geological Society of America, Special Paper, 119, 1-107.

Código Internacional de Nomenclatura Zoológica (CINZ). 2000. Comisión Internacional de Nomenclatura Zoológica, $4^{a}$ edición, adoptada por la Unióon Internacional de Ciencias Biológicas, 1-156.

Comte, P. 1938. Brachiopodes dévoniens des gisements de Ferroñes (Asturies) et de Sabero (Léon). Annales de Paléontologie, 27, 41-87.

Comte, P. 1959. Recherches sur les terrains anciens de la Cordillère Cantabrique. Memorias del Instituto Geológico y Minero de España, 60, 1-440.

García-Alcalde, J.L. 1971. Braquiópodos Devónicos de la Cordillera Cantábrica. 1) Estudio del género Pradoia COMTE, 1938 (Brachiopoda Athyridacea). Breviora Geológica Astúrica, Año XV (4), 49-59.

García-Alcalde, J.L. 1986. Pradoiinae, nouvelle sous-famille de Brachiopodes Athyrididés du Dévonien d'Europe. En: P.R. Racheboeuf \& C.C. Emig (eds.) Les Brachiopodes fossiles et actuels. Biostratigraphie du Paléozoique, 4, 65-77.

García-Alcalde, J.L. 1992. El Devónico de Santa María del Mar (Castrillón, Asturias, España). Revista Española de Paleontología, 7 (1), 53-79.

García-Alcalde, J.L. 1995. L'évolution paléogéographique pré-Varisque de la Zone Cantabrique septentrionale (Espagne). Revista Española de Paleontología, 10 (1), 9-29.

García-Alcalde, J.L. 1996. El Devónico del Dominio AsturLeonés en la Zona Cantábrica ( $\mathrm{N}$ de España). Revista Española de Paleontología, $\mathrm{n}^{\circ}$ extraordinario, 58-71.

García-Alcalde, J.L. 1999. Terebratúlidos (Braquiópodos) del Emsiense superior de Colle (Sabero, León, N. de España). Trabajos de Geología, 21, 159-176.

García-Alcalde, J.L. 2001a. Paleobiogeographical relationships between North Gondwana and South Baltica: The Ivanothyris havliceki fauna (Cantabrian Zone, latest Emsian). Journal of the Czech Geological Society, $\mathbf{4 6}$ (3-4), 121-130.

García-Alcalde, J.L. 2001b. Braquiópodos del Emsiense superior (intervalos faunísticos 11 a 13) del Dominio Astur-Leonés (Cordillera Cantábrica, N España). En: G. Meléndez, Z. Herrera, G. Delvene \& B. Azanza (eds.): Los fósiles y la Paleogeografía, XVII Jornadas SEP, Albarracín, Publicaciones Seminario Paleontología Zaragoza, 5 (2), 545-550.

García-Alcalde, J.L. 2002. El aparato braquial de Bimeristina n.gen. del Praguiense (Devónico Inferior) de España. En: 
J. Civis \& J.A. González Delgado (eds.): Actas de las XVIII Jornadas de la Sociedad Española de Paleontología y II Congreso Ibérico de Paleontología, 47-48.

García-Alcalde, J.L. 2003. Bimeristina binnekampi n.gen., n.sp., meristeloideo (Braquiópodo) del Devónico Inferior (Praguiense) de España. Revista Española de Paleontología, 18 (1), 103-112.

García-Alcalde, J.L. 2008. Eopugnax maisae n.sp. (Rhynchonellida Pugnacoidea) del Devónico (Emsiense superior) del Dominio Astur-Leonés de la Cordillera Cantábrica (N de España). Trabajos de Geología, 28, 171-178.

García-Alcalde, J.L. 2011. Subfamilia Teichostrophiinae Harper \& Boucot, 1978 (Strophomenoidea, Strophodontidae) del Devónico Inferior (Emsiense superior) de la Cordillera Cantábrica (N de España). Revista Española de Paleontología, 26 (1), 25-43.

García-Alcalde, J.L. \& Álvarez, F. 1976. Precisiones taxonómicas sobre algunas especies de braquiópodos de la Colección Verneuil. Trabajos de Geología, 8, 31-57.

García-Alcalde, J.L. \& Truyóls-Massoni, M. 1994. Lower/ Upper Emsian versus Zlichovian/Dalejan (Lower Devonian) boundary. Newsletter in Stratigraphy, 30, 83-89.

García-López, S. \& Sánz-López, J. 2002. Devonian to Lower Carboniferous conodont biostratigraphy of the Bernesga valley section (Cantabrian Zone, NW Spain). En: S. García-López \& F. Bastida (eds.), Palaeozoic Conodonts from Northern Spain, 8 Int. Conodont Symp., ECOS VIII, Cuadernos Museo Geominero, 1, 163-205.

Hall, J. 1859. Contributions to the Palaeontology of New York; being some of the results of investigations made during the years 1855, '56, '57 and '58. New York State Cabinet of Natural History Annual Report, 12, 7-110.

Hall, J. 1860. Contributions to the Palaeontology of New York; descriptions of new species of fossils from the Hamilton group of Western New York, with notices of others from the same horizon in Iowa and Indiana. New York State Cabinet of Natural History, Annual Report, 13, 53-125.

Hall, J. 1867. Palaeontology of New York. Containing descriptions and figures of the fossil Brachiopoda of the Upper Helderberg, Hamilton, Portage and Chemung Groups. New York State Geological Survey, Albany, $\mathbf{4}$ (1), $628 \mathrm{pp}$.

Hall, J. \& Clarke, J.M. 1893. An introduction to the study of the genera of Palaeozoic Brachiopoda. II. Brachiopoda Articulata (continued). New York Geological Survey, Palaeontology, 8 (2), 1-317.

Le Maître, D. 1952. La faune du Dévonien inférieur et moyen de la Saoura et des abords de l'Erg El Djemel (Sud-
Oranais). Materiaux de la Carte Géologique d'Algerie, 1st séries (Paléontologie), 12, 1-171.

Mallada, L. 1875. Sinopsis de las especies fósiles que se han encontrado en España. Boletín de la Comisión del Mapa Geológico de España, 2, pp. 1-160.

Mallada, L. 1892. Catálogo general de las especies fósiles encontradas en España. Boletín de la Comisión del Mapa Geológico, 1-253.

Oehlert, D. \& Oehlert, P. 1897. Fossiles dévoniens de Santa Lucia (Espagne) (Première partie). Bulletin de la Société Géologique de France, 24 (3), 814-875.

Oehlert, D. \& Oehlert, P. 1901. Fossiles dévoniens de SantaLucia (province de Léon, Espagne) (Deuxième partie). Bulletin Société Géologique de France, 1 (4), 233-250.

Prado, C. de \& Verneuil, E. de 1850. Note géologique sur les terrains de Sabero et de ses environs dans les montagnes de Léon (Espagne) suivie d'une déscription des fossiles de ces terrains. Bulletin de la Société Géologique de France, 7 (2), 137-186.

Schmidt, H. 1946. Beiträge zum Richtschnitt Unterdevon/ Mitteldevon bei Wetteldorf. 5). Die Terebratulidae des Wetteldorfer Richtschnittes. Senckenbergiana, 27 (1/3), 67-75.

Struve, W. 1964. Beiträge zur kenntnis devonischer brachiopoden, 8: Über einige homöomorphe Brachiopoden-Arten. Senckenbergiana lethaea, 45 (6), 507-521.

Suess, E. 1851. Ueber ein neues Brachiopoden-Geschlecht Merista. Jahrbuch der Kaiserlich-Königlichen Geologischen Reichsanstalt, 2 (4), 150.

Truyóls, J., Arbizu, M.A., García Alcalde, J.L, García López, S., Méndez Bedia, I., Soto, F. \& Truyóls Massoni, M. 1990. The Asturian-Leonese Domain (Cantabrian Zone). En: R.D. Dallmeyer \& E. Martínez García (eds.) Pre-Mezozoic Geology of Iberia. Springer Verlag Berlin Heidelberg, 10-19.

Truyóls-Massoni, M. \& García-Alcalde, J.L. 1994. Faune Rhéno-bohémienne (Dacryoconaridés, Brachiopodes) à la limite Emsien inférieur/supérieur au Cabo La Vela (Asturies, Espagne). Géobios, 27 (2), 221-241.

Vanuxem, L. 1842. Geology of New York, pt. 3 comprising the survey of the Third Geological Districts. Natural History of New York, $306 \mathrm{pp}$.

Waagen, W.H. 1883. Salt Range Fossils. I. ProductusLimestone Fossils. Geological Survey of India, Memoirs, Palaeontologia Indica (series 13), 4, 391-546.

Manuscrito recibido: 15 de julio, 2011 Manuscrito aceptado: 20 de octubre, 2011 